\author{
UNIVERSIDADE DE SÃO PAULO \\ ESCOLA DE ARTES, CIÊNCIAS E HUMANIDADES \\ PROGRAMA DE PÓS-GRADUAÇÃO EM SUSTENTABILIDADE
}

LUANA FERREIRA VASCONCELOS

Caracterização do material particulado fino, e identificação de fontes emissoras no campus leste da Universidade de São Paulo, a Escola de Artes Ciências e Humanidades (EACH-USP) 


\title{
Caracterização do material particulado fino, e identificação de fontes emissoras no campus leste da Universidade de São Paulo, a Escola de Artes Ciências e Humanidades (EACH-USP)
}

\author{
Versão Corrigida \\ (Versão original encontra-se na unidade que aloja \\ o Programa de Pós-graduação)
}

Dissertação apresentada à Escola de Artes, Ciências e Humanidades da Universidade de São Paulo para obtenção do título de Mestre em Ciências pelo Programa de Pós-graduação em Sustentabilidade.

Versão corrigida contendo as alterações solicitadas pela comissão julgadora em 29 de janeiro de 2021. A versão original encontra-se em acervo reservado na Biblioteca da EACH/USP e na Biblioteca Digital de Teses e Dissertações da USP (BDTD), de acordo com a Resolução CoPGr 6018, de 13 de outubro de 2011.

Área de Concentração: Ciência e Tecnologia

Orientador:

Prof $^{a}$. Dr ${ }^{\mathrm{a}}$. Regina Maura de Miranda 
Nome: VASCONCELOS, Luana Ferreira

Título: Caracterização do material particulado fino e identificação de fontes emissoras no Campus Leste da Universidade de São Paulo, a Escola de Artes, Ciências e Humanidades (EACH-USP).

Dissertação apresentada à Escola de Artes, Ciências e Humanidades da Universidade de São Paulo para obtenção do título de Mestre em Ciências do Programa de Pós-Graduação em Sustentabilidade.

Área de Concentração: Ciência e Tecnologia

Aprovado em: 29/01/2021

\section{Banca Examinadora}

Prof. Dr. Regina Maura de Miranda

Prof. Dr. Maria de Fátima Andrade

Prof. Dr. Simone G. El Khouri Miraglia

Prof. Dr. Andrea Cavicchioli
Instituição: Escola de Artes, Ciências e Humanidades - Universidade de São Paulo

Instituição: Instituto de Astronomia, Geofísica e Ciências Atmosféricas - Universidade de São Paulo

Instituição: Universidade Federal do Estado de São Paulo Instituição: Escola de Artes, Ciências e Humanidades - Universidade de São Paulo 
Autorizo a reprodução e divulgação total ou parcial deste trabalho, por qualquer meio convencional ou eletrônico, para fins de estudo e pesquisa, desde que citada a fonte.

CATALOGAÇÃO-NA-PUBLICAÇÃO

(Universidade de São Paulo. Escola de Artes, Ciências e Humanidades. Biblioteca)

CRB $8-4936$

\section{Vasconcelos, Luana Ferreira \\ Caracterização do material particulado fino, e identificação de fontes} emissoras no campus leste da Universidade de São Paulo, a Escola de Artes, Ciências e Humanidades (EACH-USP) / Luana Ferreira Vasconcelos ; orientadora, Regina Maura de Miranda - 2021.

$85 \mathrm{f}$ : il.

Dissertação (Mestrado em Ciências) - Programa de PósGraduação em Sustentabilidade, Escola de Artes, Ciências e Humanidades, Universidade de São Paulo Versão corrigida

1. Poluição atmosférica - São Paulo (SP). 2. Aerossol. 3. Material particulado. 4. Escola de Artes Ciências e Humanidades. I. Miranda, Regina Maura de, orient. II. Título 


\section{Agradecimentos}

Agradeço à minha orientadora Regina por acreditar no meu potencial e compartilhar comigo seus conhecimentos e experiências, pelo apoio pessoal e acadêmico, por sua paciência, compreensão e por seu olhar para o futuro.

Agradeço à professora Maria de Fátima por contribuir com o meu trabalho, tanto pela sua produção acadêmica quanto por me acolher no IAG, LAPAt, eventos e grupos acadêmicos. À Simone por agregar conhecimento ao meu trabalho, e por sua contribuição acadêmica sobre poluição e saúde à sociedade.

À Rosana, técnica de laboratório LAPAt no IAG por me ajudar com as análises laboratoriais.

Aos professores do Programa de pós graduação em Sustentabilidade.

Ao meu pai Reinaldo por ser exemplo de dedicação, caráter e integridade, por me incentivar e me dar amor e afeto em todos os momentos. À minha mãe Eliana por ser minha inspiração, por me incentivar aos estudos, por me mostrar que conhecimento nunca é demais, por ser essa mãe amorosa, guerreira, defensora e por acreditar em mim. Ao meu irmão Rafael por desde a infância me proteger e me fazer rir, por trazer movimento à minha vida e assim me lembrar de não estagnar. Obrigada família por sempre buscarem conhecimento.

À minha madrinha Elenice que me incentiva desde criança aos estudos e a buscar os meus sonhos. À prima Jéssica que sempre me inspirou com a sua dedicação e empenho aos estudos, além da sua amizade e afeto.

Aos familiares Ferreira e Vasconcelos por todo carinho.

À amiga Amanda, por sua amizade desde ensino o médio, por entrar comigo na universidade e me mostrar que seria melhor não trabalharmos juntas para não brigarmos. Por me incentivar nos estudos acadêmicos e na música, por torcer por mim, por trazer leveza com o seu jeito alegre e carismático, por ser minha irmã do coração.

À amiga Luciana pela amizade, por dividir comigo as suas experiências acadêmicas, por torcer e me incentivar. Pelas conversas da quarentena que me ajudaram a colocar os pés no chão. Pela música, que junto com a Amanda formamos um trio despretensioso, com o intuito de extravasar o estresse acadêmico.

À prima e amiga Lígia pelo apoio e amizade nas horas boas e ruins, por poder contar com a amizade mesmo quando o tempo já passou e as novas questões surgem nas nossas vidas, mas ao nos reencontrarmos temos o conforto e confiança da nossa amizade como se o tempo nunca tivesse passado.

À amiga Débora por sempre me mostrar o lado mais prático, com a sua forma 
sistemática de pensar, mas sem desconsiderar o que sinto ou creio. Obrigada pela amizade, e incentivo para a busca do melhor para a minha vida.

Aos amigos de antiga banda Draco Dormien, Rodrigo, Cleber e Thiago, pelos churrascos e momentos de descontração, junto com Suelen, Rodrigo, Miguel e João. Pela boa comida, bebida e amizade.

Ao Fabrício por ter me dado apoio nos estudos, na música e na vida pessoal em parte deste processo.

Aos amigos da EACH Eduardo, Raíssa, Leonardo, Eliane, Yohana, Maria, Douglas, Erik, Iara, Arissa, Amanda, Jack, Felipe, Janes, Vitor, pelo apoio e companhia nas aulas e almoços no bandejão.

À colega Letícia por ter me convidado para contribuir com o artigo do jornal Estadão, com o intuito de divulgação científica sobre COVID-19 e poluição em São Paulo. Obrigada pela troca.

Aos colegas da área de ciências atmosféricas Leonardo, Marcos, Rafaela, Ana Paula, Márcia, Francisco, Aline, Veronika, Guilherme Pereira, Djacinto, Guilherme Oliveira, Carla, que apesar do pouco contato contribuíram e contribuem com os seus trabalhos à minha melhor compreensão sobre a área de estudo e a minha formação.

À professora Ana Paula coordenadora do Lab do Itaim Paulista.

À Fundação de Amparo à Pesquisa do Estado de São Paulo (FAPESP) (nº 2012/246895 e $n^{\circ}$ 2008/50128-9), que deu apoio financeiro para adquirir os materiais e insumos para realização da pesquisa. 
"Estamos todos conectados; uns aos outros biologicamente, à Terra quimicamente e ao resto do universo atomicamente"

(TYSON, 2019, p.3, tradução nossa) 


\section{RESUMO}

VASCONCELOS, Luana Ferreira. Caracterização do material particulado fino, e identificação de fontes emissoras no campus leste da Universidade de São Paulo, a Escola de Artes Ciências e Humanidades (EACH-USP). 2021. 85 f. Dissertação (Mestrado em Ciências) - Escola de Artes, Ciências e Humanidades, Universidade de São Paulo, São Paulo, 2021. Versão corrigida

O Material Particulado Inalável Fino $\left(\mathrm{MP}_{2.5}\right)$ é o principal poluente relacionado às doenças do sistema respiratório, assim como também está relacionado às mortes por doenças cardiorrespiratórias e outros desfechos. Devido ao seu tamanho diminuto, o $\mathrm{MP}_{2.5}$ pode atingir profundamente o sistema respiratório, além de ter influência no clima, já que pode alterar o balanço radiativo terrestre na atmosfera. Neste trabalho foi realizado o monitoramento ambiental do $\mathrm{MP}_{2.5}$ no campus leste da Universidade de São Paulo (USP), a Escola de Artes, Ciências e Humanidades (EACH). Teve como objetivo a caracterização físico-química do aerossol urbano na região, identificação das principais fontes, avaliação da influência dos veículos circulantes na rodovia Ayrton Senna, próxima ao campus e ainda a análise de como os parâmetros meteorológicos podem influenciar a dispersão deste poluente. As amostragens foram realizadas com um amostrador Partisol, equipamento específico para a medida de $\mathrm{MP}_{2.5}$, de abril de 2016 a abril de 2017, em períodos de 24hs, e troca de filtros a cada três dias, totalizando em 114 amostras coletadas. O black carbon (BC) foi monitorado através do monitor Multi-Angle Absorption Photometer (MAAP). Após a coleta, os resultados foram obtidos através de análises por técnicas analíticas complementares, para se conhecer a concentração em massa e composição elementar do material coletado. A concentração média anual do $\mathrm{MP}_{2.5}$ foi de $17,71 \pm 11,45 \mu \mathrm{g} / \mathrm{m}^{3}$ e de $1,86 \pm 1,27 \mu \mathrm{g} / \mathrm{m}^{3}$ para o BC. O padrão diário de 24 hs para o Estado de São Paulo $\left(60 \mu \mathrm{g} / \mathrm{m}^{3}\right)$ não foi excedido. As maiores concentrações ocorreram nos meses de inverno. As principais espécies detectadas através da fluorescência de Raios-X e cromatografia de íons foram o $\mathrm{Na}, \mathrm{Al}, \mathrm{Si}, \mathrm{S}, \mathrm{Cl}, \mathrm{K}, \mathrm{Ca}, \mathrm{Fe}$ e Zn, $\mathrm{Cl}^{-}, \mathrm{NO}_{3}{ }^{-}, \mathrm{SO}_{4}{ }^{2-}, \mathrm{Na}^{+}, \mathrm{Ca}^{2+}, \mathrm{K}^{+}$, $\mathrm{NH}_{4}{ }^{+}$e $\mathrm{C}_{2} \mathrm{H}_{3} \mathrm{O}^{2-}$. E as principais fontes emissoras de poluentes identificados pelo modelo Positive Matrix Fatorization (PMF) foram os veículos pesados (34,6\%), ressuspensão de solo $(26,3 \%)$, fontes locais $(21,7 \%)$ e veículos leves $(17,3 \%)$.

Palavras chave: Aerossol Urbano. São Paulo. Black Carbon. Análise Elementar. 


\begin{abstract}
VASCONCELOS, Luana Ferreira. Characterization of fine particulate matters, and identification of emission sources on the east campus of the University of São Paulo, the School of Arts, Sciences and Humanities (SASH-USP). 2021. 85 p. Dissertation (Master in science) - School of Arts, Sciences and Humanities, University of São Paulo, São Paulo, 2021. Corrected version
\end{abstract}

The fine particulate matter $\left(\mathrm{PM}_{2.5}\right)$ is the main pollutant related to high incidence of diseases of the respiratory system, as it is also related to deaths from cardiorespiratory diseases. Due to its small size, the $\mathrm{PM}_{2.5}$ reaches deeply into the respiratory system and can influence the climate, since it can change the radiative balance of the atmosphere. In this work the environmental monitoring of $\mathrm{PM}_{2.5}$ was carried out, in the East campus of the University of São Paulo (USP), the School of Arts, Sciences and Humanities $(\mathrm{EACH})$, with the purpose of characterizing physico-chemically the urban aerosol, the main sources and relate to number of vehicles in the Ayton Senna highway, close to the campus and, with meteorological parameters that influence the dispersion of this pollutant. The samplings were carried out throughout April 2016 to April 2017, using Partisol as specific equipment to measure $\mathrm{PM}_{2.5}$, in periods of $24 \mathrm{hs}$ and filter changes every three days, in the total were collected 114 sampling. Black carbon (BC) was obtained through the MAAP monitor. After the collection, the results were obtained by complementary techniques, to know the mass concentration of the samples. The annual mean concentration was $17.71 \pm 11.45 \mu \mathrm{g} / \mathrm{m}^{3}$ for $\mathrm{PM}_{2.5}$ and $1.86 \pm 1.27 \mu \mathrm{g} / \mathrm{m}^{3}$ for BC. During the study period, the São Paulo State 24-h standard for $\mathrm{PM}_{2.5}\left(60 \mu \mathrm{g} / \mathrm{m}^{3}\right)$ was not exceeded. The highest concentrations occurred in the winter months. The main species detected by X-ray fluorescence and ion chromatography were: $\mathrm{Na}, \mathrm{Al}, \mathrm{Si}, \mathrm{S}, \mathrm{Cl}, \mathrm{K}, \mathrm{Ca}, \mathrm{Fe}$ e $\mathrm{Zn}, \mathrm{Cl}^{-}, \mathrm{NO}_{3}{ }^{-}, \mathrm{SO}_{4}{ }^{2-}$, $\mathrm{Na}^{+}, \mathrm{Ca}^{2+}, \mathrm{K}^{+}, \mathrm{NH}_{4}{ }^{+}$and $\mathrm{C}_{2} \mathrm{H}_{3} \mathrm{O}^{2-}$. The main sources of pollutants identified by the PMF are: HDVs (34.6\%); Soil (26.3\%); Local sources (21.7\%); LDVs (17.3\%)

Keywords: Urban Aerosol. São Paulo. Black Carbon. Elemental characterization. 


\section{LISTA DE FIGURAS}

Figura 1: Gráfico adaptado do grande smog de Londres e mortalidade em dezembro de 1952

Figura 2 - Esquema da formação, distribuição modal e deposição do aerossol na troposfera. Hipótese original de Whitby, et al. (1980) é mostrada na linha sólida da curva, com três modas. A quarta moda, das partículas ultrafinas, bem como os dois picos por vezes observados na moda de acumulação são mostrados pelas linhas pontilhadas.

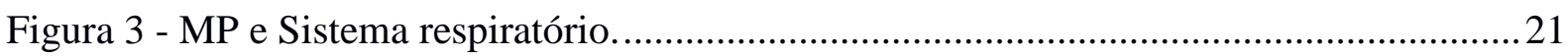

Figura 4 - Evolução da poluição atmosférica na RMSP ao longo dos últimos 30 anos...........25

Figura 5 - Porcentagem das concentrações por fontes poluentes para a RMSP..................... 25

Figura 6 - Cidade de São Paulo sob o efeito da inversão térmica no mês de julho de 2015, às $11 \mathrm{~h}$. 29

Figura 7 - 17 Objetivos para o desenvolvimento sustentável. 30

Figura 8 - Área de Estudo e seu entorno, com áreas residenciais e indústrias. ......................... 35

Figura 9 - Área de Estudo, e as distâncias aproximadas entre as principais avenidas. ............ 35

Figura 10 - Área de Estudo, e a distância aproximada entre o aeroporto de Cumbica.............. 36

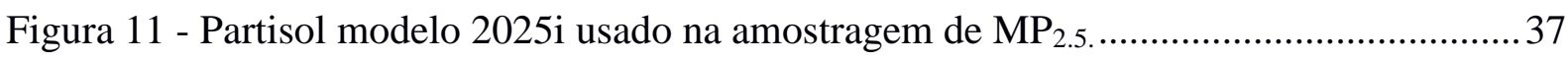

Figura 12 - Filtros em condicionamento para posterior pesagem …...................................... 38

Figura 13: Balança e eliminador de carga estática (seta amarela)..........................................38

Figura 14 - Aparelho refletômetro e suporte para filtro

Figura 15 - Monitor de BC MAAP (modelo MAAP 5012 da Thermo Scientific) e esquema da câmara de detecção.

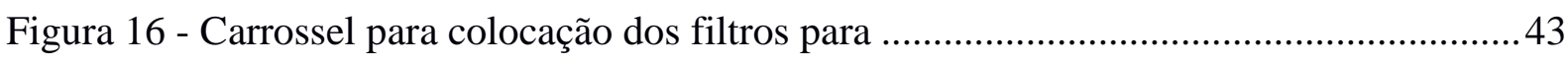

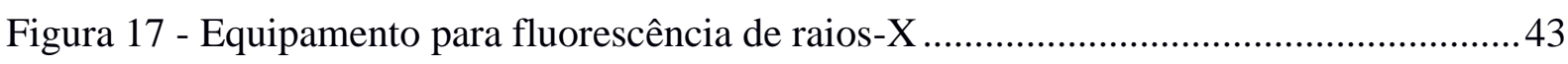

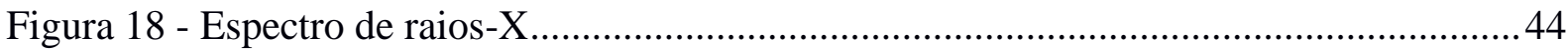

Figura 19 - a) Cromatógrafo (modelo 850 Professional IC da Metrohm) e b) esquema processo da cromatografia . 45

Figura 20 - Concentração total do período amostrado de $\mathrm{MP}_{2.5}$ e BCeq na EACH.

Figura 21 - Gráfico comparativo entre as médias de concentrações mensais de $\mathrm{MP}_{2.5}$ para as estações da CETESB de Guarulhos-Pimentas e Marginal Tietê-Ponte dos Remédios e EACH.

Figura 22 - Gráfico de porcentagem de $\mathrm{BC}_{\mathrm{Eq}}$ obtido através da refletância contido no $\mathrm{MP}_{2.5} 50$ Figura 23: Dados meteorológicos do período total amostrado. Velocidade do vento $(\mathrm{m} / \mathrm{s})$; Temperatura $\left({ }^{\circ} \mathrm{C}\right)$, Umidade Relativa do $\operatorname{Ar}(\%), \mathrm{MP}_{2.5}$ e BC. 
Figura 24 - Concentração de $\mathrm{BC}, \mathrm{MP}_{2.5}$ e variáveis meteorológicas (velocidade do vento; temperatura e umidade relativa do ar)

Figura 25 - a) Concentração de $\mathrm{MP}_{2.5}$ e Direção dos Ventos (Rosa das Poluições) e entorno da EACH; b) Rosa das Poluições aproximado

Figura 26 - Gráfico da média das concentrações de $\mathrm{MP}_{2.5}$ por quadrantes de direção do vento

Figura 27 - Total diário de LDVs e HDVs na Rodovia Ayrton Senna, em ambos os sentidos, por todo período amostrado. 56

Figura 28 - a) gráfico da média de veículos por mês; b) gráfico da média de veículos por semana;

c) gráfico da média de veículos por hora.

Figura 29 - Concentração média mensal de BC, MP 2,5 e veículos leves (LDV) e pesados (HDV) nos dois sentidos da Rodovia Ayrton Senna para o período total (abril 2016 - abril 2017) ....58 Figura 30 - Concentração média de black carbon (BC), MP 2,5 e veículos leves (LDV) e pesados (HDV) nos dois sentidos da Rodovia Ayrton Senna para os dias da semana. 59

Figura 31: Concentração média diária de BC ao longo do período de estudo 60

Figura 32: Concentração média horária de $\mathrm{BC}$ ao longo do período de estudo 62

Figura 33 - a) Gráfico de concentração média mensal de BC e NOx; b) Gráfico de concentração média semanal de BC e NOx; c) Gráfico de concentração média horária de BC e NOx. 63

Figura 34 - Concentração média das espécies químicas continas nas amostras de $\mathrm{MP}_{2.5}$.......64

Figura 35 - Concentração das principais espécies químicas por direção dos ventos

Figura 36 - Pluma de poluentes lançada pela Indústria de vidros CISPER e queima de lixo no

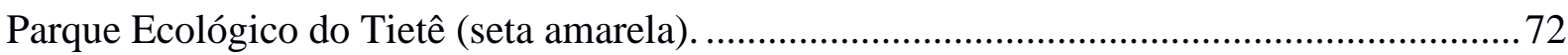

Figura 37 - PMF - Porcentagem das espécies por fonte ..................................................... 74

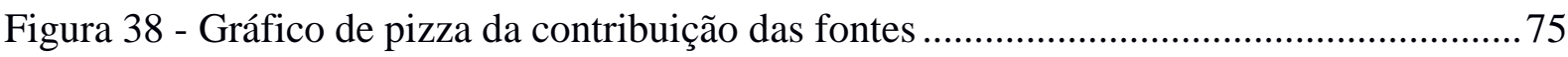




\section{LISTA DE TABELAS}

Tabela 1 - Evolução dos Padrões de Qualidade do ar. 27

Tabela 2 - Correlação de Pearson para as médias semanais de concentração de BC e número de LDVs e HDVs circulantes na rodovia Ayrton Sena. 60

Tabela 3 - Média e desvio padrão da concentração de $\mathrm{MP}_{2.5}, \mathrm{BC}$ e espécies químicas. $\mathrm{N}$ representa o número de amostras onde a espécie foi detectada, com exceção de $\mathrm{BC}$ em que $\mathrm{N}$ representa o número de medida obtidas pelo monitor MAAP 65

Tabela 4 - Matriz do coeficiente de correlação de Pearson (r) dos principais constituintes do aerossol 67

Tabela 5- PMF -Tabela de diagnósticos por número de fatores 73 


\section{SUMÁRIO}

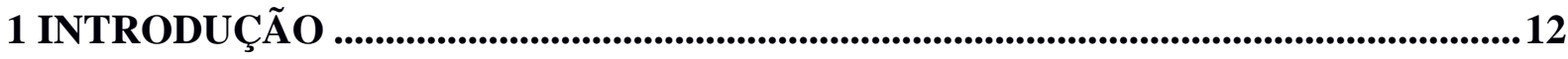

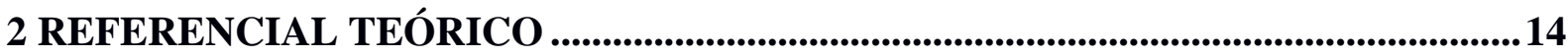

2.1 Breve contextualização histórica da poluição do ar ........................................................ 14

2.2 Aerossol Atmosférico.................................................................................................. 17

2.3 Aerossol, Clima e Saúde............................................................................................................20

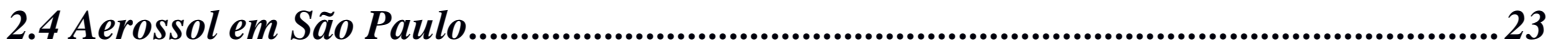

2.4.1 Padrões de qualidade do ar ........................................................................................26

2.5 A influência da meteorologia na concentração dos poluentes.................................... 28

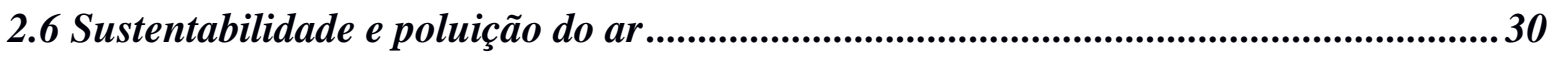

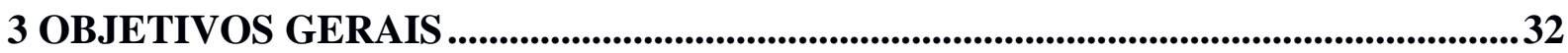

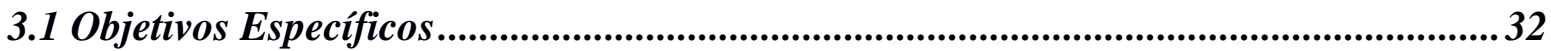

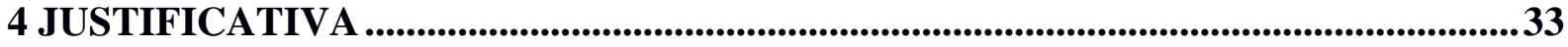

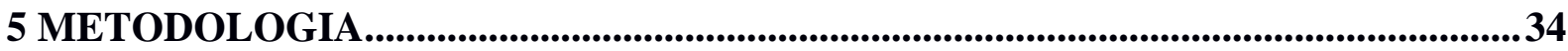

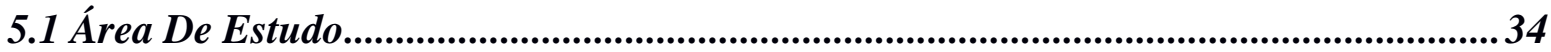

5.2 Descrição dos Equipamentos, Procedimentos e Análises..............................................36

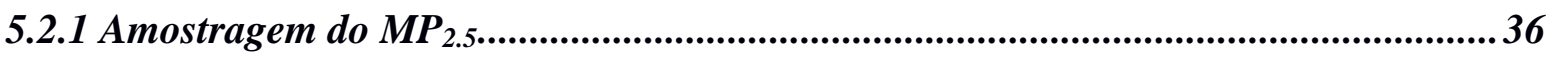

5.2.2 Determinação da concentração de $\mathrm{MP}_{2.5}$..................................................................... 37

5.2.3 Análise de carbono equivalente e carbono elementar .................................................39

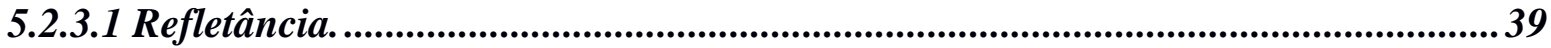

5.2.3.2 MAAP (Multi-Angle. Absorption Photometer) ......................................................... 40

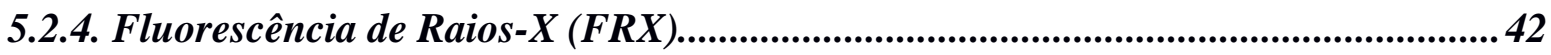

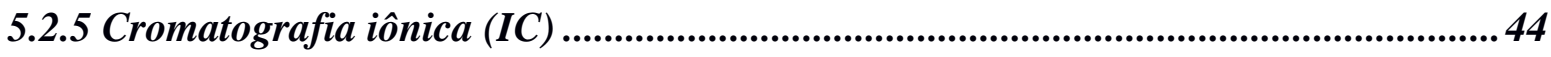

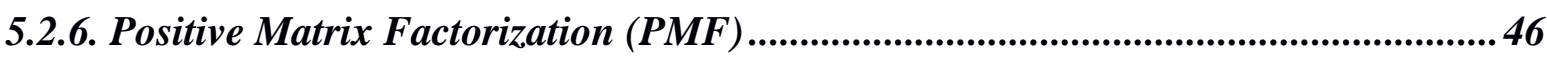

6 RESULTADOS E DISCUSSÃO _.............................................................................................4 48

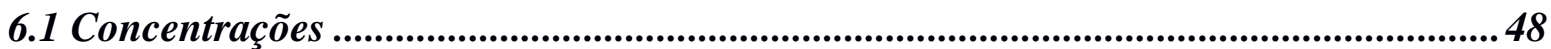

6.1.2 Concentração de MP 2.5, BC e variáveis meteorológicas .........................................51

6.1.3 Concentração de $\mathrm{MP}_{2.5}, \mathrm{BC}$ e Veículos. ...................................................................55

6.1.4 Concentrações das Espécies Químicas.............................................................................64

6.2 Análise por Positive Matrix Fatorization (PMF)........................................................... 72

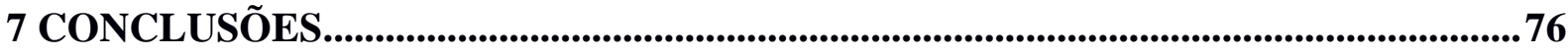

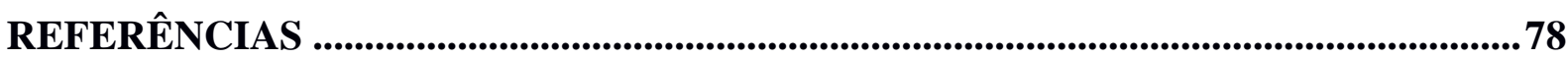

ANEXO A - DIREÇÃO E VELOCIDADE DO VENTO MENSAL DO PERÍODO 


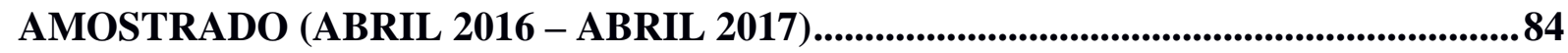




\section{INTRODUÇÃO}

A poluição do ar é definida pelo excesso de substâncias presentes no ar que podem afetar a vida humana e o meio ambiente (BRASIL, 1990; SEINFELD; PANDIS, 2006).

Grandes centros urbanos, como São Paulo, apresentam sérios problemas relacionados à poluição atmosférica, que contribuem não somente com a degradação da qualidade do ar local, mas também em escala regional e global, no que se refere aos gases do efeito estufa e aerossóis, que podem afetar a saúde humana, interferir no balanço de radiação com a superfície, alterar propriedades de nuvens, diminuir a visibilidade, além de contribuírem com efeitos como as ilhas de calor e inversões térmicas (BARROS; LOMBARDO, 2016; SEINFELD; PANDIS, 2006).

A poluição atmosférica urbana se caracteriza pelo excesso de gases nocivos e material particulado, o qual também é denominado de aerossol. O aerossol é definido por partículas sólidas ou líquidas em suspensão na atmosfera. Estas partículas podem ter sua origem através de fontes naturais, ou por ações antropogênicas. Quando de origem natural, podem ser, por exemplo, por ressuspensão do solo, ação biogênica, vulcânica e spray marinho. E quando de origem antropogênica, ocorrem pela combustão de combustíveis fósseis, queima de biomassa e vapores químicos através de fontes fixas e/ou móveis. As partículas primárias, que são geradas diretamente pelas fontes, podem se transformar em outros compostos reagindo quimicamente na atmosfera, formando aerossóis secundários (COMPANHIA AMBIENTAL DO ESTADO DE SÃO PAULO, 2018; SEINFILD; PANDIS, 2006).

As partículas inaláveis, tanto a moda grossa, com diâmetro aerodinâmico (d.a.) ${ }^{1}$ entre 2,5 $\mu \mathrm{m}$ e $10 \mu \mathrm{m}$, quanto a moda fina, com diâmetro aerodinâmico até 2,5 $\mu \mathrm{m}$, são apontadas como o poluente mais frequentemente relacionado com danos à saúde, e doenças cardiorrespiratórias, devido as suas pequenas dimensões, as partículas finas conseguem alcançar profundamente o trato respiratório (BRAGA et a.l, 2001)

Além dos efeitos na saúde, os aerossóis podem afetar o balanço radiativo terrestre pelo espalhamento ou absorção da luz quando esta atravessa a atmosfera, podendo diminuir a radiação que atinge a superfície, aumentar ou diminuir o albedo, dependendo de suas características físico-químicas (PANICKER et al., 2010).

${ }^{1} \mathrm{O}$ diâmetro aerodinâmico (d.a.) é definido para as partículas de aerossol baseando-se no diâmetro ou raio de uma partícula esférica ideal, com densidade unitária de $1 \mathrm{~g} . \mathrm{cm}^{-3}$ para determinar a sua deposição, no entanto, as partículas atmosféricas são irregulares e assim, utiliza-se o termo "diâmetro equivalente ou efetivo" dependendo das suas propriedades físicas (FINLAYSON-PITTS; PITTS, 2000). 
Compostos orgânicos encontrados no material particulado (MP) fino, como o carbono elementar, ou black carbon (BC), é um tipo de composto derivado da combustão incompleta dos combustíveis, que possui propriedade física capaz de absorver a radiação solar e aprisionar a radiação infravermelha emitida pela Terra, contribuindo para o aquecimento da atmosfera (SEINFELD; PANDIS, 2006).

A variação das amplitudes térmicas em grandes centros urbanos é afetada tanto pela concentração de poluentes atmosféricos, quanto pela cobertura da superfície terrestre. Do centro expandido da capital paulista até a Zona Leste, há predominância de áreas residenciais sem quase nenhuma arborização ou jardins, devido à ocupação irregular do solo e à excessiva urbanização (SÃO PAULO, 1999), o que favorece a impermeabilização do solo. Assim como a excessiva urbanização, alterando a superfície, juntamente com a emissão de poluentes na atmosfera, o efeito urbano climático chamado de "Ilhas de calor" se torna comum em áreas urbanas, cujas implicações podem ocasionar fortes chuvas com risco de inundações e alteração das amplitudes térmicas urbanas (BARROS; LOMBARDO, 2016; HUANG et al., 2008).

Na Zona Leste de São Paulo este efeito urbano climático ocorre com frequência, pois além desta área ser uma das regiões mais impermeabilizadas da cidade, a sua localização geográfica e topografia favorecem a formação de fortes tempestades, pois o ar mais frio e úmido que vem do oceano (brisa marítima) encontra o ar quente da região leste favorecendo a formação das fortes chuvas e consequentemente enchentes que ocorrem principalmente nos meses de verão (VEMADO; PEREIRA FILHO, 2016).

A Zona Leste da cidade de São Paulo é caracterizada por 12 subprefeituras e dividida em 33 distritos, mais de 4 milhões de habitantes (ano de 2016), sendo 1.054.187 pessoas na faixa da idade escolar entre 0 e 17 anos, e 542.376 de pessoas acima dos 60 anos de idade (SÃO PAULO, 2021). É uma região composta em sua maior parte por uma população jovem e ativa economicamente para a sociedade. Esta relação afeta diretamente a dinâmica da região, principalmente no que se refere ao transporte. A predominância dos postos formais de emprego se encontra distante da moradia dessa população, que vive em situação de vulnerabilidade, pois recebem em média menos de meio salário mínimo per capita (SÃO PAULO, 2015). Contudo, além das questões econômicas e sociais, a qualidade do ar devido à emissão veicular se torna um fator significativo e relevante à saúde, bem-estar, e qualidade ambiental para a população da região. Estudos de MIRANDA et al. (2018), apresentam que a maior parte da composição do $\mathrm{MP}_{2.5}$ tem origem nas emissões veiculares, seguido da ressuspensão do solo, que também podem ter relação com o tráfego veicular.

Portanto, tendo em vista a importância de se estudar e monitorar o MP por sua relação direta com a saúde e ambiente, e considerando as características sociais, urbanas e climáticas 
da Zona Leste da capital paulista, o objetivo deste trabalho foi caracterizar o material particulado fino $\left(\mathrm{MP}_{2.5}\right)$, coletado ao longo de 2016 no campus leste da Universidade de São Paulo (USP), onde se situa a Escola de Artes Ciências e Humanidades (EACH), e identificar as principais e mais frequentes fontes emissoras do poluente.

\section{REFERENCIAL TEÓRICO}

Neste capítulo será abordado o referencial teórico no âmbito da poluição atmosférica. Inicia-se com um breve contexto histórico da poluição do ar, seguido das definições de aerossol atmosférico e a teoria de sua formação. Após, serão apresentadas as implicações do aerossol no clima e na saúde humana, assim como a caracterização do aerossol urbano na Região Metropolitana de São Paulo (RMSP), seus padrões de qualidade do ar, a influência da meteorologia na concentração deste poluente e, por último, serão apresentados os objetivos e metas para o desenvolvimento sustentável e como a poluição do ar está inserida para a obtenção dos mesmos até 2030.

\subsection{Breve contextualização histórica da poluição do ar}

A poluição atmosférica não é uma preocupação atual. Alguns autores sugerem o seu início com a descoberta do fogo pelos nossos ancestrais, para cozinhar, aquecer e se protegerem de predadores. Na idade média há relatos, em textos históricos, sobre a falta de visibilidade ocasionada pelos nevoeiros, estes relacionados ao tipo de matriz energética utilizada na época, como a queima de lenha e carvão. Ao longo das décadas a busca por energia se intensifica, e a demanda torna-se cada vez maior. Assim, inicia-se a revolução industrial, e mais energia é necessária para produzir, porém a matriz energética da época, o carvão, se torna um problema quando as condições meteorológicas locais não são favoráveis à dispersão dos poluentes (ALVES, 2005).

Em 1930, mais especificamente entre os dias 1 e 5 de dezembro daquele ano, ocorreu um grande nevoeiro no vale de Meuse na Bélgica que afetou um grande número de pessoas, sendo que centenas sofreram com problemas respiratórios e 63 pessoas morreram com dificuldades respiratórias somente entre o quarto e o quinto dia. No sexto dia o nevoeiro desapareceu e consequentemente as pessoas foram melhorando gradativamente (FIRKET, 1936). 
Em 1952 ocorre o primeiro smog sulfuroso na capital Londres no Reino Unido, onde milhares de pessoas morreram por intoxicação, devido a altíssimas concentrações de fumaça contendo enxofre vindo da queima de carvão, como pode ser visto na Figura 1. Ocorreram muitas mortes também por acidentes ocasionados devido à falta de visibilidade. Após o smog, o índice de mortalidade nos meses seguintes continuou acima dos níveis normais, e foi estipulada pelo governo a diminuição do uso do carvão não somente em Londres, mas em várias regiões do mundo (ALVES, 2005; BELL et al., 2004; FINLAYSON-PITTS; PITTS, 2000).

Figura 1: Gráfico adaptado do grande smog de Londres e mortalidade em dezembro de 1952

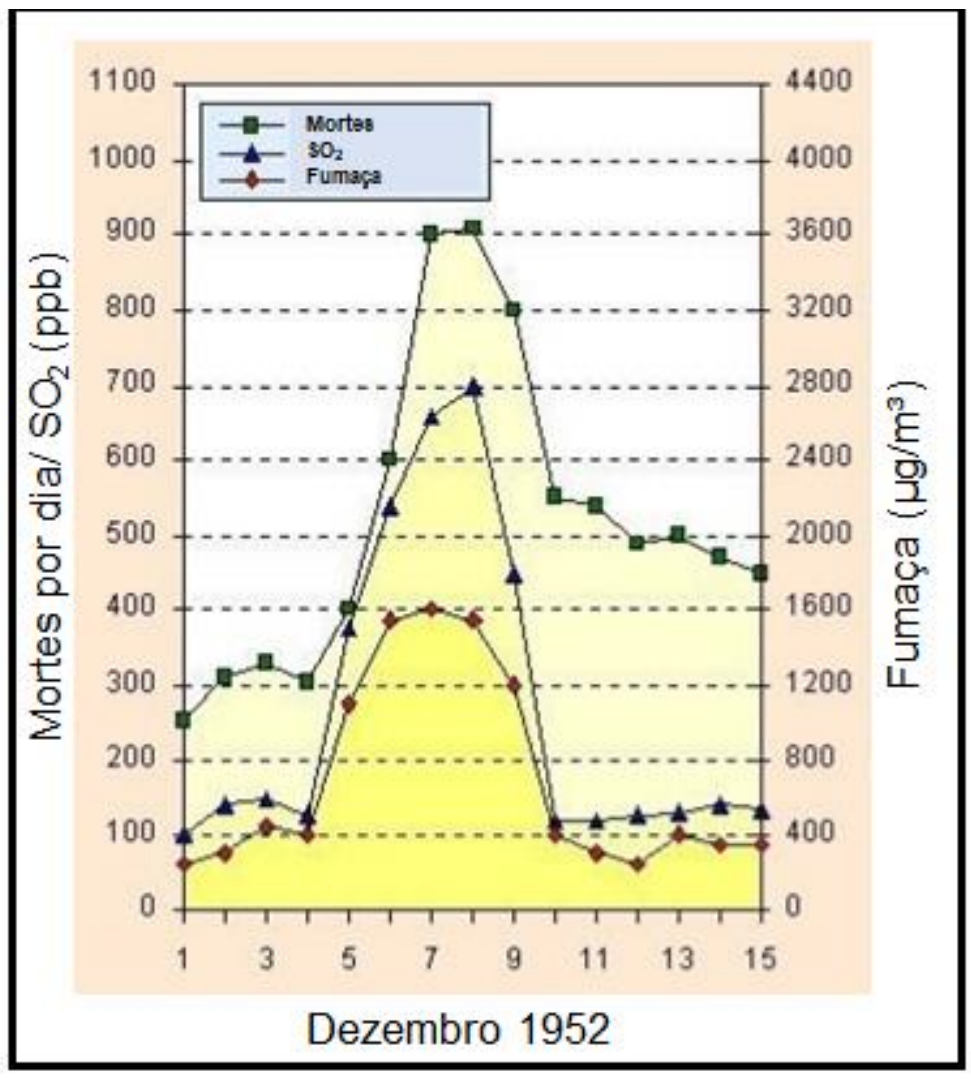

Fonte: Adaptado de AIR POLLUTION [1952].

A partir dessas grandes ocorrências, o mundo todo se voltou para a necessidade de cuidar do ar e do meio ambiente. O clube de Roma nos anos 60 foi uma das primeiras reuniões internacionais para discutir adoções de políticas sobre o uso de recursos naturais.

No Brasil, em agosto do ano de 1952, ocorreu um desastre ambiental na cidade de Bauru, devido a emissão industrial do processo de extração do óleo vegetal de mamona. O pó produzido pela moagem da mamona afetou a população da região, mais de 150 pessoas deram entrada nos hospitais com problemas respiratórios e 9 pessoas vieram a falecer (DERISIO, 
$1992^{2}$, apud, DANNI-OLIVEIRA, 2008).

Contudo, a preocupação com o ar que respiramos iniciou-se, no Brasil, após o início da década de 80 quando as emissões das indústrias da região do polo petroquímico e siderúrgico de Cubatão afetaram a qualidade ambiental e o bem estar da população local. No mesmo período, em Cubatão, ocorreram duas explosões e o incêndio causados por vazamento de gás, causando muitas mortes na Vila Socó (COMPANHIA AMBIENTAL DO ESTADO DE SÃO PAULO, 1999; KLANOVICZ E FERREIRA, 2018).

Após esses casos, houve a necessidade de controlar e administrar a incidência de emissões à atmosfera.

Em São Paulo, um dos primeiros trabalhos a ser realizado com o intuito de caracterizar o aerossol e mostrar a contribuição de cada fonte poluidora na concentração deste, foi o estudo feito pelos autores Boueres e Orsini (1981). Neste trabalho, após análise da composição elementar do MP, pôde-se correlacionar os elementos traço obtidos nas amostras aos tipos de fontes emissoras de poluição.

No mesmo período, a Companhia Ambiental do Estado de São Paulo (CETESB) inicia seus trabalhos de monitoramento, controle e licenciamento de atividades promotoras de poluição, com o intuito de preservar e recuperar o ambiente e a saúde humana. Dentre as atividades realizadas, o monitoramento de material particulado evidenciou que $60 \%$ de todo o MP coletado, a partir de 1987, se encontrava na fração fina do aerossol da Região Metropolitana de São Paulo (RMSP) e a principal fonte emissora deste poluente era de origem veicular, tanto pela emissão direta da combustão, quanto pela emissão de gases como os compostos orgânicos voláteis (COVs) e o dióxido de enxofre $\left(\mathrm{SO}_{2}\right)$, que reagem na atmosfera dando origem ao $\mathrm{MP}$ secundário (COMPANHIA AMBIENTAL DO ESTADO DE SÃO PAULO, 2014).

Nos anos 80, o Programa de Controle de Poluição do Ar Por Veículos Automotores (PROCONVE) do Instituto Brasileiro do Meio Ambiente dos Recursos Naturais (IBAMA), criado pela Resolução Conama $n^{\circ}$ 18/1986, ficou responsável por executar as políticas estabelecidas pelo Conselho Nacional do Meio Ambiente (CONAMA) para implementar uma redução nas emissões veiculares. Este programa estabelece para os fabricantes de veículos metas de limites de emissão progressivas. No mesmo período, anos 80, o CONAMA estabeleceu os primeiros padrões federais de qualidade do ar (BRASIL, 1990).

Os padrões de qualidade do ar são uma forma de gerenciar a qualidade do ar seguindo as diretrizes da Organização Mundial da Saúde (OMS), e conforme as condições de cada país. Estas metas buscam alcançar a redução de concentração de poluentes, sendo os poluentes legislados: monóxido de carbono $(\mathrm{CO})$, chumbo $(\mathrm{Pb})$, material particulado $(\mathrm{MP})$, dióxido de

\footnotetext{
${ }^{2}$ DERISIO, José Carlos. Introdução ao controle de poluição ambiental. São Paulo: CETESB, 1992.
} 
enxofre $\left(\mathrm{SO}_{2}\right)$, dióxido de nitrogênio $\left(\mathrm{NO}_{2}\right)$ e ozônio $\left(\mathrm{O}_{3}\right)$ (COMPANHIA AMBIENTAL DO ESTADO DE SÃO PAULO, 2014).

Até 2013 o $\mathrm{MP}_{2.5}$ não era legislado no Brasil. A partir desse ano, após diversos estudos que apresentam o seu potencial efeito à saúde da população, dado as suas pequenas dimensões e sua capacidade de penetrar profundamente no trato respiratório, foi incluído entre os principais poluentes padronizados buscando seguir os padrões internacionais (COMPANHIA AMBIENTAL DO ESTADO DE SÃO PAULO, 2014).

Nos anos 70 o Programa Nacional do Álcool (PROÁLCOOL) surgiu com o objetivo de estimular o uso de biocombustíveis e incentivar a produção da cana-de-açúcar no Brasil, o que contribuiu para a diminuição da dependência do petróleo como matriz energética. Também contribuiu com o meio ambiente por ser uma fonte renovável, e ainda, no balanço do ciclo de vida a cana-de-açúcar, que absorve o $\mathrm{CO}_{2}$ durante o plantio (ALISSON, 2016). Entretanto, com a combustão do etanol são emitidos hidrocarbonetos (HC) que são precursores de poluentes secundários como o $\mathrm{O}_{3}$, sendo este altamente prejudicial à saúde e ao meio ambiente (ANDRADE et al., 2017).

Portanto, podemos concluir que no decorrer da história, a poluição vem sendo um problema a ser superado por todo o globo, pois este afeta diretamente a saúde humana, principalmente quando os grupos de risco como idosos, crianças e pessoas com morbidades prévias são expostas. Porém, as consequências da exposição à poluição, tanto a curto, quanto a longo prazo, também afetam as outras áreas da sociedade, como o sistema econômico e o meio ambiente (MIRAGLIA; GOUVEIA, 2014; SALDIVA, 1994).

\subsection{Aerossol Atmosférico}

Aerossóis atmosféricos são definidos por partículas sólidas ou líquidas suspensas na atmosfera, podendo ter origem primária ou secundária e possuir diferentes composições químicas e propriedades físicas (tamanho e forma). A determinação da distribuição de tamanho das partículas é dada a partir do diâmetro aerodinâmico (d.a.), dado que a sua forma é relativamente irregular e esférica e admite um comportamento aerodinâmico. O material particulado pode variar de alguns nanômetros $(\mathrm{nm})$ a dezenas de micrometros $(\mu \mathrm{m})$. Conforme a Figura 2, o material particulado é dividido em quatro modas: ultrafina, núcleos de Aitken, moda de acumulação e a moda grossa. De uma forma geral, separam-se em dois grupos:

- Frações grossa: apresenta d.a. entre $2,5 \mu \mathrm{m}$ e $10 \mu \mathrm{m}$

- Fração fina: apresenta d.a. <2,5 $\mu \mathrm{m}$. 
Essa classificação é determinante para compreender os processos de deposição e sedimentação, e a permanência do aerossol na atmosfera (HINDS, 1982; SEINFELD; PANDIS, 2006;).

As partículas na atmosfera podem ter a sua origem de forma natural ou antropogênica. Quando de origem natural, podem ocorrer principalmente por:

- ressuspensão do solo, ação biogênica, pelo espalhamento de pólens, esporos, vulcanismo, ou por spray marinho.

Quando de origem antropogênica, podem ser formadas a partir de:

- combustão de combustíveis fósseis de fontes fixas (indústrias, pizzarias etc.) e móveis (veículos leves e pesados), fumaças de queima de biomassa e vapores químicos.

As partículas de origem primária podem reagir entre si na atmosfera, e gerar outros compostos, formando aerossóis secundários (COMPANHIA AMBIENTAL DO ESTADO DE SÃO PAULO, 2018; SEINFELD; PANDIS, 2006).

O aerossol é transportado pelo ar de maneiras diferentes, devido as suas características físico-químicas que dependem da sua formação (HINDS, 1982).

A figura 2 apresenta um esquema da evolução da formação do aerossol na atmosfera e como é dada a sua deposição e/ou sedimentação. 
Figura 2 - Esquema da formação, distribuição modal e deposição do aerossol na troposfera. Hipótese original de Whitby, et al. (1980) é mostrada na linha sólida da curva, com três modas. A quarta moda, das partículas ultrafinas, bem como os dois picos por vezes observados na moda de acumulação são mostrados pelas linhas pontilhadas.
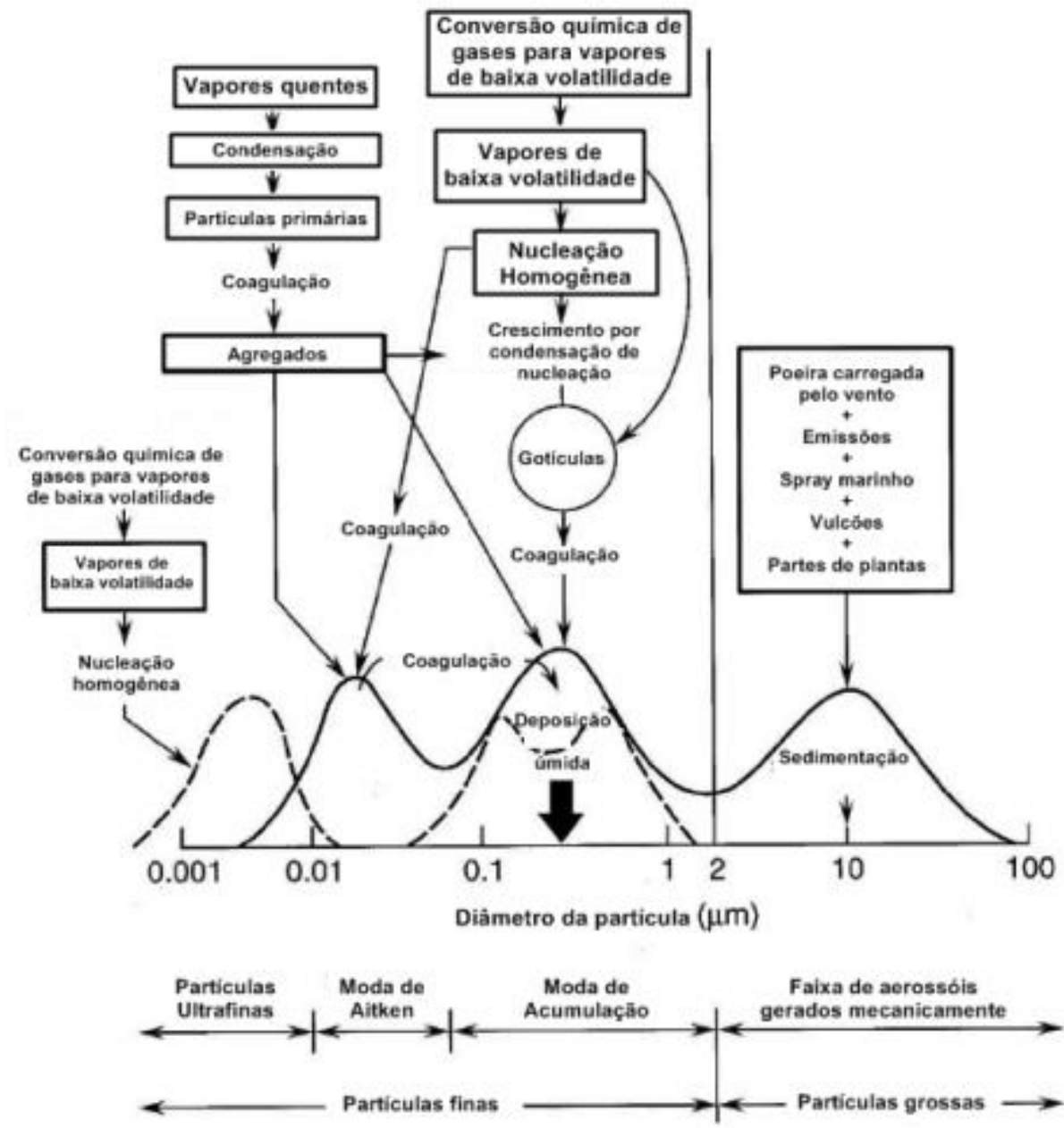

Fonte: YONUE (2004) adaptado de FINLAYSON-PITTS; PITTS (2000)

A conversão gás-partícula ocorre a partir de gases de baixa volatilidade na atmosfera, e são geradas partículas ultrafinas pelo processo de nucleação desses gases, formando partículas nanométricas com d.a. em torno de $10 \mathrm{~nm}$.

Na moda dos núcleos de Aitken as partículas apresentam um d.a. entre 10-100 nm, e devido às suas pequenas dimensões, essa fração do aerossol tem pequena contribuição na massa total de partículas transportadas pelo ar.

$\mathrm{Na}$ fase de acumulação, as partículas finas se condensam, e partículas menores são agregadas às partículas maiores, alcançando d.a. entre 0,1-2,5 $\mu \mathrm{m}$. Esta é a fração responsável por grande parte da massa total de aerossol atmosférico, e os mecanismos de remoção são menos eficientes devido ao seu pequeno tamanho, assim, persistem por mais tempo em suspensão na atmosfera.

A remoção dos aerossóis da atmosfera envolve dois processos básicos: deposição seca 
(partículas caem em direção à superfície por ação da gravidade), deposição úmida, que envolve rainout (incorporação de partículas em gotas de chuva, em processos que ocorrem dentro da nuvem) e washout (incorporação de partículas em gotas de chuva, mas em processos que ocorrem abaixo da base da nuvem).

A fração grossa $(2,5<$ d.a. $<10 \mu \mathrm{m})$ geralmente têm a sua fonte de origem natural, por meio de processos mecânicos, como a ressuspensão do solo, spray marinho, vulcanismos e pólens de plantas. Devido ao seu d.a, sua permanência na atmosfera é mais breve, sendo logo sedimentada pelo processo de deposição seca (SEINFELD; PANDIS, 2006).

\subsection{Aerossol, Clima e Saúde}

Segundo o IPCC (2013), o aerossol é um dos responsáveis por afetar o balanço radiativo do planeta. As propriedades físicas das partículas colaboram para o aumento do albedo terrestre, quando estas partículas possuem propriedades reflexivas, e podem aumentar a temperatura da Terra quando suas propriedades físicas forem absorvedoras de radiação, como no caso do black carbon.

Atividades vulcânicas são exemplos de fontes naturais de aerossóis que agem como forçantes radiativas negativas da Terra. Em 1991 a erupção do vulcão Pinatubo nas Filipinas, foi a primeira explosão vulcânica estudada em detalhes suficientes para avaliar seus efeitos no clima terrestre. A temperatura global diminuiu $\sim 0.6^{\circ} \mathrm{C}$ durante o verão daquele ano, e o efeito de resfriamento durou por volta de dois anos após a erupção (RUDDIMMAN, 2014; QIN, 2013).

O efeito de resfriamento causado pelas emissões vulcânicas é dado, em grande parte, pela alta concentração de partículas de sulfato ejetadas na atmosfera. $\mathrm{O}$ dióxido de enxofre $\left(\mathrm{SO}_{2}\right)$ reage com o vapor d'agua $\left(\mathrm{H}_{2} \mathrm{O}\right)$ e é transformado em partículas de sulfato $\left(\mathrm{SO}_{4}{ }^{2-}\right)$. Estas partículas se tornam mais reflexivas aumentando assim o albedo terrestre temporariamente (RUDDIMMAN, 2014).

Os aerossóis podem alterar o balanço de radiação na atmosfera de dois modos: o primeiro, espalhando e absorvendo radiação, reconhecido como o efeito direto, o segundo é modificando as propriedades ópticas, quantidade e tempo de vida das nuvens, denominado como efeito indireto. As mudanças antrópicas, via de alteração nas concentrações naturais dos aerossóis, podem induzir alterações na quantidade de nuvens, já que as partículas agem como núcleos de condensação de nuvens, e ainda podem modificar a refletividade das mesmas. Para entender as propriedades ópticas e os efeitos radiativos dos aerossóis é necessário conhecer a 
sua composição química e tamanho, já que estas características modulam a interação entre o aerossol e a radiação.

Os efeitos indiretos das partículas na atmosfera, quanto à ação das nuvens como forçante radiativa, também dependerá da dinâmica e evolução do vapor d'água na atmosfera (BAIRD, 2011; RUDDIMMAN, 2014).

Além dos efeitos no clima e meio ambiente, o aerossol atmosférico está relacionado a doenças cardiorrespiratórias e óbitos da população mais vulnerável, como crianças e idosos. Com o seu tamanho diminuto, as partículas podem penetrar profundamente no sistema respiratório e causar desde alergias a doenças mais sérias (BRAGA et al., 2001).

Conforme mostra a figura 3 , as dimensões das partículas emitidas pela combustão veicular, possuem d.a. muito pequeno, e quanto menor forem essas partículas, maior será a penetração no sistema respiratório, chegando aos alvéolos pulmonares e podendo atingir a circulação sanguínea. A toxicidade causada pelas partículas depende da composição química das partículas, e dos elementos que estão adsorvidos nelas.

Figura 3 - MP e Sistema respiratório.

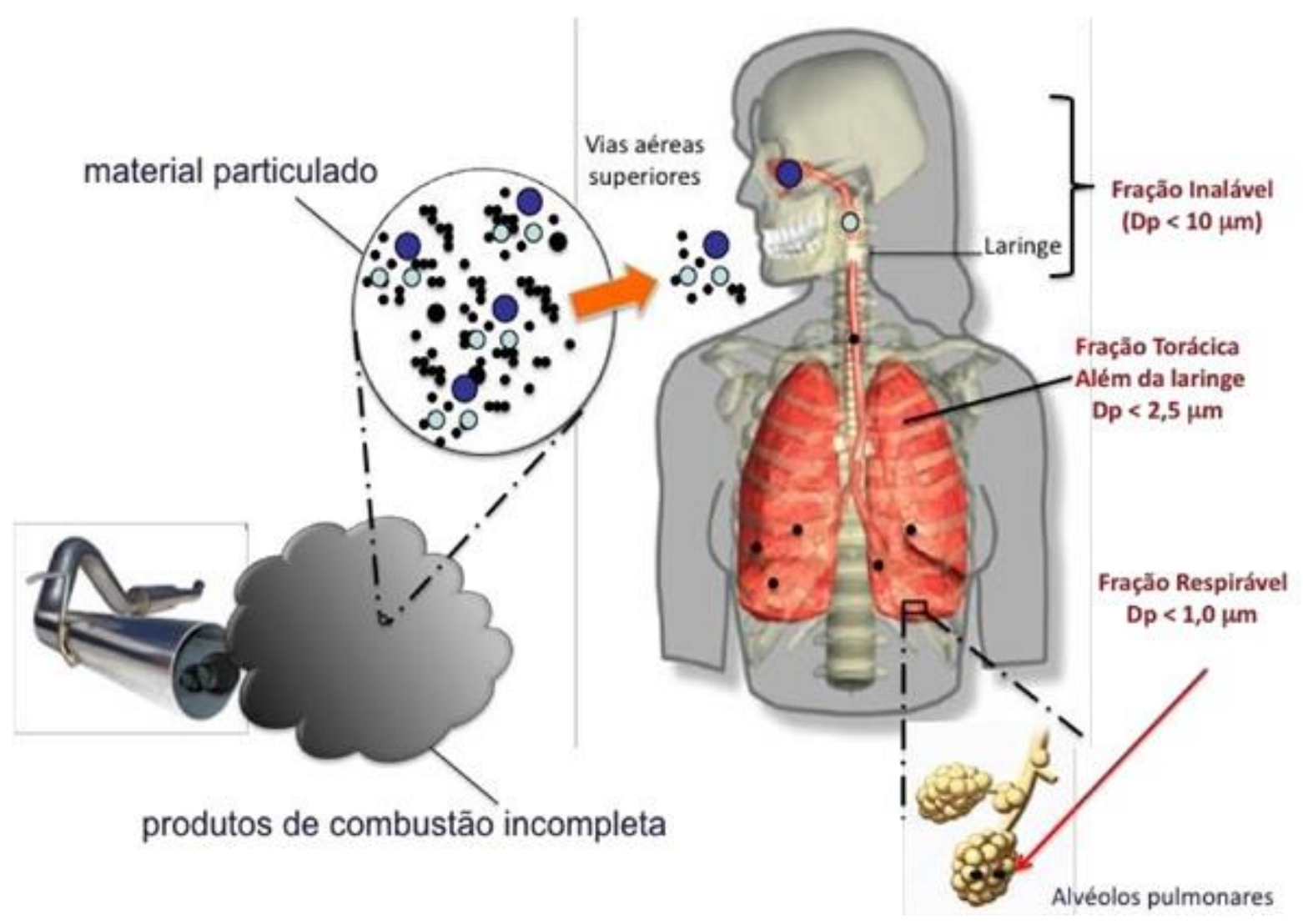

Fonte: GUARIEIRO et al. (2011)

Através de diversos estudos realizados em centros urbanos que utilizaram técnicas de análises estatísticas para estudos epidemiológicos, foram avaliados os efeitos de morbidade e 
mortalidade ocasionados pelos poluentes atmosféricos, concluindo-se que as partículas encontradas nas grandes cidades acarretam afecções agudas e crônicas no trato respiratório, mesmo que em baixas concentrações relativas ao padrão de qualidade do ar, evidenciando que os padrões de qualidade do ar estão inadequados para a saúde da população, principalmente quando esta é mais suscetível, como as crianças, idosos e pessoas que já apresentam doenças crônicas do sistema respiratório. Vários estudos demonstraram ocorrência de efeitos mórbidos, como a asma e bronquite, tendo incidência em baixas concentrações de poluentes. A mortalidade por patologias do sistema respiratório apresenta uma forte associação com a poluição atmosférica e atinge as populações com maior vulnerabilidade, assim como casos de mortalidade por doenças cardiovasculares, e sua relação está amplamente associada à poluição atmosférica urbana, sendo o material particulado inalável o principal poluente associado (BRAGA, 2001; NASCIMENTO et al., 2017; WORLD HEALTH ORGANIZATION, 2006).

Segundo a OMS (2006), a concentração mínima de $\mathrm{MP}_{2.5}$ considerada, que não afeta a saúde humana, é de até $25 \mu \mathrm{g} / \mathrm{m}^{3}$ a curto prazo, ou padrão médio de $24 \mathrm{~h}$. Entretanto, a própria OMS revela que não é possível estabelecer um limite mínimo de concentração de MP que abaixo do qual não afete a saúde.

Diversos estudos epidemiológicos quantificam o impacto da concentração de $\mathrm{MP}_{2.5} \mathrm{e}$ número de casos graves decorrentes de problemas respiratórios, com o intuito de estipular o nível mínimo de concentração que não afetará a saúde humana. Mostram que mesmo que a concentração média de $24 \mathrm{~h}$ do $\mathrm{MP}_{2.5}$ não tenha ultrapassado o limite considerado mínimo para manter a segurança à saúde, ainda assim foi associada a incidência de internação de crianças com problemas respiratórios (NASCIMENTO et al., 2017).

Segundo Miraglia e Gouveia (2014), em um estudo realizado para avaliar os custos da poluição atmosférica na saúde, para algumas das grandes regiões metropolitanas brasileiras foi estimado, a partir de modelagem de cálculo da mortalidade e análise da valoração dos efeitos da poluição na saúde, que os custos resultam em mais de 1 bilhão de dólares para o período de um ano, levando em consideração a cotação do dólar de 02/2012. E a estimativa de mortes devido a poluição chega a ser de mais de 20 mil óbitos.

Medidas governamentais de controle de poluentes e de diminuição de emissões são importantes para a manutenção da qualidade do ar. Assim, a diminuição das concentrações de poluentes atmosféricos afetará positivamente na qualidade de vida, no meio ambiente e na sociedade.

Em fevereiro de 2020 iniciou-se a pandemia pelo vírus COVID-19 no Brasil. Este é um vírus que afeta principalmente o sistema respiratório e se espalha de pessoa para pessoa através do ar, a partir de gotículas de saliva ou secreções nasais. Por isso a OMS e governos 
recomendaram manter uma distância interpessoal de 1,5 a $2 \mathrm{~m}$ para minimizar o risco de contágio pelas gotículas que costumamos disseminar em torno de nós pelo nariz e pela boca, além de estipularem a obrigatoriedade do uso de máscaras em locais públicos. No entanto, estudos publicados apoiam a hipótese de transmissão do vírus a uma distância maior que $2 \mathrm{~m}$ de uma pessoa infectada (SETTI et al., 2020b).

Cidades com altas concentrações de poluentes, especialmente com altas concentrações de partículas finas, foram muito afetadas pela pandemia de COVID-19. Estudos sugerem que o poluente pode influenciar a propagação do vírus, pois a partir de um espirro de uma pessoa infectada, o vírus pode ficar adsorvido nas partículas e ser carregado pelo vento (SETTI et al., 2020b).

WU et al. (2020), descobriram que um aumento de apenas $1 \mu \mathrm{g} / \mathrm{m}^{3}$ na $\mathrm{MP}_{2.5}$ está associado a um aumento de $8 \%$ na taxa de mortalidade por COVID-19.

Estudos na China e Itália relacionaram o aumento de casos de infectados por COVID19 com o aumento das concentrações de aerossol. Estudos preliminares da universidade de Bologna na Itália apresentaram um aumento no número de infectados mesmo quando houve o lockdown (entre os dias 24 de fevereiro e 13 de março deste ano) por toda a Itália, reforçando a hipótese do espalhamento do vírus através das partículas de poluição no ar (SETTI et al., 2020a).

Com a pandemia e com as medidas de restrições, ocorreu uma diminuição expressiva nas concentrações de $\mathrm{MP}_{2.5}$, $\mathrm{CO}$ e $\mathrm{NO}_{2}$ nas grandes cidades como São Paulo, Nova York, Los Angeles e Paris, no entanto houve aumento do poluente secundário $\mathrm{O}_{3}$. Essa redução expressiva contribui para a saúde da população de ambiente, além de poder ajudar a prevenir mortes causadas pela epidemia de COVID-19 em megacidades, diminuindo a pressão sobre o sistema de saúde (CONNERTON et al., 2020).

\subsection{Aerossol em São Paulo}

A Região Metropolitana de São Paulo (RMSP), localizada na região sudeste do Brasil, é uma das maiores do mundo, possui em torno de 21,570 milhões de habitantes, em um espaço de 7.946,96 km² (INSTITUTO BRASILEIRO DE GEOGRAFIA E ESTATÍSTICA, 2018).

Em estudos realizados pela Companhia Ambiental do Estado de São Paulo (CETESB) sobre a qualidade do ar da RMSP, é apresentado que os diversos problemas relacionados à poluição atmosférica ocorrem devido, principalmente, ao excesso de veículos, seguido das emissões industriais (COMPANHIA AMBIENTAL DO ESTADO DE SÃO PAULO, 2017).

Somente na capital paulista a frota veicular passa dos 8 milhões de veículos automotores, 
dentre eles os automóveis são a maioria, com mais de 5 milhões registrados na capital (BRASIL, 2018).

Desde os primeiros estudos realizados na RMSP sobre poluição atmosférica, foram mostradas e identificadas as mais importantes contribuições das principais fontes poluidoras. Em BOUERES e ORSINI (1981), um dos primeiros estudos sobre poluição atmosférica na RMSP, é mostrada a caracterização das frações grossa e fina do material particulado atmosférico coletado na capital no ano de 1977. Os elementos encontrados na fração grossa das amostras foram relacionados à composição solo, que pode ter sua ocorrência com a ressuspensão tanto por ação natural dos ventos, quanto por ações antrópicas, e por tráfego veicular em vias não pavimentadas e pavimentadas. Os elementos caracterizados nesta fração foram Al, Si, K, Ca, Ti e Fe. Já na fração fina, foram identificados elementos traço de origem antropogênica provenientes da industrialização e combustão de veículos leves e pesados. Os elementos encontrados foram $\mathrm{Fe}, \mathrm{Zn}, \mathrm{S}, \mathrm{Br}$ e $\mathrm{Pb} .85 \%$ do $\mathrm{S}$ coletado se encontrava na fração fina das amostras, e sua formação na atmosfera é sugerida pelo processo de conversão gáspartícula da combustão de gasolina e óleo diesel.

Em estudos mais recentes realizados na cidade de São Paulo, foi mostrado que aproximadamente $40 \%$ da concentração do material particulado fino é proveniente da emissão veicular (ANDRADE et al., 2010).

Ao longo dos últimos trinta anos, o uso e ocupação do solo da capital passou por diversas alterações, entre elas a migração de grande parte das indústrias para o interior paulista, e a consolidação de moradias e prédios comerciais na capital. Essas alterações afetaram não somente na ocupação do solo, como também na composição química da atmosfera da cidade (ANDRADE et al., 2017).

Na figura 4 pode-se observar a ilustração esquemática que exemplifica a dinâmica e evolução da RMSP com o passar dos anos, onde as indústrias foram dando lugar aos prédios comerciais e moradias, e com o aumento populacional da capital o número de veículos de passeio também aumentou. Essa dinâmica afeta diretamente a qualidade do ar da cidade. Atualmente a concentração dos poluentes secundários tem crescido devido ao aumento do uso de combustíveis alternativos, como o etanol, em contrapartida o enxofre (S) foi diminuído drasticamente graças a essas alterações e a evolução nas tecnologias para melhoria dos combustíveis, como a criação do diesel S10 (10 mg de enxofre por kg de óleo diesel) que é a versão diesel com menor concentração de enxofre, muito utilizada por veículos pesados como os caminhões e ônibus. 


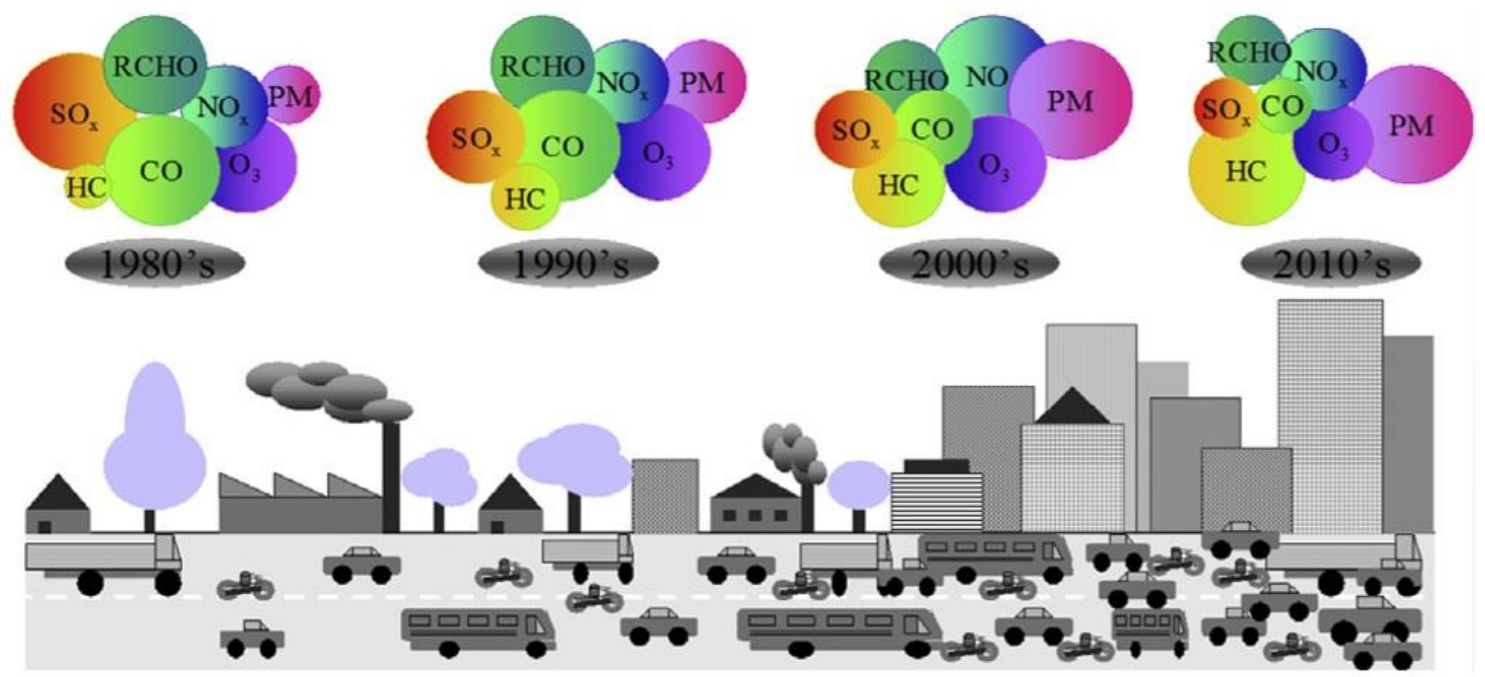

Fonte: ANDRADE et al. (2017)

Na figura 5 a seguir observa-se a contribuição de cada tipo de fonte para os poluentes regulamentados.

Figura 5 - Porcentagem das concentrações por fontes poluentes para a RMSP.

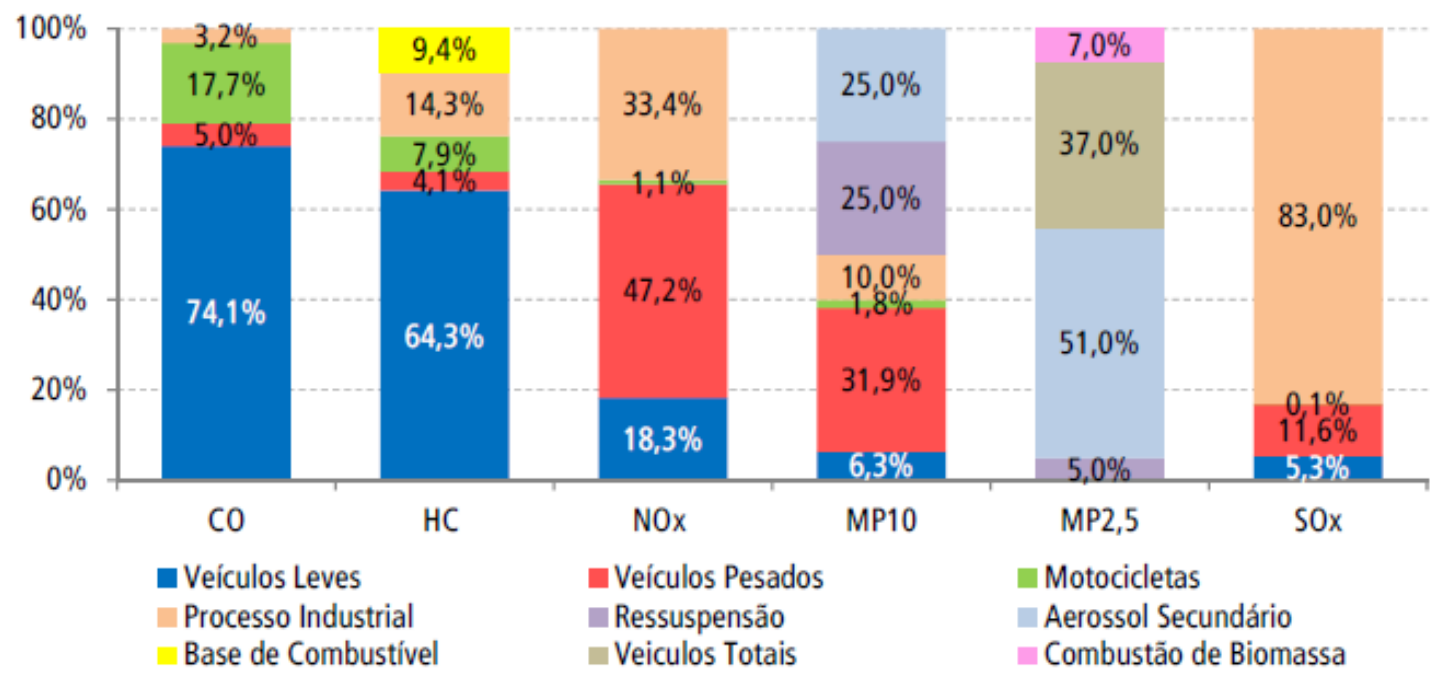

Fonte: Relatório de qualidade do ar da CETESB (2018)

Verifica-se na figura, que atualmente na RMSP a maior contribuição para com o $\mathrm{MP}_{2.5}$ tem sua origem no aerossol secundário que envolve a combustão veicular, com 51\%; $37 \%$ relacionado a combustão de veículos totais; os veículos pesados possuem a contribuição de 31,9\% no $\mathrm{MP}_{10}$. 
A contribuição veicular como principal fonte de emissão do aerossol é analisada em diversos estudos, como mencionado anteriormente, e a sua participação é cada vez mais presente em grandes centros urbanos como São Paulo.

A CETESB monitora e controla a emissão do aerossol, e em suas análises evidencia que a maior parte de todo o MP coletado se encontra na fração fina do aerossol, e seus principais contribuintes são da emissão direta da combustão veicular, seguido da emissão de gases como os COVs e o dióxido de enxofre, que podem reagir na atmosfera dando origem ao MP secundário (COMPANHIA AMBIENTAL DO ESTADO DE SÃO PAULO, 2013).

Estudos recentes mostram que as partículas submicrométricas têm forte contribuição sobre o $\mathrm{MP}_{2.5}$, indicando que em algumas regiões da cidade de São Paulo o MP 10 (partículas com d.a. < $10 \mu \mathrm{m}$ ) contribuem com aproximadamente $80 \%$ do $\mathrm{MP}_{2.5}$ (COMPANHIA AMBIENTAL DO ESTADO DE SÃO PAULO, 2020).

\subsubsection{Padrões de qualidade do ar}

Os padrões de qualidade do ar estipulam os limites para as concentrações de poluentes atmosféricos que, quando em excesso, afetam a saúde, segurança, bem-estar, flora, fauna e os materiais. Portanto, poluente atmosférico é considerado qualquer forma de matéria ou energia com intensidade e em quantidade, concentração, tempo ou características em desacordo com os níveis estabelecidos, que tornem ou possam tornar o ar impróprio, nocivo ou ofensivo à saúde e ao meio ambiente, e inconveniente ao uso e gozo da propriedade e às atividades normais da comunidade (BRASIL, 2018).

Os poluentes padronizados são definidos por sua importância nos danos à saúde e ao meio ambiente, assim como também na sua frequência de ocorrência. Os poluentes indicadores mais abrangentes da qualidade do ar são: monóxido de carbono (CO), dióxido de enxofre $\left(\mathrm{SO}_{2}\right)$, material particulado $\left(\mathrm{MP}_{10}, \mathrm{MP} 2.5\right)$, ozônio $\left(\mathrm{O}_{3}\right)$ e dióxido de nitrogênio $\left(\mathrm{NO}_{2}\right)(\mathrm{COMPANHIA}$ AMBIENTAL DO ESTADO DE SÃO PAULO, 2017).

Em 2005 a Organização Mundial de Saúde (OMS) publicou que as nações deveriam considerar as questões econômicas, políticas, sociais, condições técnicas e capacidade de gerir a qualidade do ar, visando a saúde pública, antes de estipular os padrões de qualidade do ar nacionais e suas políticas. Em 2013, através do Decreto Estadual no 59.113, de 23/04/2013 (SÃO PAULO, 2013), o governo de São Paulo estabeleceu novos padrões de qualidade do ar, baseando-se nas diretrizes da OMS, seguindo os critérios de Metas Intermediárias (MI) e Padrões Finais (PF), que são valores de redução de concentração de poluentes a serem atingidos 
por etapas, sem prazo estabelecido, com o intuito de melhorar a qualidade do ar de forma gradativa, reduzindo as emissões de fontes fixas e móveis. O Padrão Final (PF) foi determinado baseando-se nos conhecimentos científicos preconizando a preservação da saúde da população, buscando o desenvolvimento sustentável. As políticas de controle de emissões veiculares são um exemplo de ação que visa melhorar a qualidade do ar e estão relacionadas à implementação de novas tecnologias de combustíveis e motores, assim como na ampliação do uso de energias alternativas, limpas e renováveis (COMPANHIA AMBIENTAL DO ESTADO DE SÃO PAULO, 2014).

A tabela 1 ilustra a evolução dos padrões de qualidade do ar para o Estado de São Paulo e as metas intermediárias e padrão final a serem atingidos, para os poluentes indicadores mais frequentes.

Tabela 1 - Evolução dos Padrões de Qualidade do ar.

Padrões nacionais de qualidade do ar para os poluentes: $\mathrm{MP}_{10}, \mathrm{MP}_{2.5}, \mathrm{SO}_{2}, \mathrm{NO}_{2}, \mathrm{O}_{3}, \mathrm{CO}, \mathrm{FMC}$, PTS e Pb.

\begin{tabular}{|c|c|c|c|c|c|c|c|}
\hline \multicolumn{2}{|l|}{ Anol } & \multicolumn{3}{|c|}{1990} & \multicolumn{2}{|c|}{2013} & \multirow[b]{2}{*}{ PF } \\
\hline Poluente & $\begin{array}{c}\text { Tempo de } \\
\text { Amostragem }\end{array}$ & $\begin{array}{l}\text { Padrão } \\
\text { Primário }\end{array}$ & $\begin{array}{c}\text { Padräo } \\
\text { Secundánio }\end{array}$ & $\begin{array}{c}\mathrm{MI}-1 \\
(\mu g / m 3)\end{array}$ & $\underset{\left(\mu g / m^{3}\right)}{M I-2}$ & $\begin{array}{c}\mathrm{Ml}-3 \\
\left(\mu g / \mathrm{m}^{3}\right)\end{array}$ & \\
\hline $\begin{array}{c}\text { Material } \\
\text { particulado } \\
\text { Inalável (PM10) }\end{array}$ & $\begin{array}{l}24 \mathrm{~h} \\
\mathrm{MAA}^{*}\end{array}$ & $\begin{array}{l}150 \\
50\end{array}$ & $\begin{array}{l}150 \\
50\end{array}$ & $\begin{array}{l}120 \\
40\end{array}$ & $\begin{array}{l}100 \\
35\end{array}$ & $\begin{array}{l}75 \\
30\end{array}$ & $\begin{array}{l}50 \\
20\end{array}$ \\
\hline $\begin{array}{c}\text { Material } \\
\text { particulado } \\
\text { Inalável }(\mathrm{PM} 2,5)\end{array}$ & $\begin{array}{l}24 \mathrm{~h} \\
\mathrm{MAA}\end{array}$ & - & - & $\begin{array}{l}60 \\
20\end{array}$ & 50 & $\begin{array}{l}37 \\
15\end{array}$ & $\begin{array}{l}20 \\
10\end{array}$ \\
\hline $\begin{array}{c}\text { Dióxido de } \\
\text { Enxofre (SO2) }\end{array}$ & $\begin{array}{l}24 \mathrm{~h} \\
\text { MAA }\end{array}$ & $\begin{array}{l}365 \\
80\end{array}$ & $\begin{array}{l}100 \\
40\end{array}$ & $\begin{array}{l}60 \\
40\end{array}$ & $\begin{array}{l}40 \\
30\end{array}$ & $\begin{array}{l}30 \\
20\end{array}$ & $\begin{array}{r}20 \\
-\end{array}$ \\
\hline $\begin{array}{c}\text { Dióxido de } \\
\text { Nitrogên io (NO2) }\end{array}$ & $\begin{array}{l}1 \mathrm{~h} \\
M A A\end{array}$ & $\begin{array}{l}320 \\
100\end{array}$ & $\begin{array}{l}190 \\
100\end{array}$ & $\begin{array}{l}260 \\
60\end{array}$ & $\begin{array}{l}240 \\
50\end{array}$ & $\begin{array}{l}220 \\
45\end{array}$ & $\begin{array}{l}200 \\
40\end{array}$ \\
\hline Ozônio (03) & $\begin{array}{l}1 \mathrm{~h} \\
8 \mathrm{~h}\end{array}$ & 160 & 160 & 140 & 130 & 120 & 100 \\
\hline $\begin{array}{l}\text { Monóxido de } \\
\text { Carbono (CO) }\end{array}$ & $8 \mathrm{~h}$ & $\begin{array}{l}10000 \\
9 \mathrm{ppm}\end{array}$ & $\begin{array}{l}10000 \\
9 p p m\end{array}$ & - & - & - & $\begin{array}{c}- \\
9 \mathrm{ppm}\end{array}$ \\
\hline Fumaţa (FMC) & $\begin{array}{l}24 \mathrm{~h} \\
\mathrm{MAA}\end{array}$ & $\begin{array}{c}150 \\
60\end{array}$ & $\begin{array}{c}100 \\
40\end{array}$ & $\begin{array}{c}120 \\
40\end{array}$ & $\begin{array}{c}100 \\
35\end{array}$ & $\begin{array}{l}75 \\
30\end{array}$ & $\begin{array}{l}50 \\
20\end{array}$ \\
\hline $\begin{array}{l}\text { Partículas Totais } \\
\text { em Suspensão } \\
\text { (PTS) }\end{array}$ & $\begin{array}{c}24 \mathrm{~h} \\
M G A^{* *}\end{array}$ & $\begin{array}{l}240 \\
80\end{array}$ & $\begin{array}{l}150 \\
60\end{array}$ & - & - & - & $\begin{array}{l}240 \\
80\end{array}$ \\
\hline Chumbo (Pb) & MAA & - & - & - & - & - & 0,5 \\
\hline
\end{tabular}

Fonte: Adaptado da COMPANHIA AMBIENTAL DO ESTADO DE SÃO PAULO (2014 e 2018)

Nota: Padrões vigentes na coluna MI de 2013.

*MAA - Média aritmética anual.

**MGA - Média geométrica anual. 
Na coluna MI - 1, destacada em vermelho, encontram-se os parâmetros de qualidade do ar em vigor na RMSP, seguido de suas metas intermediárias a serem alcançadas por etapas.

Os padrões federais de qualidade do ar foram recentemente alterados pela Resolução CONAMA n 491/2018, que revogou e substituiu a Resolução CONAMA n 3/1990 (BRASIL, 2018).

\subsection{A influência da meteorologia na concentração dos poluentes}

As condições meteorológicas podem influenciar de forma bastante significativa a concentração dos poluentes. A mudança de uma situação desfavorável para favorável à dispersão de poluentes ocorre normalmente quando um sistema frontal atinge a RMSP, uma vez que torna instável a atmosfera e aumenta a velocidade do vento. A precipitação também influi de forma considerável. A ocorrência de precipitação, além de ser um indicador de que a atmosfera está instável, ou seja, com movimentos de ar que favorecem a dispersão de poluentes, promove a remoção dos mesmos, pois uma parcela significativa desses poluentes é incorporada à água da chuva, e assim são depositados.

Segundo Barros e Lombardo (2016), um dos fenômenos mais frequentes que ocorre em áreas urbanas é o chamado "Efeitos de Ilhas de Calor". Este fenômeno tem como a sua principal causa a relação com a ausência da vegetação, seguido das alterações da superfície do solo, como a presença de asfalto, concreto, e a utilização de materiais de cobertura residenciais, como os telhados de zinco, alumínio e amianto. Esses materiais contribuem para a maior propagação e armazenamento de calor em até $8^{\circ} \mathrm{C}$ a mais do que quando comparado a áreas rurais.

A Zona Leste da capital possui as características favoráveis à incidência de ilhas de calor, por ser uma das áreas mais impermeabilizadas da capital. Quando a fria e úmida brisa marítima encontra o ar quente da região urbana formam-se tempestades, e dada a vasta impermeabilização do solo por ocupações irregulares, em sua maior parte, podem ocorrer enchentes e inundações. Este fenômeno e sua ocorrência são mais favoráveis nos meses de verão (PREFEITURA DE SÃO PAULO, 1999; VEMADO; PEREIRA FILHO, 2016).

Outro fenômeno meteorológico chamado de inversão térmica, pode agravar a qualidade do ar noturna em áreas de intensa urbanização, principalmente nos meses de inverno, pois neste período as baixas temperaturas e umidade não favorecem a dispersão dos poluentes, tornando estável a circulação atmosférica. Ao anoitecer a superfície terrestre resfria rapidamente, o efeito de convecção da atmosfera é alterado, e na camada limite planetária acumulam-se os poluentes 
entre duas camadas de ar frio. As camadas de ar frio aprisionam os poluentes próximos à superfície, e abaixo de $200 \mathrm{~m}$ esse fenômeno se torna altamente prejudicial à saúde e ao meio ambiente. Após o amanhecer, o ar começa a ser aquecido novamente, e o efeito convectivo volta a se formar, favorecendo a dispersão dos poluentes. A figura 6 mostra a cidade sob o efeito de uma situação de inversão térmica.

Figura 6 - Cidade de São Paulo sob o efeito da inversão térmica no mês de julho de 2015, às $11 \mathrm{~h}$.

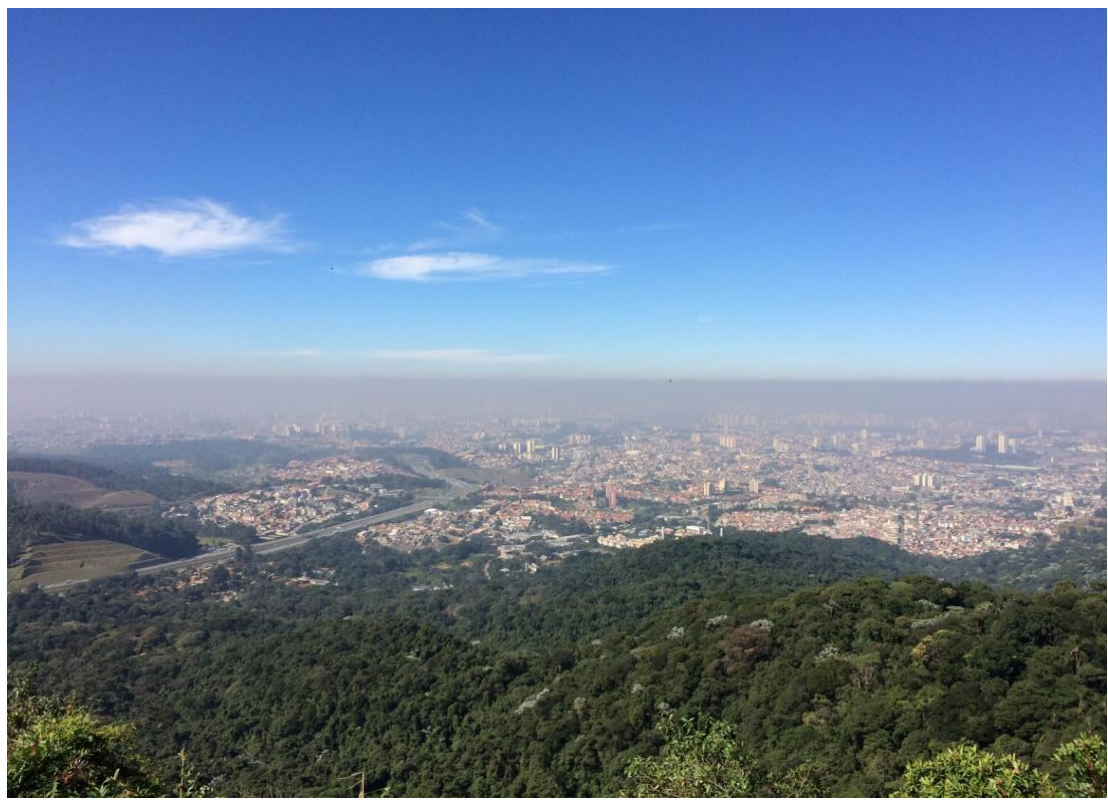

Fonte: Arquivo pessoal de Regina Maura de Miranda

Na figura 6, observa-se no horizonte uma camada cinza cobrindo a cidade, esta é a camada de poluição aprisionada por duas camadas de ar mais frio. Esta foto foi tirada no mês Julho de 2015 às 11 horas. Neste dia e horário a incidência de radiação ainda não foi suficiente para causar convecção na superfície e dispersar os poluentes aprisionados.

A concentração dos poluentes na atmosfera da RMSP é influenciada diretamente pela distribuição e intensidade das emissões dos poluentes atmosféricos, e a sua dispersão é influenciada diretamente pela topografia e condições meteorológicas. As variações sazonais devem ser consideras de forma significativa quando se trata das condições atmosféricas e das concentrações dos poluentes. Nos períodos de inverno, entre os meses de junho e agosto, encontram-se as maiores concentrações de poluentes, pois neste período há a maior ocorrência de inversões térmicas em baixos níveis de altitude, em conjunto com a estabilidade atmosférica, caracterizada por eventos de calmaria, ventos fracos e baixos índices pluviométricos, que promovem o acúmulo de poluentes. Já no verão, a alta umidade relativa do ar característica deste período, entre os meses de dezembro e março, altos níveis pluviométricos e entrada de 
frentes, favorecem a dispersão dos poluentes (COMPANHIA AMBIENTAL DO ESTADO DE SÃO PAULO, 2014; SÁNCHEZ-CCOYLLO; ANDRADE, 2002).

\subsection{Sustentabilidade e poluição do ar}

A sustentabilidade se refere ao equilíbrio das relações entre a sociedade e o meio ambiente. O desenvolvimento sustentável é o caminho para a busca da sustentabilidade, e este é influenciado pela economia, sociedade, meio ambiente e mudanças políticas. $\mathrm{O}$ desenvolvimento implica na decisão de milhares de pessoas, negócios, indústrias, e das leis regulamentares, que causam efeito tanto micro quanto macro na sociedade e ambiente (CHANDRAPPA et al., 2016).

A Organização das Nações Unidas (ONU) estipulou 17 metas para o desenvolvimento sustentável global, a serem atingidas até 2030 (figura7). Um dos principais intuitos é de promover a diminuição da temperatura global através da redução das emissões de carbono para a atmosfera.

Figura 7 - 17 Objetivos para o desenvolvimento sustentável.

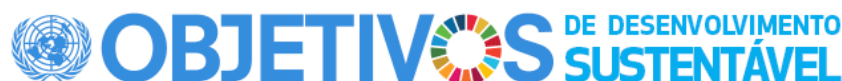
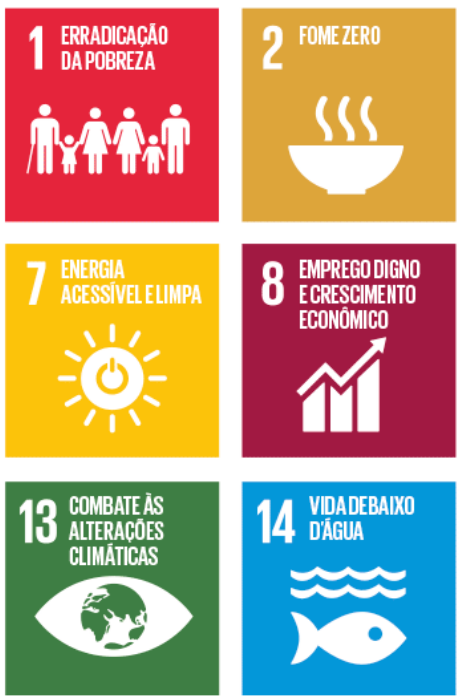
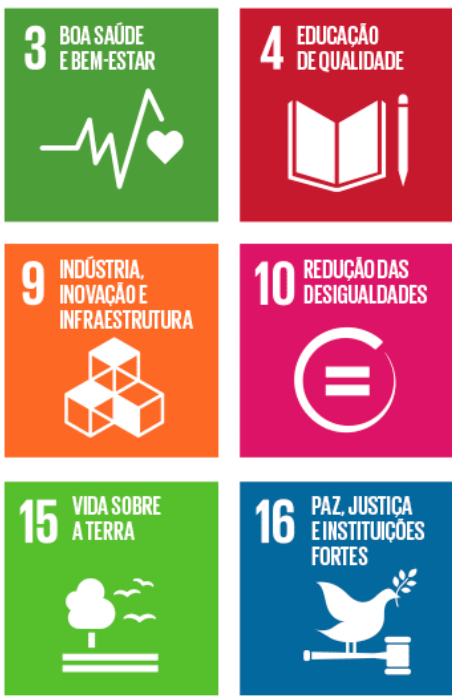
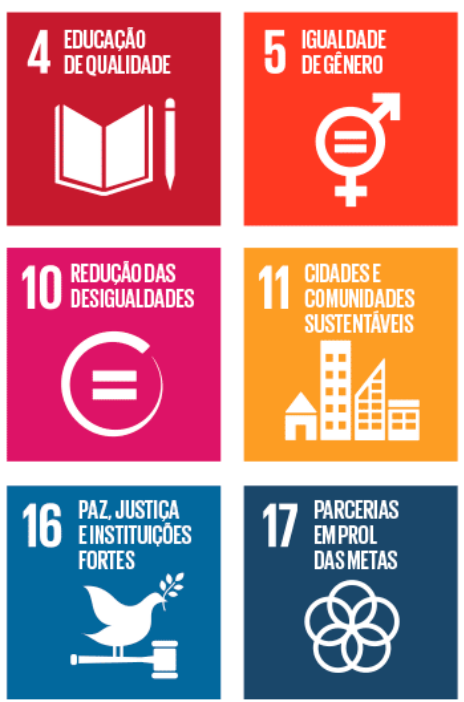
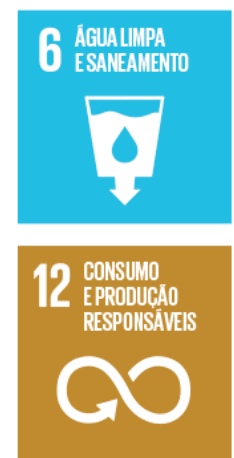

(6)

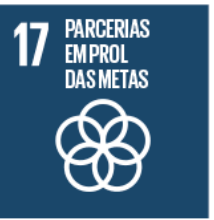

OBJETIVOS VIMENTO SUSTENTÁVEL 
Dentre as metas para a obtenção do desenvolvimento sustentável, há a necessidade da diminuição dos poluentes atmosféricos, principalmente dos gases dióxido de carbono $\left(\mathrm{CO}_{2}\right)$ e metano $\left(\mathrm{CH}_{4}\right)$, para que ocorra a minimização dos efeitos do aquecimento global. No que tange a saúde e bem estar, relacionados à qualidade do ar, não há enfoque explícito nas metas do desenvolvimento sustentável. Os objetivos 3, 7, 11 e 13, que visam assegurar a saúde e bemestar da população, energia limpa para todos, qualidade das cidades e transporte sustentável, medidas urgentes para combater a mudança climática e seus impactos, respectivamente, são os objetivos que implicitamente envolvem a problemática da poluição atmosférica.

Entretanto, em 2018 ocorreu a primeira Conferência Global da Organização Mundial da Saúde (OMS) sobre Poluição do Ar e Saúde, com o tema, "Melhorando a Qualidade do Ar, Combatendo a Mudança Climática: Salvando Vidas”, em Genebra na Suíça. O principal objetivo do encontro foi de reduzir as mortes relacionadas à poluição atmosférica em dois terços até 2030. Os pesquisadores e os envolvidos na conferência reconheceram a urgente necessidade de ampliar a proposta global para prevenir doenças e mortes causadas pela poluição do ar, que causa a morte de mais de sete milhões de pessoas por ano por doenças cardiorrespiratórias e cânceres de pulmão, assim como afeta diretamente na aceleração das mudanças climáticas (WORLD HEALTH ORGANIZATION, 2018).

A "Agenda de Ação de Genebra para Combater a Poluição do Ar" estipula medidas a serem tomadas para alcançar os objetivos e reduzir as mortes por poluição do ar. Algumas das ações a serem realizadas são:

- Redução maciça de queimadas a céu aberto e do uso de combustível;

- Melhorar a educação ambiental sobre a poluição do ar;

- Intensificar a ação conjunta entre os setores financeiro, de saúde e ambiental;

- Fortalecer ações para proteger as populações mais vulneráveis, especialmente as crianças;

- Aumentar o acesso à energia limpa e tecnologias;

- Apoiar as cidades para melhorar a qualidade do ar urbano (SDG KNOWLEDGE HUB, 2018). 


\section{OBJETIVOS GERAIS}

O objetivo principal deste trabalho foi realizar a caracterização físico-química do Material Particulado Fino ( $\mathrm{MP}_{2.5}$ ) amostrado ao longo do ano de 2016 na Escola de Artes, Ciências e Humanidades (EACH) da Universidade de São Paulo (USP), localizado na região leste da cidade de São Paulo.

\subsection{Objetivos Específicos}

- Analisar a série temporal de concentrações de $\mathrm{MP}_{2.5}$ e black carbon ao longo do ano de 2016;

- Caracterizar a composição química do aerossol coletado durante o período;

- Identificar as principais fontes emissoras utilizando modelos estatísticos específicos para do $\mathrm{MP}_{2.5}$;

- Caracterizar as variações sazonais para concentrações, composição química e sua relação com as condições meteorológicas e fontes. 


\section{JUSTIFICATIVA}

A Zona Leste é uma região populosa, com mais de 4 milhões de habitantes, e em sua maioria é composta pela população jovem que vive em situação de vulnerabilidade. A região é composta predominantemente por residências, contém grande atividade industrial, é uma das mais impermeabilizadas da cidade, com poucas áreas verdes, grandes avenidas e vias de intenso tráfego como a rodovia Ayrton Senna e Dutra, que interligam diversas cidades com a capital e o aeroporto internacional de São Paulo (GRU) e o campus da Universidade de São Paulo, a EACH. Dada a importância da região e a falta de estudos específicos, a caracterização do $\mathrm{MP}_{2.5}$ se faz importante para se conhecer a composição elementar do aerossol e assim identificar as principais fontes emitentes na região. 


\section{METODOLOGIA}

O material particulado fino $\left(\mathrm{MP}_{2.5}\right)$ foi coletado por $24 \mathrm{hs}$ a cada três dias na $\mathrm{EACH}$, no período de um ano, abril de 2016 à abril de 2017, por equipamento específico (Partisol 2025i) instalado a $\sim 15 \mathrm{~m}$ de altura no prédio A1 da $\mathrm{EACH}$, utilizando filtros (membranas) de teflon.

As análises laboratoriais foram realizadas no Laboratório de Análise dos Processos Atmosféricos (LAPAt) no Instituto de Astronomia, Geofísica e Ciências Atmosféricas (IAG) da USP.

Através da gravimetria (pesagem dos filtros), obteve-se a concentração em massa do particulado.

As concentrações de black carbon equivalente (BCeq) contido nas amostras coletadas, foram obtidas através de medidas de refletância, utilizando o refletômetro Smoke Stain Reflectometer, Diffusion System, modelo M43D, e o black carbon elementar (BC) foram monitoradas utilizando o monitor Multi-Angle Absorption Photometer 5012 Thermo (MAAP).

Os elementos inorgânicos foram identificados através da fluorescência de raios-X (FRX).

Os íons das amostras foram obtidos através da cromatografia líquida.

Os dados de contagem de veículos foram cedidos pela Agência de Transporte do Estado de São Paulo (ARTESP).

\section{1 Área De Estudo}

Foram coletadas as amostras de material particulado fino na Escola de Artes, Ciências e Humanidades da Universidade de São Paulo (EACH-USP), que está localizada na Av. Arlindo Bettio, 1000, Vila Guaraciaba, São Paulo capital. (23.48'S, 46.49'O).

A EACH situa-se na Zona Leste da capital paulista, próxima a indústrias, a Rodovia Ayrton Senna ( 250 m de distância), Av. Dr. Assis Ribeiro ( 400 m de distância), Aeroporto de Cumbica ( 6km) e da cidade de Guarulhos, conforme Figuras 8, 9 e 10. 
Figura 8 - Área de Estudo e seu entorno, com áreas residenciais e indústrias.

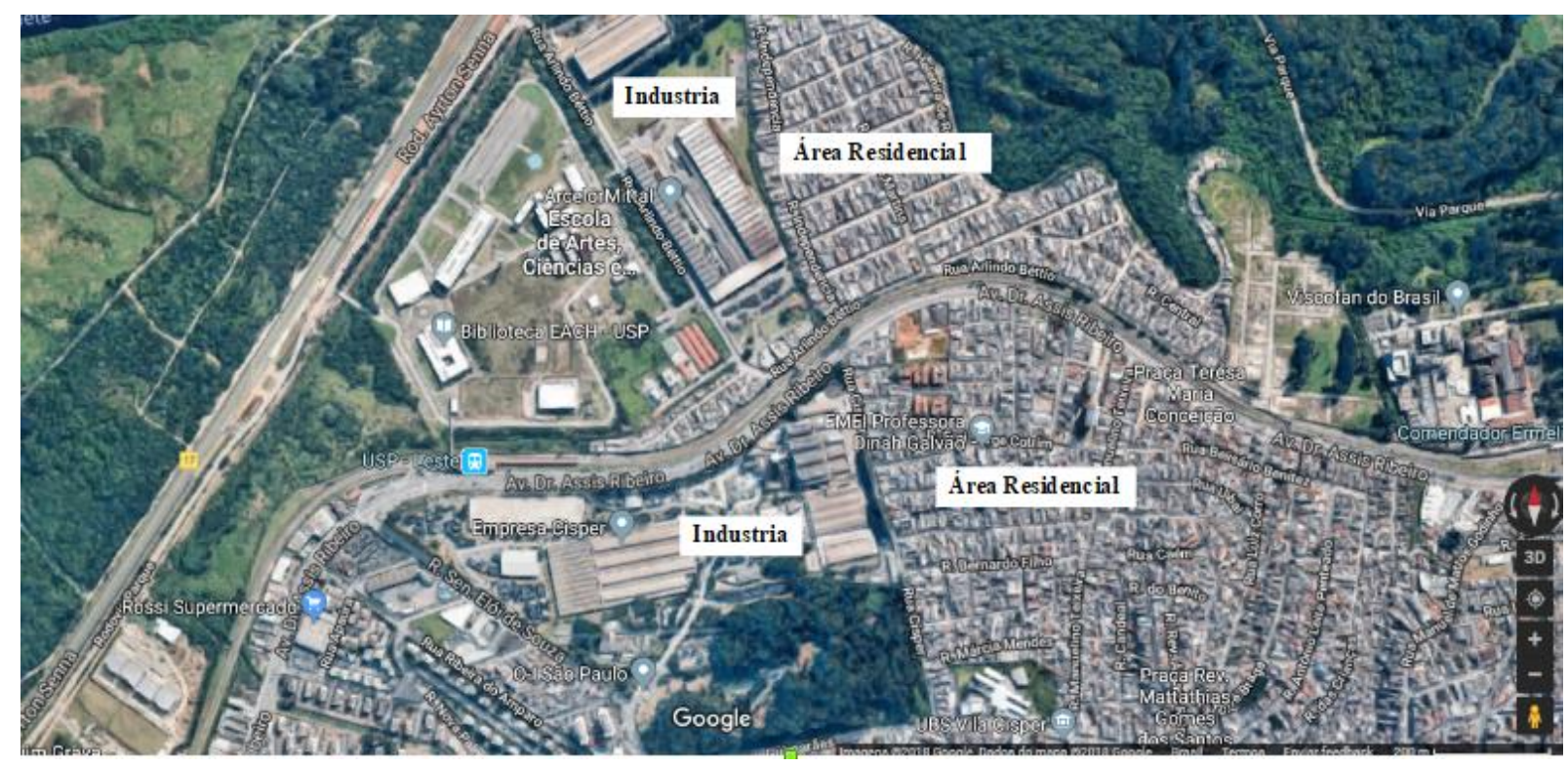

Fonte: Adaptado de GOOGLE MAPS (2018).

Figura 9 - Área de Estudo, e as distâncias aproximadas entre as principais avenidas.

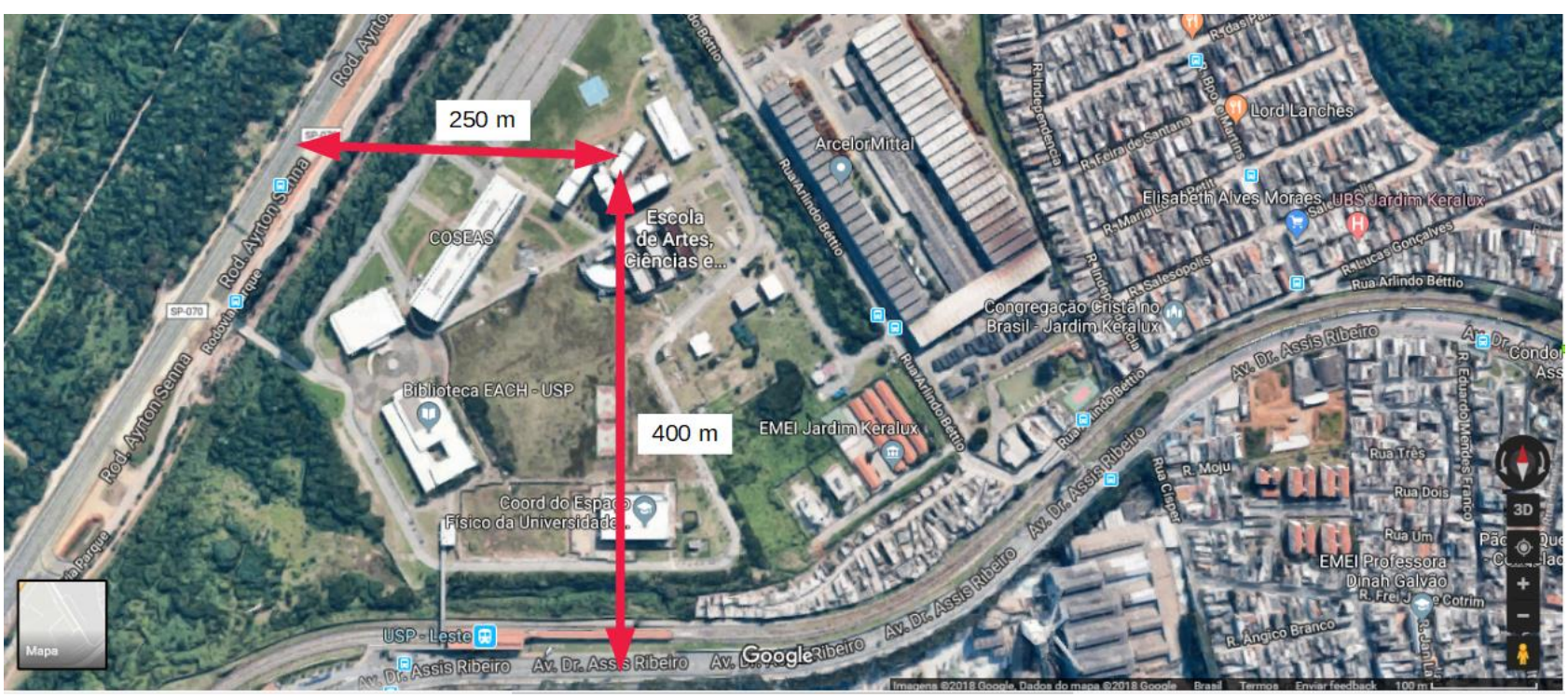

Fonte: Adaptado de GOOGLE MAPS (2018). 
Figura 10 - Área de Estudo, e a distância aproximada entre o aeroporto de Cumbica.

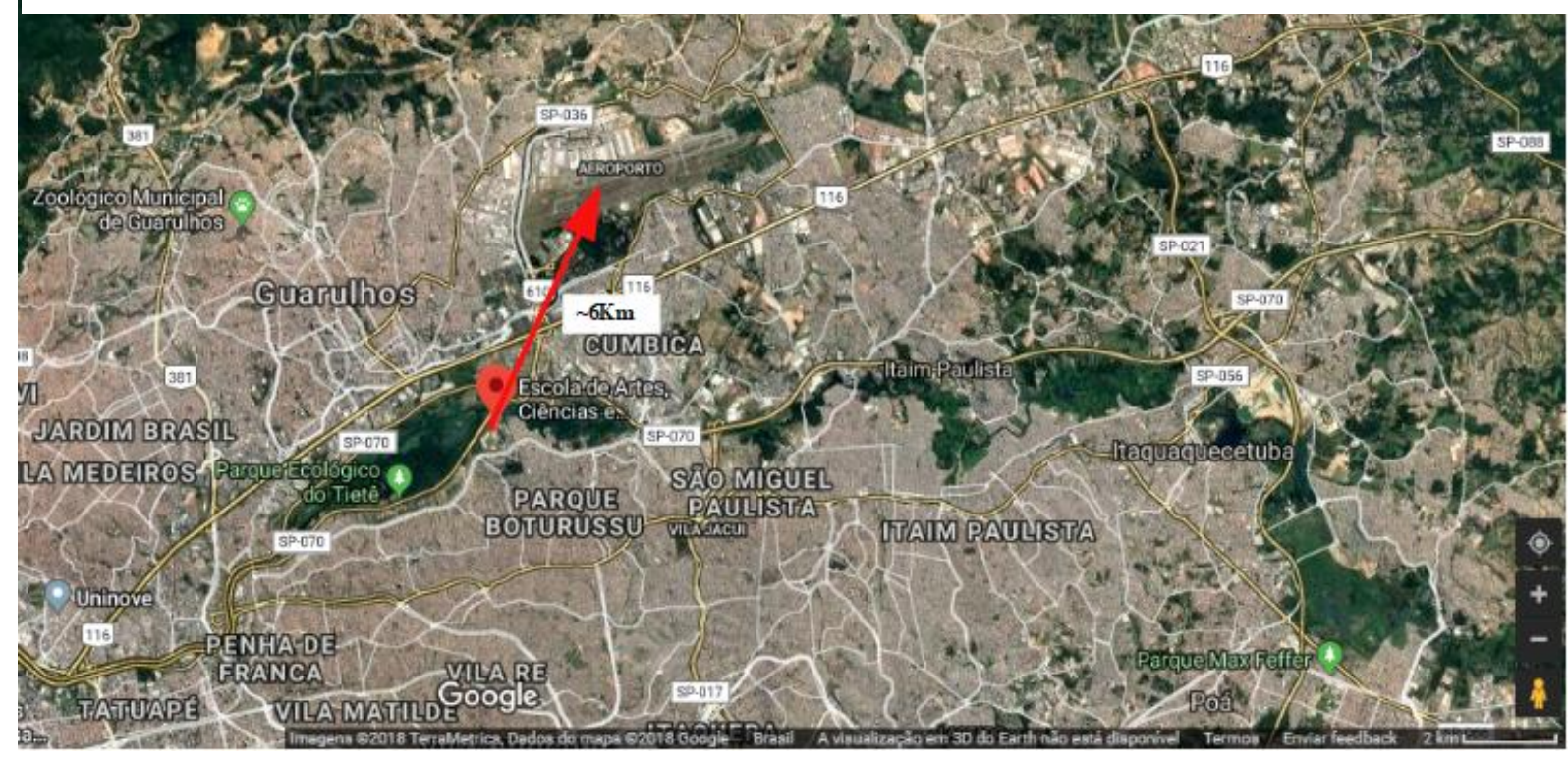

Fonte: Adaptado de GOOGLE MAPS (2018).

A rodovia Ayrton Senna, localizada na região leste da capital, é uma das principais vias de acesso à Região Metropolitana de São Paulo (RMSP), com ligação a outras cidades do Vale do Paraíba e litoral norte, possui tráfego intenso de veículos leves e pesados. A proximidade dessa via com a Escola de Artes, Ciências e Humanidades (EACH), campus leste da Universidade de São Paulo (USP), é de aproximadamente 250m, como mencionado acima.

Além da proximidade com a rodovia, ao redor do campus ainda existe a indústria de vidros Cisper, além da Avenida Assis Ribeiro, que possui tráfego intenso de veículos pesados e leves, e o aeroporto de Guarulhos que está a aproximadamente 6 km do campus.

\subsection{Descrição dos Equipamentos, Procedimentos e Análises}

Neste item serão descritos os equipamentos e procedimentos realizados para as análises do aerossol, e os modelos receptores que foram utilizados para a análise dos dados.

\subsubsection{Amostragem do $\mathrm{MP}_{2.5}$}

As amostras de material particulado fino $\left(\mathrm{MP}_{2.5}\right)$ foram coletadas a cada três dias por 24 horas na EACH, pelo período de um ano, de 27 de abril de 2016 à 26 de abril de 2017, totalizando 120 amostras. Esta metodologia de coleta foi determinada em virtude da limitação 
de insumos e pessoal, porém é considerada representativa para o estudo e recomendada pela Agência de Proteção Ambiental dos Estados Unidos (EPA). Foi utilizado o equipamento Partisol da Thermo Sientific modelo 2025i (figura 11), sendo este um amostrador sequencial com capacidade de armazenamento de 16 filtros, para coleta de amostras de material particulado fino. Neste trabalho foram utilizados filtros de teflon da marca "PALL", com $47 \mathrm{~mm}$ de diâmetro e $2 \square \mathrm{m}$ de poro.

Figura 11 - Partisol modelo $2025 i$ usado na amostragem de $\mathrm{MP}_{2.5}$.

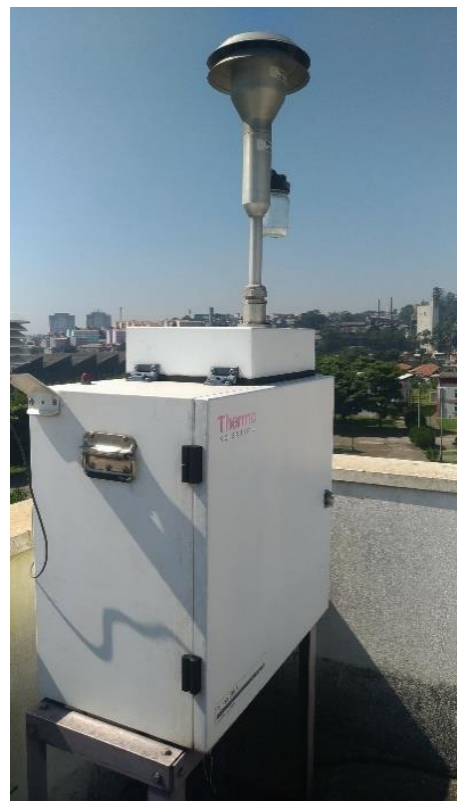

Fonte: Luana Ferreira Vasconcelos, 2020.

Os equipamentos estão localizados no topo do prédio A1 da EACH, a aproximadamente $15 \mathrm{~m}$ de altura.

\subsubsection{Determinação da concentração de $M_{2.5}$}

Para se obter a concentração em massa do $\mathrm{MP}_{2.5}$ depositado nos filtros, utilizou-se o método de gravimetria, que consiste na pesagem dos filtros antes e depois da amostragem. Esta técnica requer alguns cuidados, como controle de umidade e temperatura na hora da pesagem e um ambiente limpo. Um eliminador de cargas eletrostáticas é utilizado com o intuito de se diminuir a eletricidade estática presente nos filtros, o que dificulta o manuseio e pesagem dos mesmos. Antes de qualquer pesagem, os filtros permanecem por um período de 24 horas em um ambiente com controle de temperatura e umidade relativa do ar $\left(\mathrm{T} \sim 22^{\circ} \mathrm{C}\right.$ e UR 45\%), para evitar a interferência desses fatores nos resultados. Em seguida, as pesagens são realizadas em 
duplicata e é calculada a média de concentração. A figura 12 mostra os filtros em fase de condicionamento na sala onde são pesados.

Figura 12 - Filtros em condicionamento para posterior pesagem

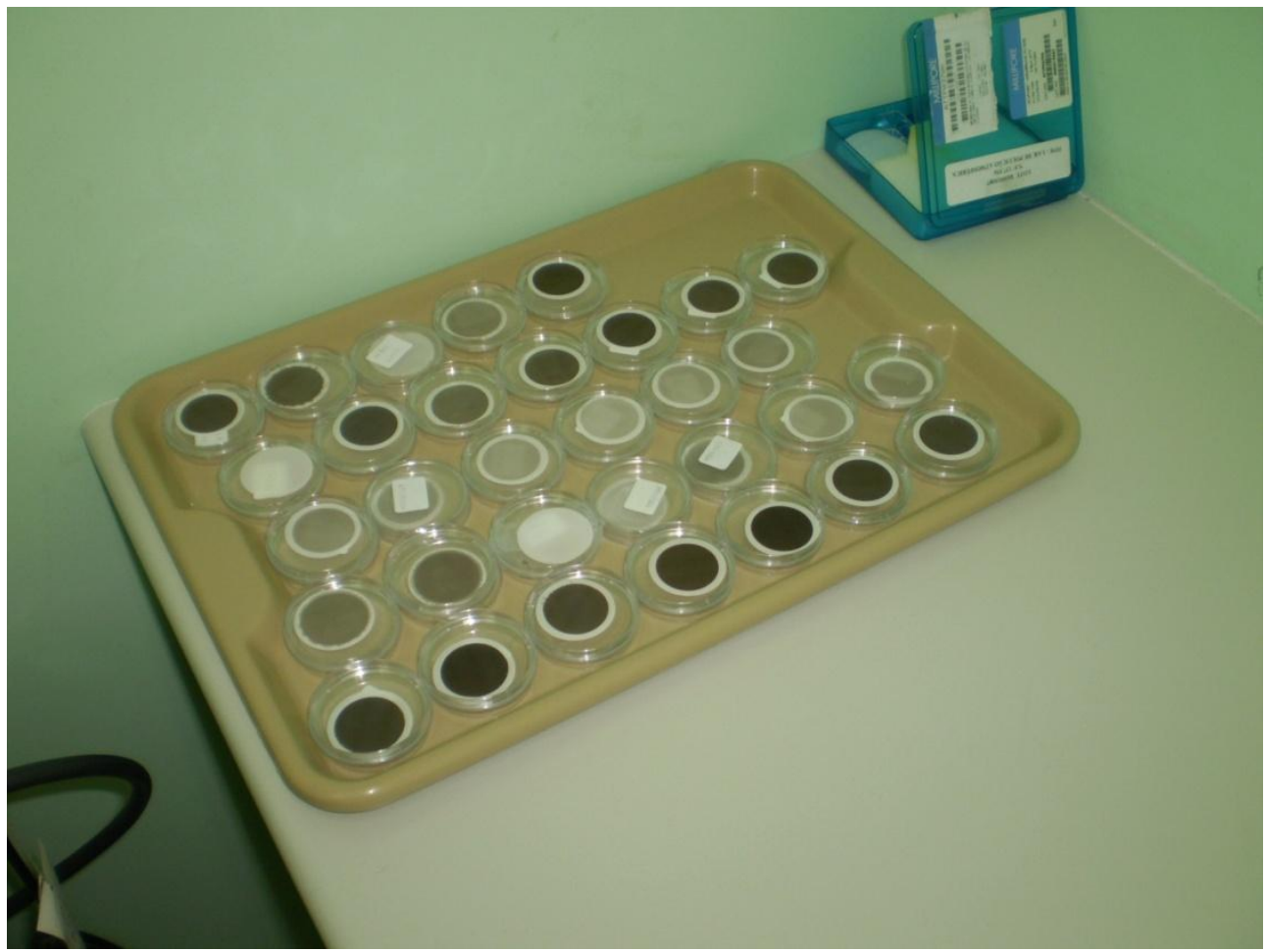

Fonte: arquivo pessoal Regina Maura de Miranda

Para a pesagem das amostras utilizou-se uma balança de precisão de seis casas decimais “Mettler Toledo" modelo MX5 (figura 13).

Figura 13: Balança e eliminador de carga estática (seta amarela)

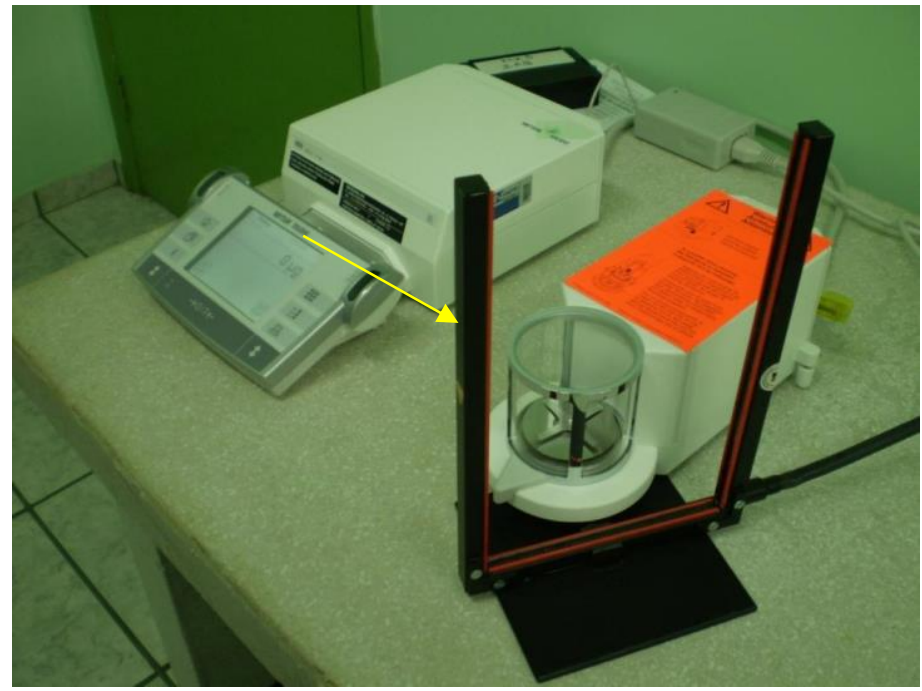

Fonte: arquivo pessoal Regina Maura de Miranda 
Através do cálculo da vazão de ar utilizado pelo equipamento Partisol, e a quantidade de $\mathrm{MP}_{2.5}$ calcula-se a concentração, na unidade de $\mu \mathrm{g} / \mathrm{m}^{3}$.

$$
\mathrm{C} f=\mathrm{M} f / \mathrm{V} f
$$

Onde:

$\mathrm{C} f=$ Concentração $\left(\mu \mathrm{g} / \mathrm{m}^{3}\right)$ de $\mathrm{MP}_{2.5}$

$\mathrm{M} f=\operatorname{Massa}(\mu \mathrm{g})$ das amostras de $\mathrm{MP}_{2.5}$

$\mathrm{V} f=$ Volume $\left(\mathrm{m}^{3}\right)$ de ar amostrado

\subsubsection{Análise de carbono equivalente e carbono elementar}

\subsubsection{Refletância.}

A análise de refletância foi utilizada para determinar a concentração de black carbon equivalente (BCeq), presente nos filtros amostrados, predominante na fração fina do aerossol. A técnica baseia-se na propriedade do composto possuir alta seção de choque de absorção de luz na região do visível. Foi utilizado um refletômetro Smoke Stain Reflectometer, Diffusion System, modelo M43D (figura 14). O filtro é iluminado por uma lâmpada de tungstênio e a luz refletida é detectada por um sensor. Quanto menor a intensidade dessa luz, maior é a quantidade de BCeq presente na amostra, pois este absorve uma parcela da luz incidente. A curva de calibração da luz refletida pela quantidade de BCeq foi obtida empiricamente, e é dada pela equação abaixo, que indica como, a partir da refletância medida, pode-se determinar a massa de BCeq presente na amostra:

$$
\left.B C_{E q}\left[\mu \mathrm{g} / \mathrm{m}^{3}\right]=\left((81,95-(71,83 * \log (R)))+15,43 *(\log (R))^{2}\right) * A\right) /(V)
$$

onde:

$\mathrm{R}=$ Refletância $(\%)$

$\mathrm{A}=$ Área do filtro $\left(\mathrm{cm}^{2}\right)$

$\mathrm{V}=$ Volume de ar amostrado $\left(\mathrm{m}^{3}\right)$

A curva de calibração foi obtida empiricamente através da análise de filtros de policarbonato com concentrações conhecidas de BC. Os alvos para a calibração do aparelho foram preparados por nebulização ultra-sônica (CLARKE et al., 1987) com o padrão "Monarch 71”. Este padrão foi introduzido por Heintzenberg (1982) como um material de referência para 
medidas de absorção de luz e é comercialmente disponível.

O método da refletância não mede $100 \%$ do black carbon presente na amostra e dessa forma recomenda-se o uso do termo black Carbon Equivalente (BCeq) quando se mede a massa de carbono por métodos de absorção ópticos (PETZOLD et al., 2013).

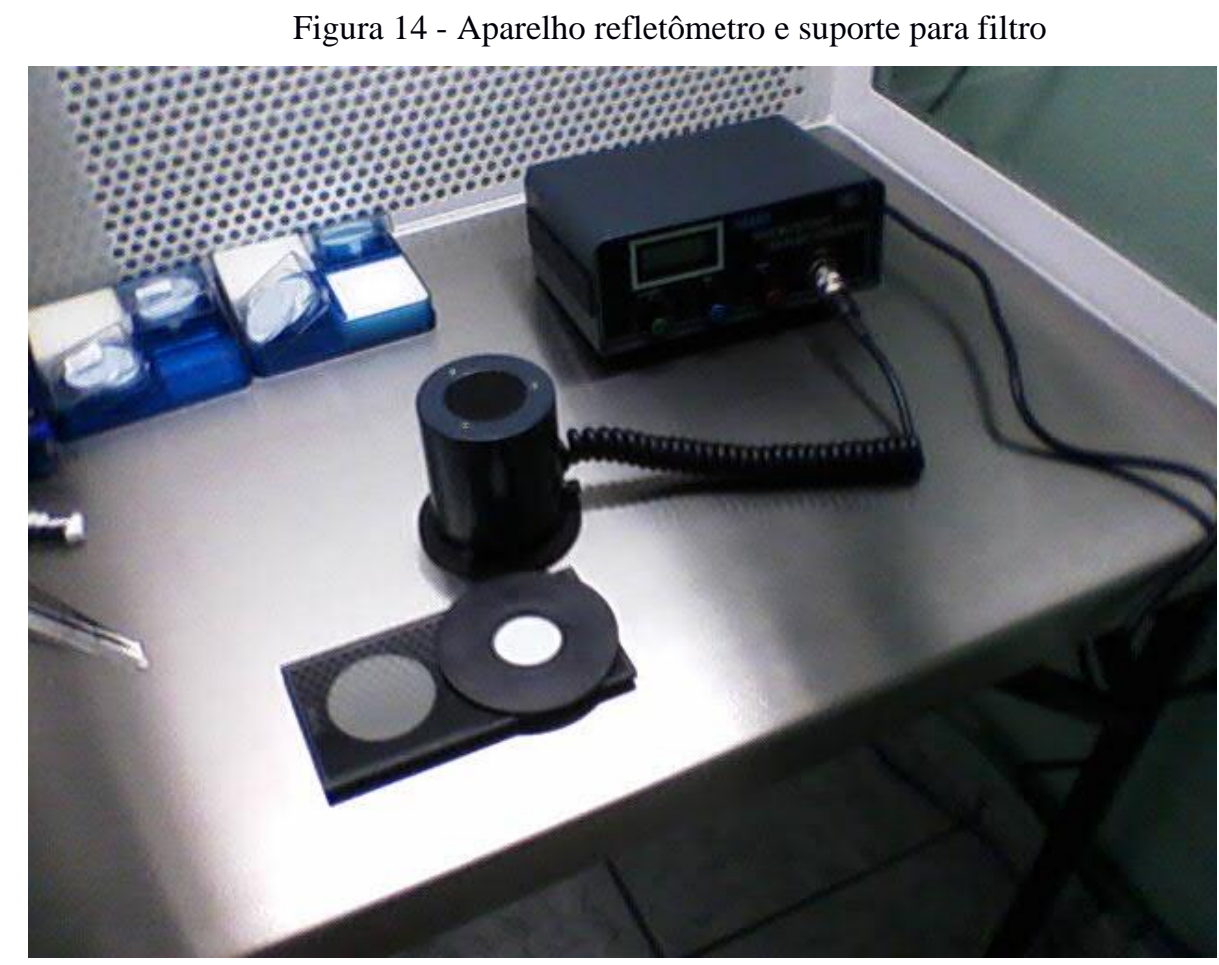

Fonte: Luana Ferreira Vasconcelos, 2020.

\subsubsection{MAAP (Multi-Angle. Absorption Photometer)}

O equipamento de medida MAAP (Multi-Angle. Absorption Photometer) modelo MAAP 5012 da Thermo Scientific, figura 15, mede a concentração de BC a cada minuto. 
Figura 15 - Monitor de BC MAAP (modelo MAAP 5012 da Thermo Scientific) e esquema da câmara de detecção.
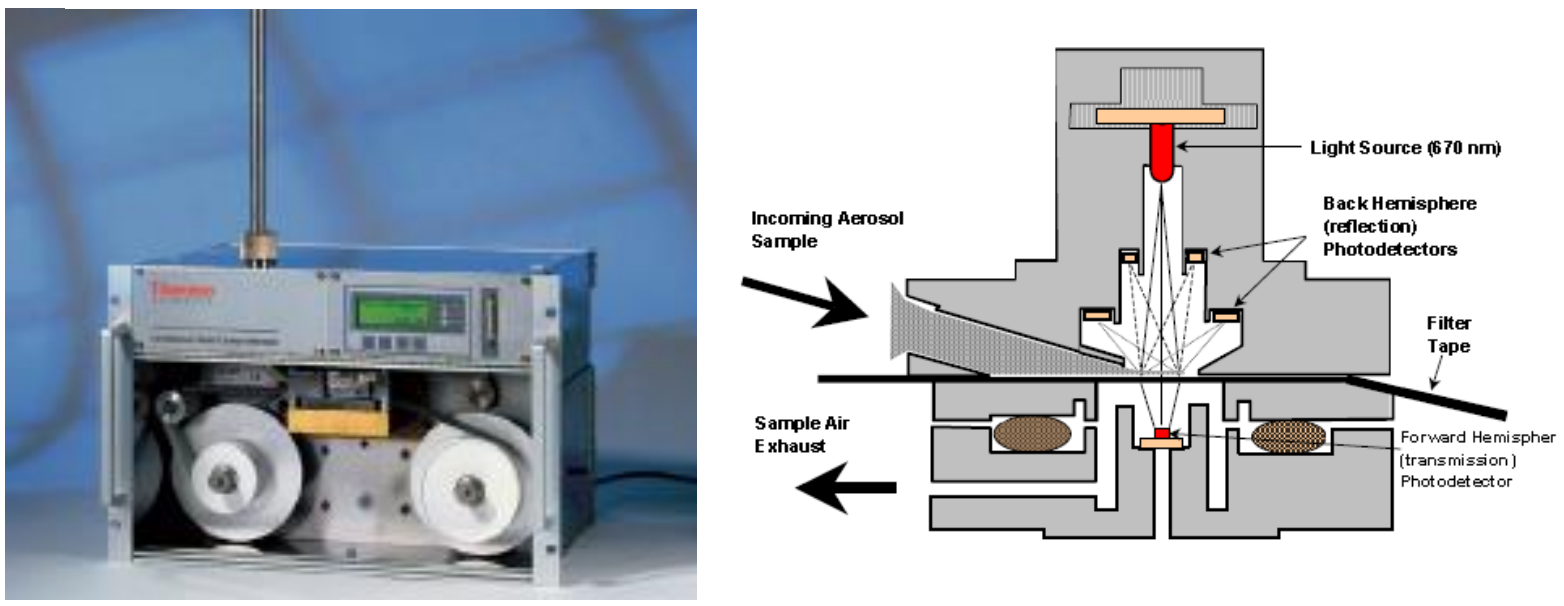

Fonte: MODELO 5012 - MANUAL, 2009

O Modelo 5012 é baseado no princípio da absorção de luz relacionada ao aerossol e sua correspondente concentração de massa de black carbon atmosférico. O modelo usa um fotômetro de absorção de múltiplos ângulos para analisar a modificação dos campos de radiação no hemisfério anterior e posterior de um filtro de fibra de vidro, causado pela deposição das partículas. O equipado utiliza um algoritmo para inverter os dados, que é baseado em um método de transferência de radiação e, portanto, leva múltiplos processos de espalhamento na câmara de detecção. $\mathrm{O}$ aerossol se acumula na fita até um determinado limite, quando esta avança automaticamente antes de atingir a saturação. Dentro da câmara, uma fonte de luz visível de $670 \mathrm{~nm}$ é direcionada para o aerossol depositado na fita; a luz transmitida e refletida é medida por uma série de fotodetectores (figura 15). A redução da transmissão da luz, as múltiplas intensidades de reflexão e o volume amostrado são continuamente integrados durante a amostragem a fim de fornecer a concentração do poluente (MODELO 5012 - MANUAL, 2009).

Em Kanaya et al. (2013), é apresentado que o MAAP tem maior consistência nos dados obtidos, quando comparado com um outro monitor contínuo de fuligem. Portanto, dada a frequência de obtenção dos dados (por minuto), foram utilizados os dados do MAAP na maior parte das análises, identificado como BC, assim como proposto por Petzold et al. (2013), para diferenciar os tipos metodologias empregadas na obtenção dos dados. 


\subsubsection{Fluorescência de Raios-X (FRX)}

A técnica analítica instrumental de FRX - Fluorescência de raios-X tem sido utilizada na avaliação quali-quantitativa da composição química em vários tipos de amostras, de interesse agropecuário, agroindustrial, geológico e ambiental. Esta técnica é de grande importância na análise multi-elementar em amostras oriundas de sistemas biológicos, pois pode determinar tanto macro-elementos como cálcio $(\mathrm{Ca})$ e potássio $(\mathrm{K})$, como elementos traço, como cobre $(\mathrm{Cu})$ e chumbo $(\mathrm{Pb})$, ou também de elementos não-metais como enxofre (S).

Com o desenvolvimento do detector semicondutor $\mathrm{Si}(\mathrm{Li})$, capaz de discriminar raios-X de energias próximas, foi possível o surgimento da fluorescência de raios-X por dispersão de energia (ED-XRF, Energy Dispersive X-ray Fluorescence), também conhecida como fluorescência de raios-X não dispersiva, com instrumentação menos dispendiosa e emprego mais prático. Assim, na análise de FRX têm-se três fases:

- Excitação dos elementos que constituem a amostra;

- Dispersão dos raios-X característicos emitidos pela amostra;

- Detecção desses raios.

Desse modo, ao se considerar as intensidades (número de raios- $\mathrm{X}$ detectados por unidade de tempo) dos raios-X característicos emitidos pela amostra, obtém-se linhas espectrais com energias características de cada elemento, onde a intensidade está relacionada à concentração do elemento na amostra. A concentração de cada elemento é, normalmente, expressa em termos de massa desse elemento dividido pela massa total da amostra, sendo habitualmente expressa em $\mu \mathrm{g} / \mathrm{g}$. Analisa-se diretamente o filtro com o material coletado. É utilizado para esta análise o equipamento marca SHIMADZU modelo EDX-700HS.

Após as análises de gravimetria e refletância, os filtros são então preparados para a fluorescência, colocados em um suporte específico (figuras 16 e 17) e cada amostra é analisada por 20 minutos. O espectro obtido (Figura 18), juntamente com os dados de calibração do aparelho, são analisados em software específico para obtenção da concentração elementar em $\mu \mathrm{g} / \mathrm{m}^{3}$. O equipamento, métodos de calibração e parâmetros de análise são descritos detalhadamente em Veríssimo (2016). 
Figura 16 - Carrossel para colocação dos filtros para

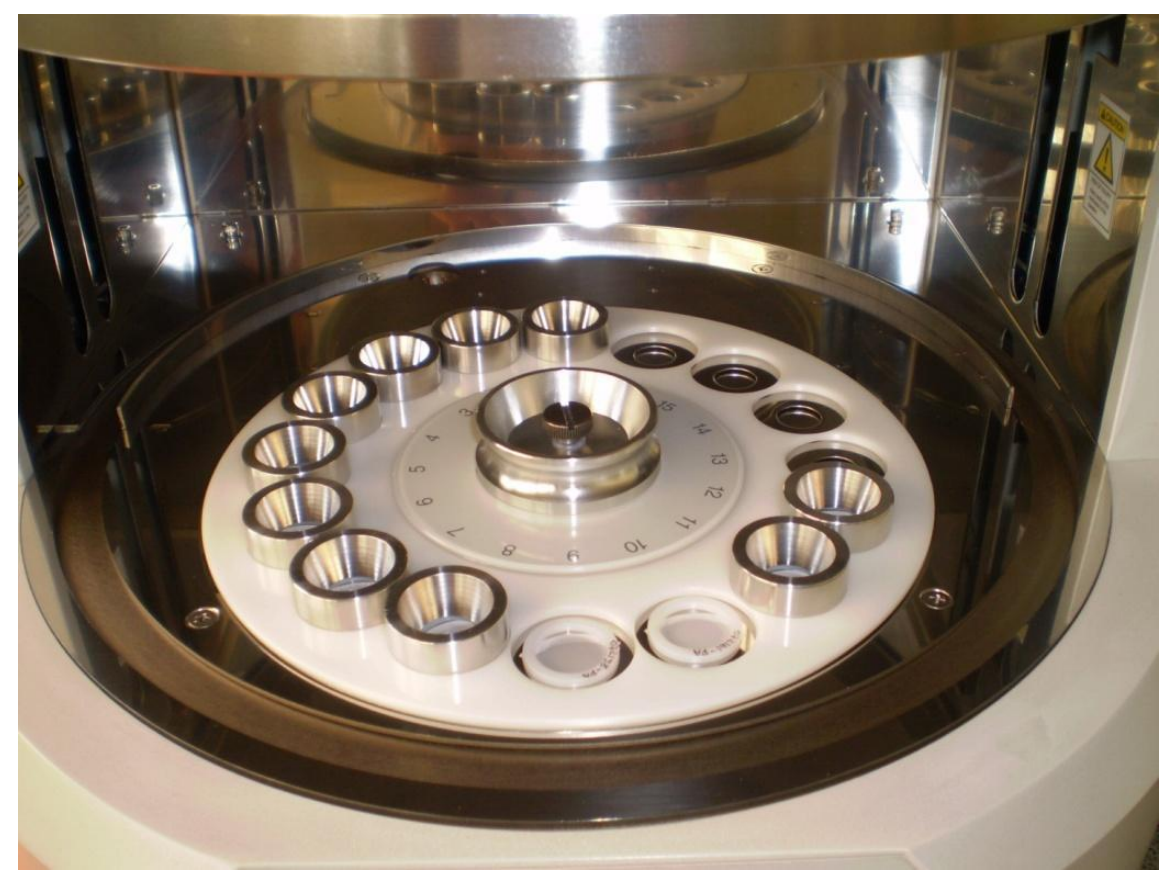

Fonte: arquivo pessoal Regina Maura de Miranda

Figura 17 - Equipamento para fluorescência de raios-X

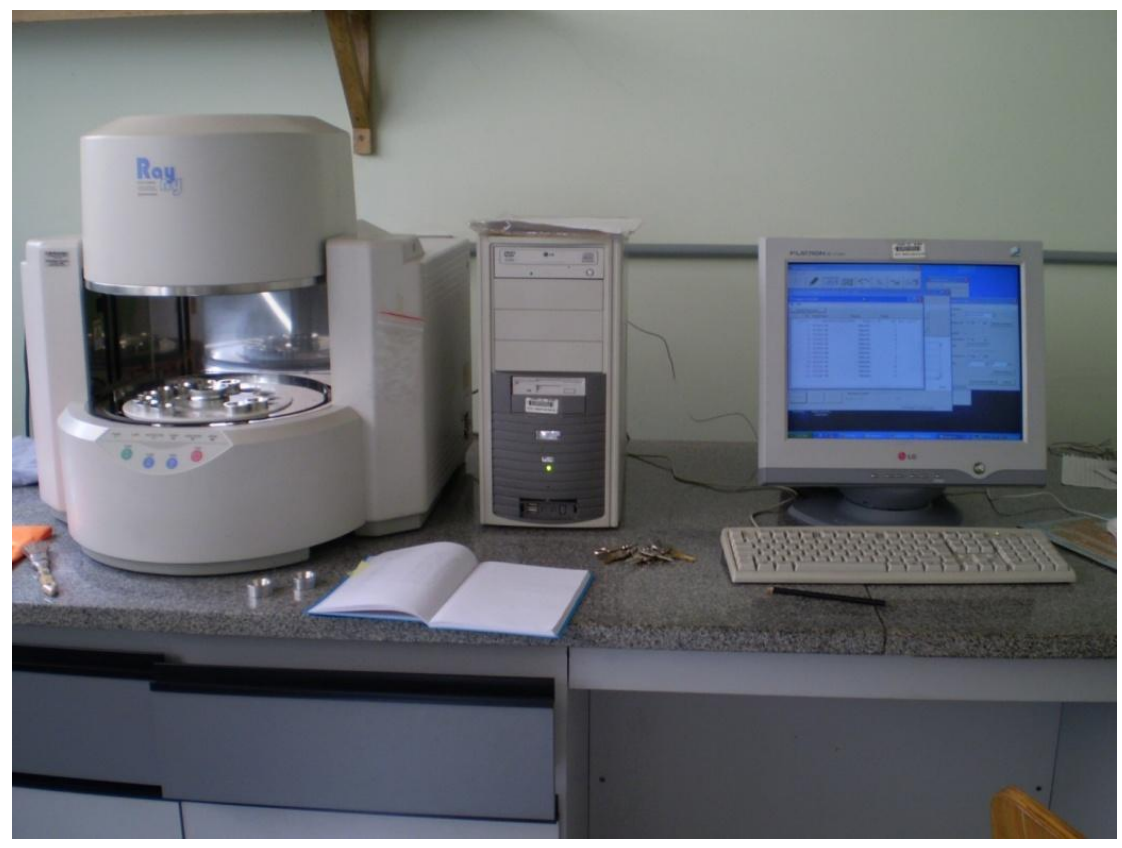

Fonte: Luana Ferreira Vasconcelos, 2020. 
Figura 18 - Espectro de raios-X

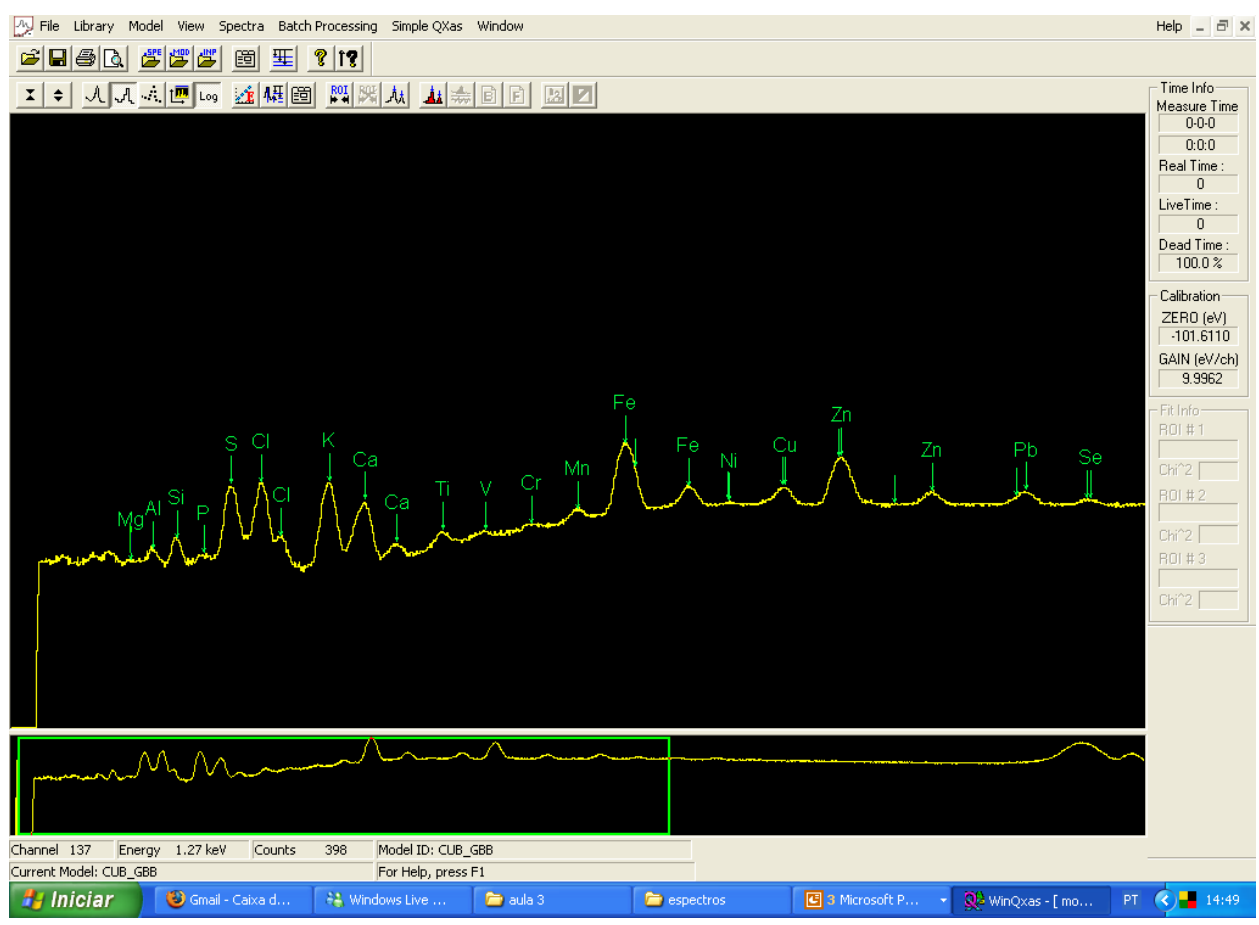

Fonte: arquivo pessoal Regina Maura de Miranda

\subsubsection{Cromatografia iônica (IC)}

Utilizou-se o Cromatógrafo de íons, modelo 850 Professional IC da Metrohm para a obtenção dos íons solúveis em água contidos nas amostras (figura 19a).

Os filtros com $\mathrm{MP}_{2.5}$ foram colocados em tubos com $10 \mathrm{ml}$ de água ultra purificada e agitados por 1h. Após, a solução foi filtrada em um filtro de difluoreto de polivinilideno da marca Millex (Tamanho de poro de $0,22 \mu \mathrm{m}$ ) e mantidos congelados até a análise do cromatógrafo. (MIRANDA et al., 2012)

A técnica de cromatográfica líquida baseia-se em mecanismos de troca e supressão de íons, com detecção condutométrica para separação e determinação de cátions e ânions (BAIRD, 2011). 
Figura 19 - a) Cromatógrafo (modelo 850 Professional IC da Metrohm) e b) esquema processo da cromatografia
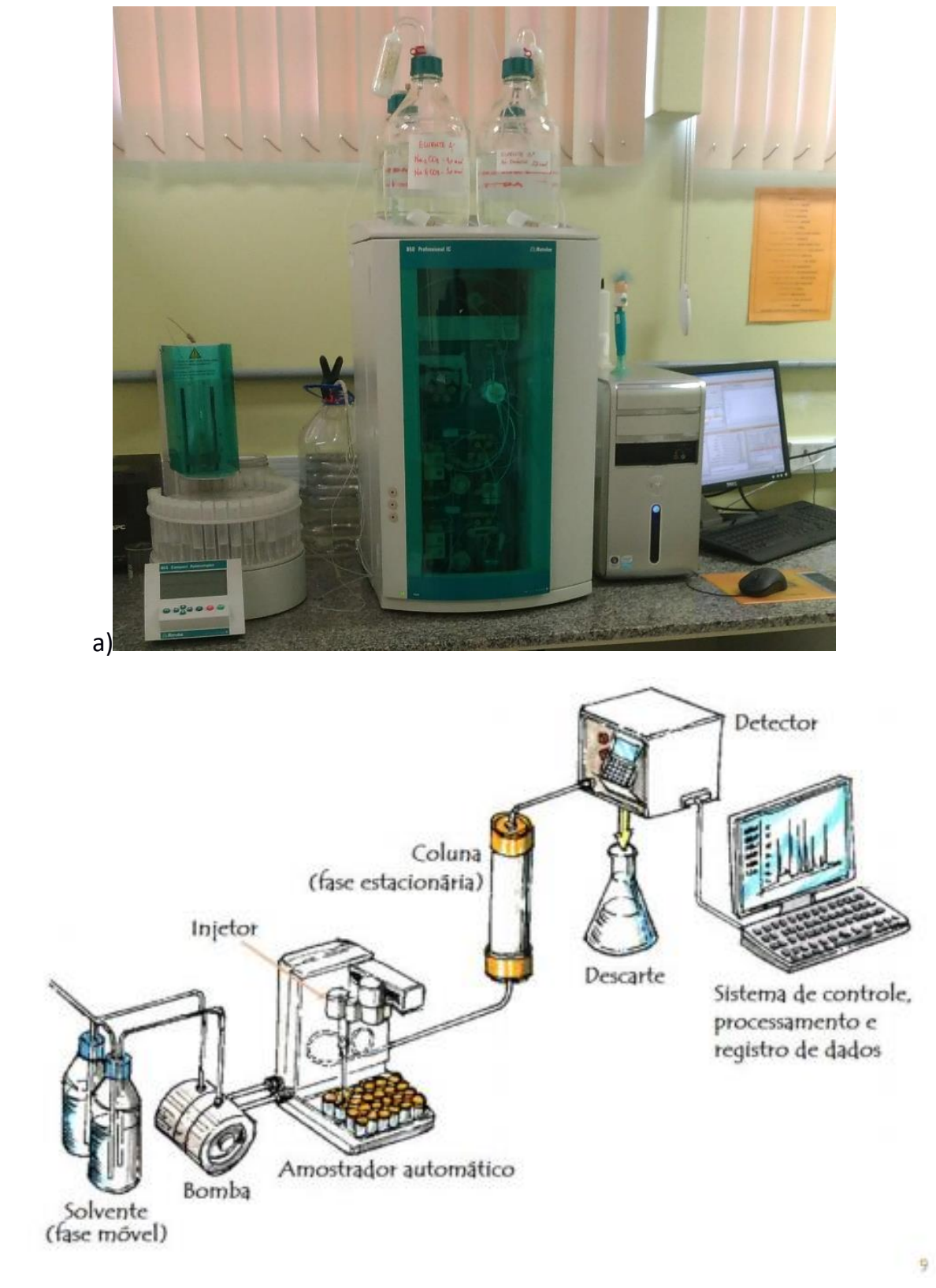

Fonte: a) Luana Ferreira Vasconcelos, 2020; b) UNIVERSIDADE FEDERAL SÃO JOÃO DEL-REI [2021]

No cromatógrafo são utilizadas duas colunas, separadora e supressora (os solventes da fase móvel), sendo a supressora instalada entre a coluna separadora e o detector condutométrico. A coluna supressora realiza as funções: (a) diminuir quimicamente a condutividade dos íons do eluente que saem da coluna separadora e (b) converter, simultaneamente, as espécies de interesse numa forma mais condutora, que são monitoradas pela célula condutométrica (fase estacionária).

Os solventes da fase móvel interagem com as soluções das amostras, que estão no amostrador automático, estes são misturados com e levados até na fase estacionária (coluna separadora) e dessa forma as amostras interagem com os eluentes $\mathrm{Na}_{2} \mathrm{CO}_{3} \quad 4,0 \mathrm{mmol} / \mathrm{L} /$ 
$\mathrm{NaHCO}_{3}$ 1,0 mmol/L, a uma vazão de $0,7 \mathrm{ml} / \mathrm{min}$, com a coluna supressora e regenerante constituída da solução de $\mathrm{H}_{2} \mathrm{SO}_{4} 50 \mathrm{mmol} / \mathrm{L}$ e água deionizada sob vazão de $0,8 \mathrm{ml} / \mathrm{min}$, para detecção dos ânions das amostras $\left(\mathrm{SO}_{4}{ }^{2-}, \mathrm{NO}_{3}{ }^{-}, \mathrm{Cl}^{-}, \mathrm{F}^{-}\right)$, e o eluente de ácido tartárico à $4 \mathrm{mmol} / \mathrm{L}$ /ácido dipicolínico $0,75 \mathrm{mmol} / \mathrm{L}$ detecta os cátions das amostras $\left(\mathrm{Na}^{+}, \mathrm{K}^{+}, \mathrm{Ca}^{+}, \mathrm{Mg}^{+} \mathrm{e} \mathrm{NH}_{4}^{+}\right)$ (MIRANDA et al., 2012; METROHM, 2019).

\subsubsection{Positive Matrix Factorization (PMF)}

Positive Matrix Factorization (PMF) ou Fatoração da Matriz Positiva (em português), é uma ferramenta desenvolvida pela Agência de Proteção Ambiental dos Estados Unidos (EPA), que realiza análises de dados multivariada, aplicada na identificação e classificação de fontes de poluição. Este modelo receptor utiliza a matriz de dados de composição elementar do MP, e seus erros de variação, para quantificar a contribuição de cada tipo de fonte emissora vinculando os dados (BROWN et al., 2015; NORRIS, 2014).

Pode ser considerado um aprimoramento das técnicas multivariadas aplicadas a área de poluição do ar por incorporar as incertezas das variáveis associadas às medidas de concentração, e ainda por forçar todos os valores na solução dos perfis e das contribuições a serem não negativos, o que tornam os resultados mais realísticos que o método de Análise de Componentes Principais, pois uma fonte participa ou não na formação do poluente, nunca podendo ter uma contribuição negativa de sorvedouro (NORRIS, 2014; REFF et al., 2007).

Diferente da Análise de Componentes Principais (ACP), que usa matrizes de correlação e covariância, o PMF usa o método dos mínimos quadrados em seu ajuste. A principal diferença entre os resultados obtidos por esses modelos receptores está no fato da ACP apresentar valores negativos nas matrizes decompostas, o que não é interpretado fisicamente nos modelos (HUANG et al., 1999; PAATERO; TAPPER, 1994).

O PMF permite que cada medida seja ponderada pelo erro individualmente. Esta característica possibilita que o usuário ajuste a influência de cada dado, dependendo da confiança na medida (NORRIS et al., 2008).

Segundo Brown et al. (2015), o objetivo dos modelos receptores multivariados é identificar o número de fatores (p), o perfil das espécies elementares (f) por fonte e a quantidade de massa (g) atribuída em cada fator para cada amostra. Através da equação 3 é possível quantificar a contribuição de cada fonte emissora, utilizando-se de uma matriz de dados da composição elementar das amostras e seus erros de variação:

$$
x i j=\sum_{k=1}^{p} g i k f k j+e i j=c i j=e i j
$$




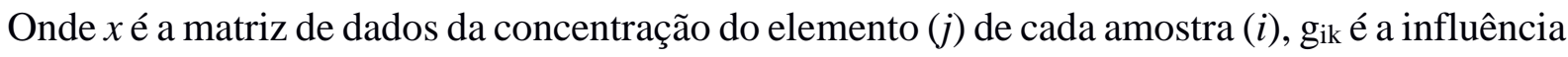
da fonte $(k)$ em massa por cada amostra, e $f_{k j}$ é a participação da concentração do elemento na fonte. $e_{i j}$ é o erro residual para cada amostra de elemento, e $c_{i j}$ é a solução modelada da matriz $x_{i j}$.

$$
Q=\sum_{1=1}^{n} \sum_{j=1}^{m}\left(\frac{x_{i j}-\sum_{k=1}^{p} g_{i k} f_{k j}}{U_{i j}}\right)^{2}
$$

O PMF permite que os valores de dados sejam individualmente ponderados, permitindo ajustar a influência em cada ponto dado, dependendo da confiança da medição, e números negativos não são permitidos.

A função do objeto Q (equação 4) é minimizada por meio de um algoritmo de gradiente conjugado com base nas incertezas ou erros estimados $\left(u_{i j}\right)$.

A quantidade de fatores deve ser determinada no programa pelos usuários, e há a necessidade de se testar com diferentes números de fatores a fim de diagnosticar a melhor combinação entre as possíveis fontes. O Q robusto $(\mathrm{Qr}), \mathrm{Q}$ verdadeiros $(\mathrm{Qv})$ fornecem a comparação dos ajustes de cada execução.

A razão S/N (signal to noise) avalia a relação entre a concentração do elemento (ou espécie química) e sua incerteza. Se este parâmetro for menor que 0,5, a espécie e considerada ruim ( $b a d$ ), até 1 como fraca (weak) e acima de 1 como forte (strong). Além de terem sido retirados os elementos iguais em íon e não metal, assim como proposto por Norris et al. (2014).

As estimativas dos erros, Bootstrap (BS) e Displacement (DS), determinam as incertezas da rotação dos dados nas análises do PMF. O BS seleciona a aleatoriamente de blocos não sobrepostos de amostras e cria novos bancos de dados a partir do original, garantindo assim a assinatura do perfil das fontes. O DS explora as possíveis ambiguidades da solução, suaviza a função Q com a verificação das variabilidades das soluções. 


\section{RESULTADOS E DISCUSSÃO}

Neste capítulo os resultados das análises laboratoriais serão apresentados e discutidos, iniciando-se pelas análises de concentração do $\mathrm{MP}_{2.5}$ e carbono elementar na forma de $\mathrm{BC}_{\mathrm{eq}}$ obtidos nas amostras. Após, discute-se a influência da meteorologia na concentração dos poluentes, seguido da análise e relação entre concentração dos poluentes e a quantidade de veículos, leves e pesados, que passaram pela rodovia Ayrton Senna, nos dois sentidos, no período estudado; a composição elementar das amostras e, por fim, a análise do PMF que relaciona os elementos com os tipos de fontes emissoras.

\subsection{Concentrações}

A partir da coleta do material, os filtros foram pesados e assim obteve-se a concentração de massa do aerossol (equação 1). A concentração média anual do $\mathrm{MP}_{2.5}$ foi de $17.72 \pm 11.45$ $\mu \mathrm{g} / \mathrm{m}^{3}, \mathrm{BC}_{\text {eq }} 2,0 \pm 1,4 \mu \mathrm{g} / \mathrm{m}^{3}$ e para o BC $1.86 \pm 1.27 \mu \mathrm{g} / \mathrm{m}^{3}$.

A figura 20 mostra a concentração diária total do $\mathrm{MP}_{2.5}$ e $\mathrm{BC}_{\text {eq }}$ coletado no período de um ano (abril de 2016 à abril de 2017). A linha vermelha destaca o limite do padrão diário (24h) de qualidade do ar para o aerossol $\left(60 \mu \mathrm{g} / \mathrm{m}^{3}\right)$.

Figura 20 - Concentração total do período amostrado de $\mathrm{MP}_{2.5}$ e BCeq na EACH. Padrão Estadual 24h, $60 \mu \mathrm{g} / \mathrm{m}^{3}$ (linha vermelha); Padrão OMS 24h, $20 \mu \mathrm{g} / \mathrm{m}^{3}$ (linha laranja).

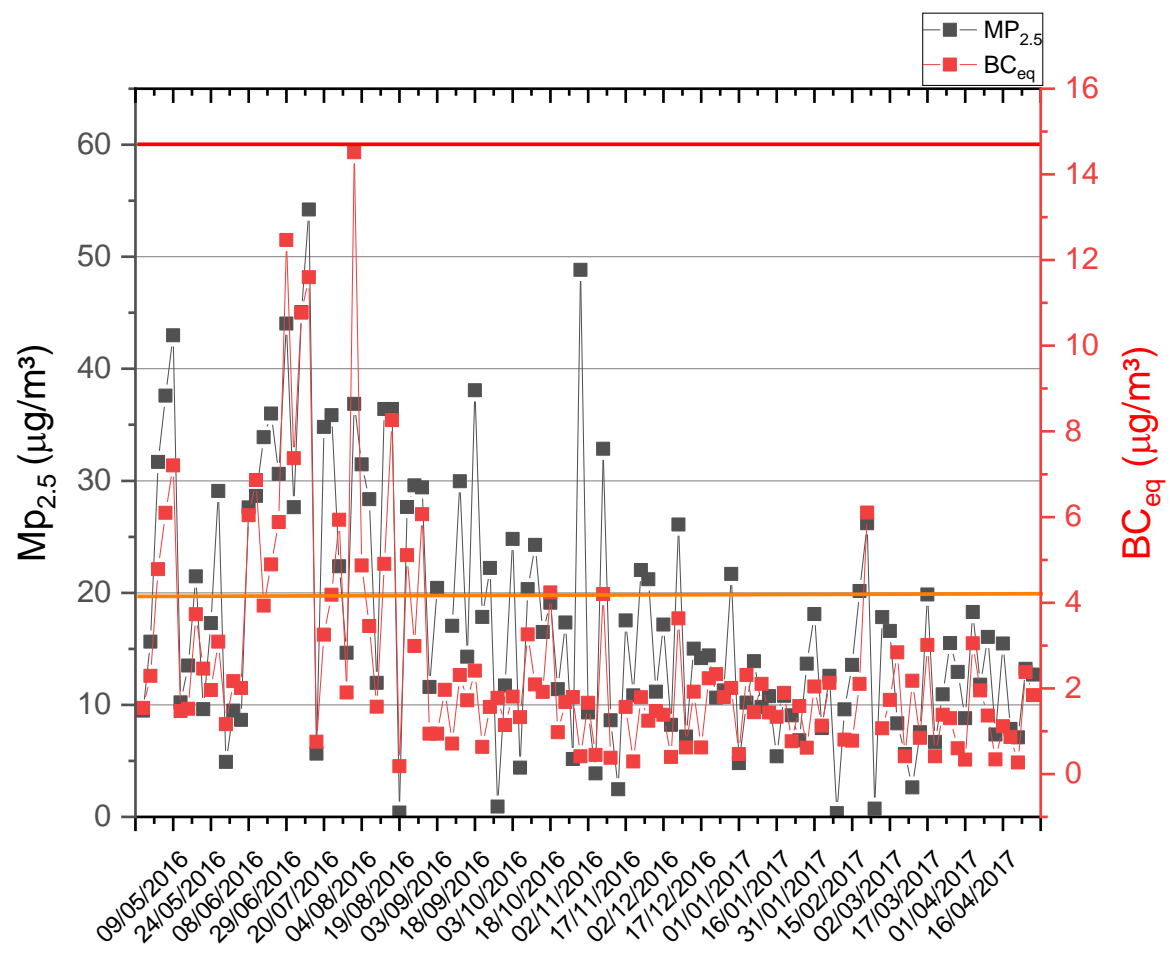


Conforme a figura 20, é observado que não ocorreram ultrapassagens dos padrões de qualidade do ar diários para o $\mathrm{MP}_{2.5}\left(60 \mu \mathrm{g} / \mathrm{m}^{3}\right)$ (linha vermelha destacada no gráfico), durante o período amostrado. A concentração máxima do poluente obtida durante um período de $24 \mathrm{~h}$ na EACH foi de $54,21 \mu \mathrm{g} / \mathrm{m}^{3}$, no dia 12/07/2016, e a mínima concentração foi de $0,92 \mu \mathrm{g} / \mathrm{m}^{3}$ no dia $25 / 09 / 2016$. A média anual foi de $17,63 \mu \mathrm{g} / \mathrm{m}^{3}$, abaixo do padrão estadual anual (20 $\mu \mathrm{g} / \mathrm{m}^{3}$ ) ilustrado em linha laranja.

Segundo relatório anual da estação da CETESB de Guarulhos-Pimentas, que é a mais próxima ao campus da $\mathrm{EACH}$ com dados válidos, a média da concentração do $\mathrm{MP}_{2.5}$ do período total foi de $19 \mu \mathrm{g} / \mathrm{m}^{3}$, abaixo do padrão estadual vigente, mas quase o dobro do estabelecido pela OMS para o padrão anual $\left(10 \mu \mathrm{g} / \mathrm{m}^{3}\right)$. Ao analisar as médias das concentrações para o período de $24 \mathrm{~h}$, segundo os padrões de qualidade do ar da OMS, as médias de concentração obtidas na amostragem da EACH estão muito elevadas, principalmente no período do inverno, conforme destacado em laranja no gráfico $\left(20 \mu \mathrm{g} / \mathrm{m}^{3}\right)$.

Para a OMS, médias de concentração do poluente acima de $20 \mu \mathrm{g} / \mathrm{m}^{3}$ passam a ser consideradas nocivas à saúde humana e ao ambiente. Contudo, como discutido no capítulo “Aerossol, Clima e Saúde” acima, não há evidências científicas que estipulam um mínimo de concentração do aerossol considerado como saudável para a população.

A figura 21, é um comparativo das médias de concentrações mensais do aerossol entre as estações da CETESB de Guarulhos-Pimentas e Marginal Tietê-Ponte dos Remédios, com a EACH.

Figura 21 - Gráfico comparativo entre as médias de concentrações mensais de $\mathrm{MP}_{2.5}$ para as estações da CETESB de Guarulhos-Pimentas e Marginal Tietê-Ponte dos Remédios e EACH.
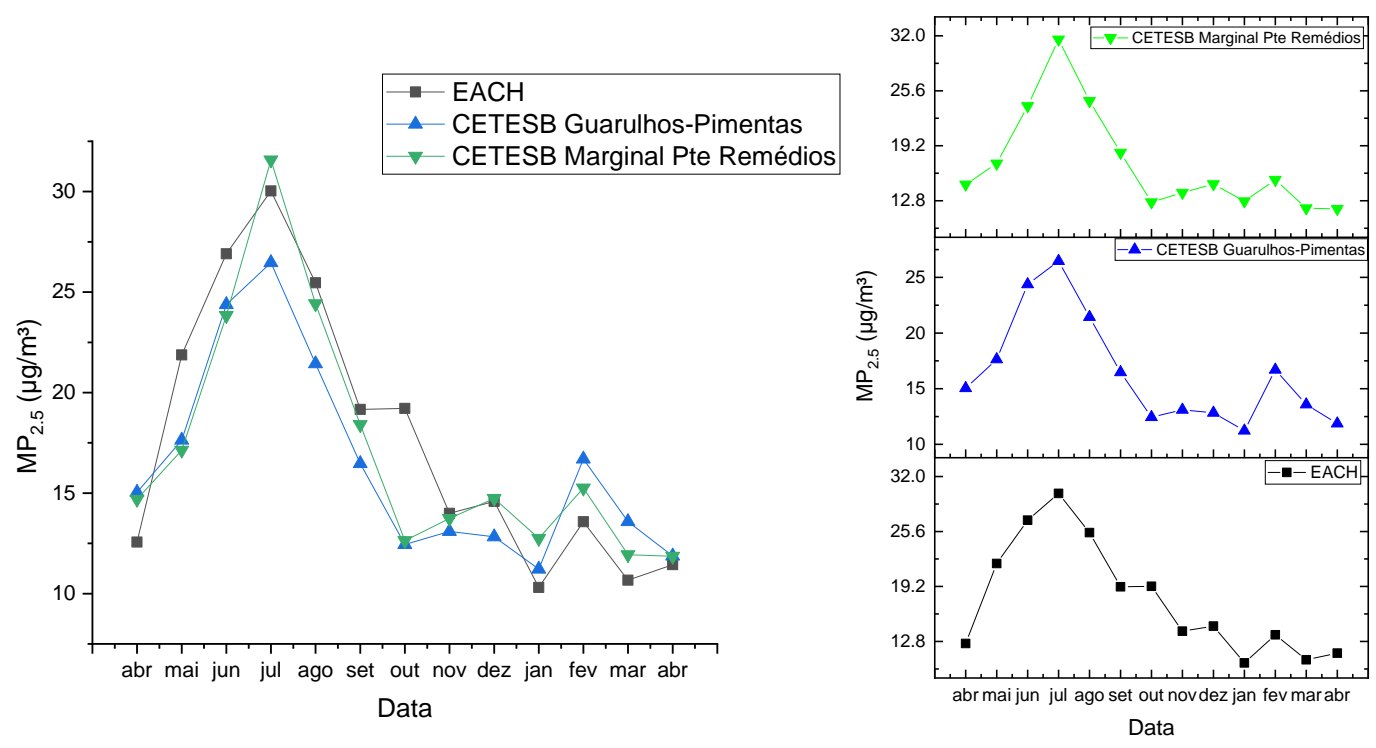

Fonte: Luana Ferreira Vasconcelos, 2020. 
A estação da CETESB de Guarulhos-Pimentas é a mais próxima do campus da EACH com dados válidos para o período amostrado, e para compor o gráfico comparativo de análise da tendência das médias de concentrações de $\mathrm{MP}_{2.5}$, foram considerados também os dados da estação da Marginal Tietê-Ponte dos Remédios.

Ao relacionar as médias de concentrações das estações da CETESB, pode-se notar que há uma mesma tendência entre as variações de concentrações do aerossol coletado na EACH e as estações da CETESB de Guarulhos e Marginal Tietê no decorrer do período amostrado. Apesar da distância entre os pontos, as fontes são parecidas nos três locais. Considerando a qualidade dos dados das estações da CETESB, esta comparação serve também para mostrar que os dados apresentados na pesquisa são consistentes.

O BC ainda não é um poluente padronizado, porém, seus efeitos no clima, meio ambiente e saúde são significativos, sendo um dos principais poluentes relacionados ao aquecimento global e doenças do trato respiratório (SEINFILD; PANDIS, 2006).

Para obter a concentração $\mathrm{BC}_{\text {eq }}$, utilizou-se a refletância como metodologia. Neste método foi possível identificar que o $\mathrm{BC}_{\mathrm{eq}}$, contido no aerossol, representa $14 \%$ da massa total do aerossol (figura 22), e no restante da massa de $\mathrm{MP}_{2.5}$ encontram-se, além das espécies químicas analisadas neste trabalho e que serão apresentadas a seguir, água, bactérias, vírus, material orgânico como pólen, entre outras partículas contidas no ar, que não foram o alvo da análise deste trabalho, e que para obter a sua identificação seriam necessários outros métodos laboratoriais.

Figura 22 - Gráfico de porcentagem de $\mathrm{BC}_{\mathrm{Eq}}$ obtido através da refletância contido no $\mathrm{MP}_{2.5}$

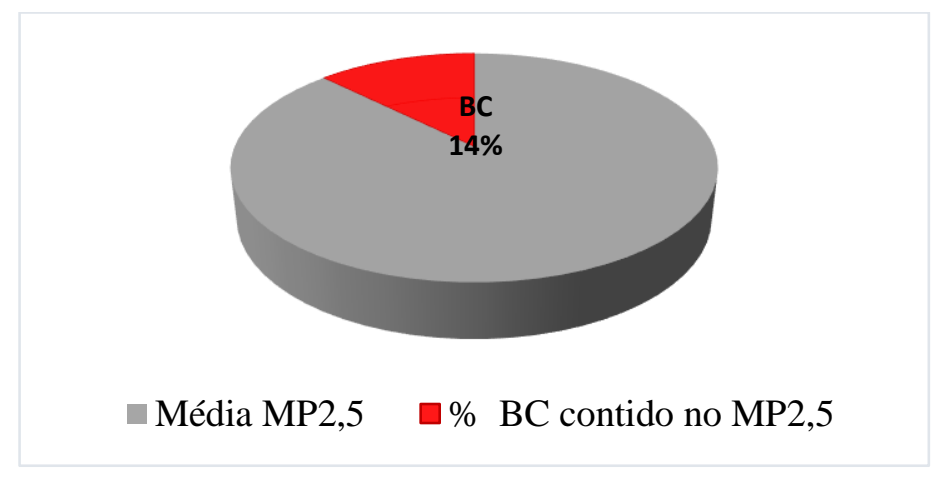

Fonte: Luana Ferreira Vasconcelos, 2020.

Para as demais análises deste estudo foram utilizados os dados de $\mathrm{BC}$ obtidos pelo monitor MAAP, pois como mencionado anteriormente, este equipamento apresentou dados a cada minuto por todo período amostrado, tendo assim melhor resolução temporal e confiabilidade (KANAYA, 2013). 


\subsubsection{Concentração de MP 2.5, BC e variáveis meteorológicas}

Na figura 23 são apresentados os dados diários de temperatura do ar, umidade relativa, velocidade do vento e concentração do $\mathrm{MP}_{2.5}$ e $\mathrm{BC}$.

Os dados meteorológicos foram coletados na estação meteorológica localizada no Aeroporto de Guarulhos, fornecidos pela Rede de Meteorologia do Comando da Aeronáutica (www.redemet.aer.mil.br), e organizados pelo Laboratório Master do IAG/USP.

Figura 23: Dados meteorológicos do período total amostrado. Velocidade do vento $(\mathrm{m} / \mathrm{s})$; Temperatura $\left({ }^{\circ} \mathrm{C}\right)$, Umidade Relativa do $\mathrm{Ar}(\%), \mathrm{MP}_{2.5}$ e BC.

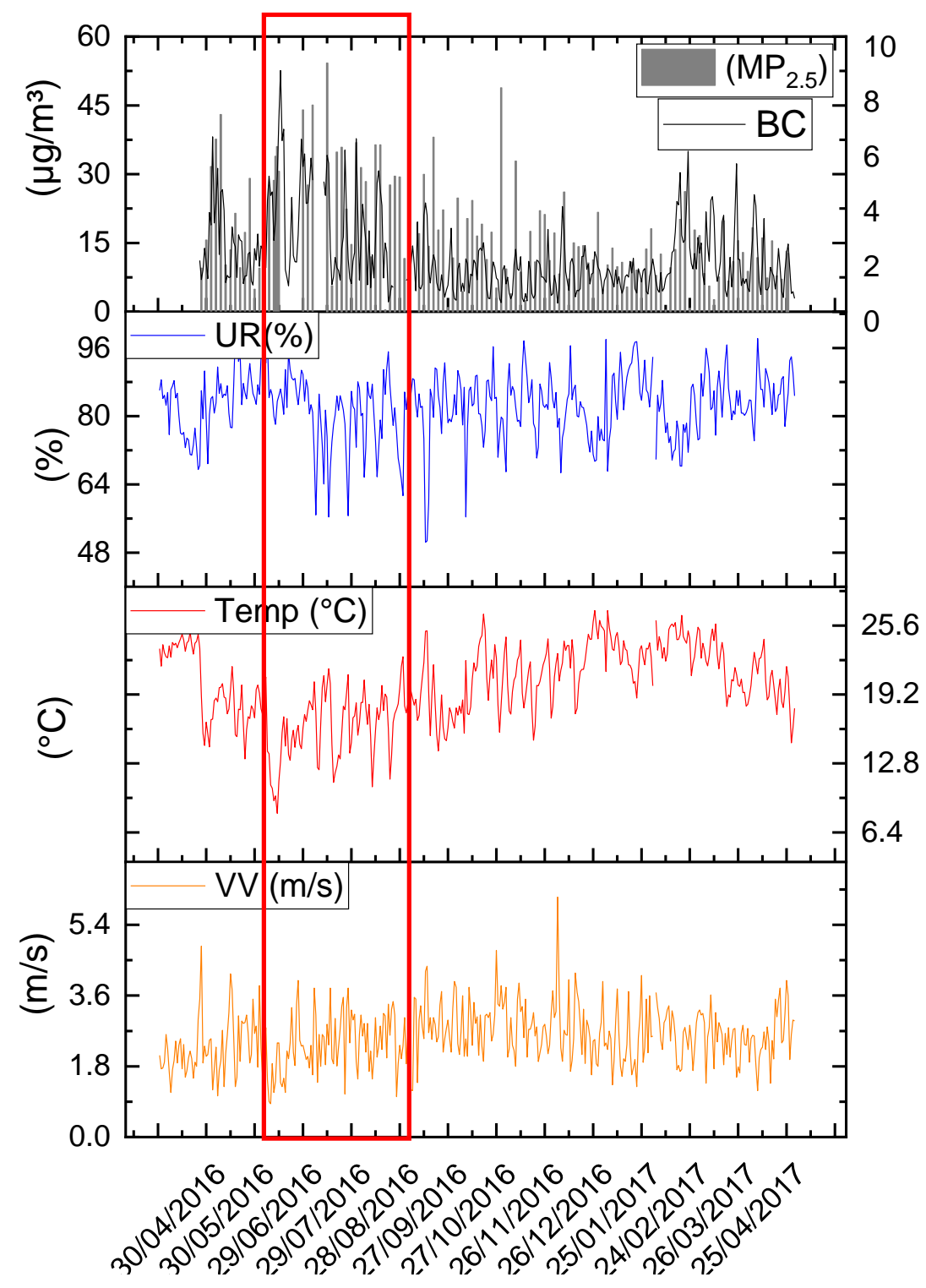

É possível analisar na figura 23, que as variações meteorológicas possuem influência direta na concentração dos poluentes, dependendo da sazonalidade. 
Pode-se observar na faixa relativa aos meses de inverno (junho, julho e agosto), destacado em vermelho, o aumento de concentração do aerossol. As características do período de inverno, como o tempo seco devido à baixa umidade e precipitação, ocorrências de sistemas de alta pressão e inversões térmicas mais frequentes, favorecem o aumento das concentrações de poluentes neste período.

Já no verão, o aumento da umidade relativa do ar, da temperatura, assim como os sistemas de baixa pressão atmosférica e o alto índice pluviométrico do período, tornam a atmosfera mais instável, o que contribui para a dispersão dos poluentes, e a diminuição das concentrações destes, na atmosfera.

No ano de 2016 a acumulação pluviométrica registrada para a cidade de São Paulo foi de $1539.2 \mathrm{~mm}, 9.2 \%$ acima da média climatológica $(1409.5 \mathrm{~mm})$. Os meses mais chuvosos do ano foram fevereiro, maio e junho. No total foram 200 dias com precipitação. Já no ano de 2017, foi registrada a acumulação pluviométrica de $1648.8 \mathrm{~mm}, 16.7 \%$, também acima da média climatológica. Os meses mais chuvosos foram janeiro, abril, maio, junho e novembro. Foram 187 dias no total de precipitação, considerado abaixo da média (188 dias) (INSTITUTO DE ASTRONOMIA, GEOFÍSICA E CIÊNCIAS ATMOSFÉRICAS DA UNIVERSIDADE DE SÃO PAULO 2016 e 2017).

O alto índice pluviométrico do período estudado, que é um dos fatores que contribui para a melhora da qualidade do ar, pode ter favorecido a concentração abaixo do estabelecido pelo padrão de qualidade do ar Estadual anual do $\mathrm{MP}_{2.5}$ do período.

A relação entre as concentrações dos poluentes e a meteorologia é corroborada em diversos estudos realizados na RMSP, como em Andrade e Orsini (1994) e Sanchez-Ccoyollo e Andrade (2002), nos quais, são apresentados que a influência da meteorologia pode ser positiva, quando esta favorece a dispersão dos poluentes, ou negativa, quando as condições meteorológicas não favorecem a dispersão dos poluentes. E essa relação é amplamente vinculada à sazonalidade.

A figura 24 , ilustra a relação das médias de concentrações mensais dos poluentes para o período estudado com os parâmetros meteorológicos. A concentração do $\mathrm{MP}_{2.5}$, apresenta a alta máxima do período quando há a diminuição da umidade relativa do ar (rosa). Conforme destacado em vermelho, no mês de julho, a média de concentração de $\mathrm{MP}_{2.5}$ foi a mais alta do período estudado $\left(30,03 \mu \mathrm{g} / \mathrm{m}^{3}\right)$ e o pico de concentração do poluente $\left(54,21 \mu \mathrm{g} / \mathrm{m}^{3}\right)$ foi atingido no dia 14/07/2016, quando a porcentagem de umidade relativa do ar se encontrava no seu ponto mínimo do período $(\sim 56 \%)$. Como mencionado anteriormente, nos meses de inverno as condições de dispersão dos poluentes são ruins devido às condições meteorológicas, favorecendo sua acumulação. 
Figura 24 - Concentração de $\mathrm{BC}, \mathrm{MP}_{2.5}$ e variáveis meteorológicas (velocidade do vento; temperatura e umidade relativa do ar)

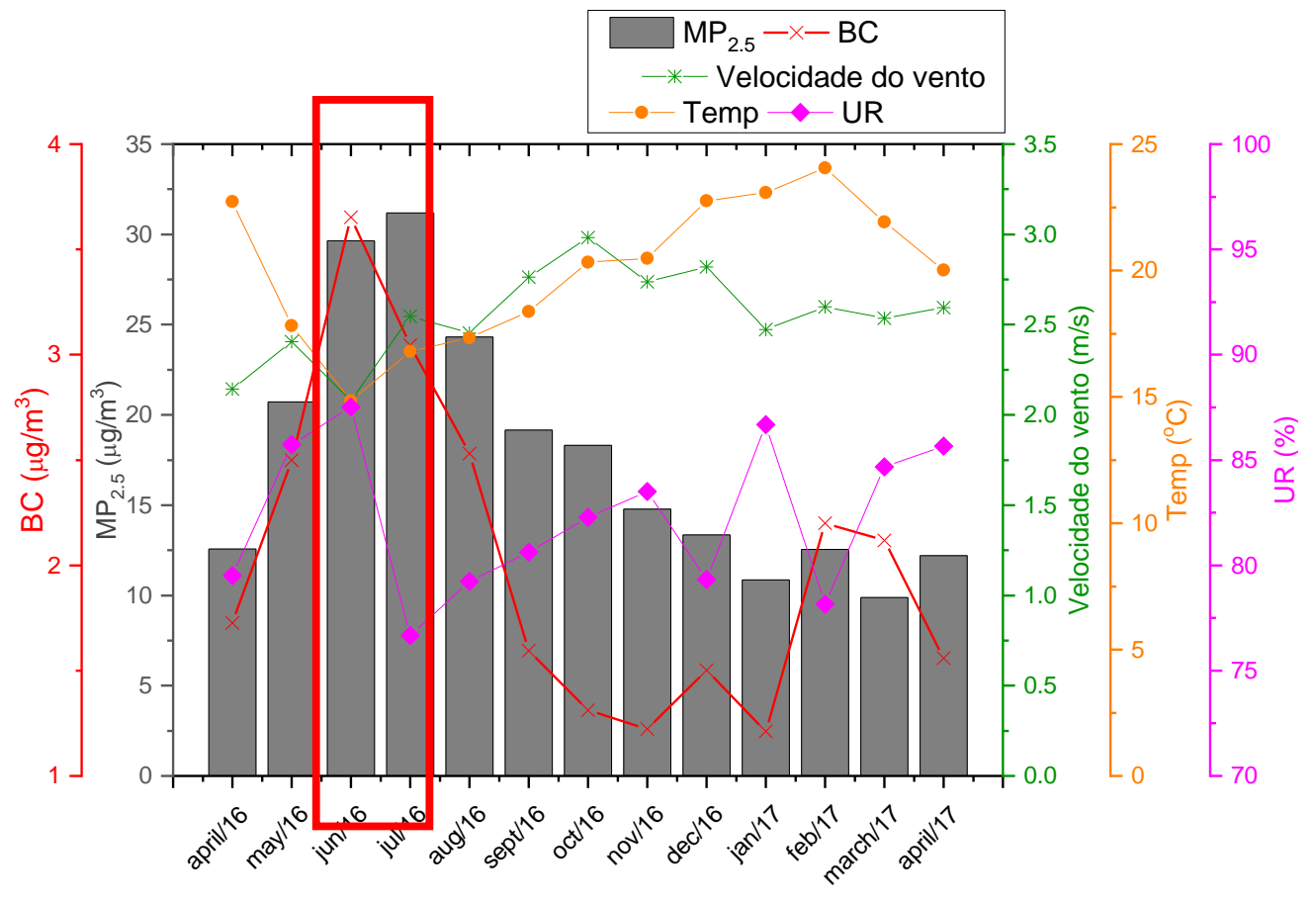

Fonte: Luana Ferreira Vasconcelos, 2020.

Na figura 25 (a e b) pode-se observar a rosa das poluições, no qual o parâmetro direção dos ventos está correlacionado com a concentração do aerossol. Observa-se que a maior frequência da direção e concentração do aerossol é a contribuição das direções sudeste, leste e nordeste. 
Figura 25 - a) Concentração de $\mathrm{MP}_{2.5}$ e Direção dos Ventos (Rosa das Poluições) e entorno da EACH; b) Rosa das Poluições aproximado
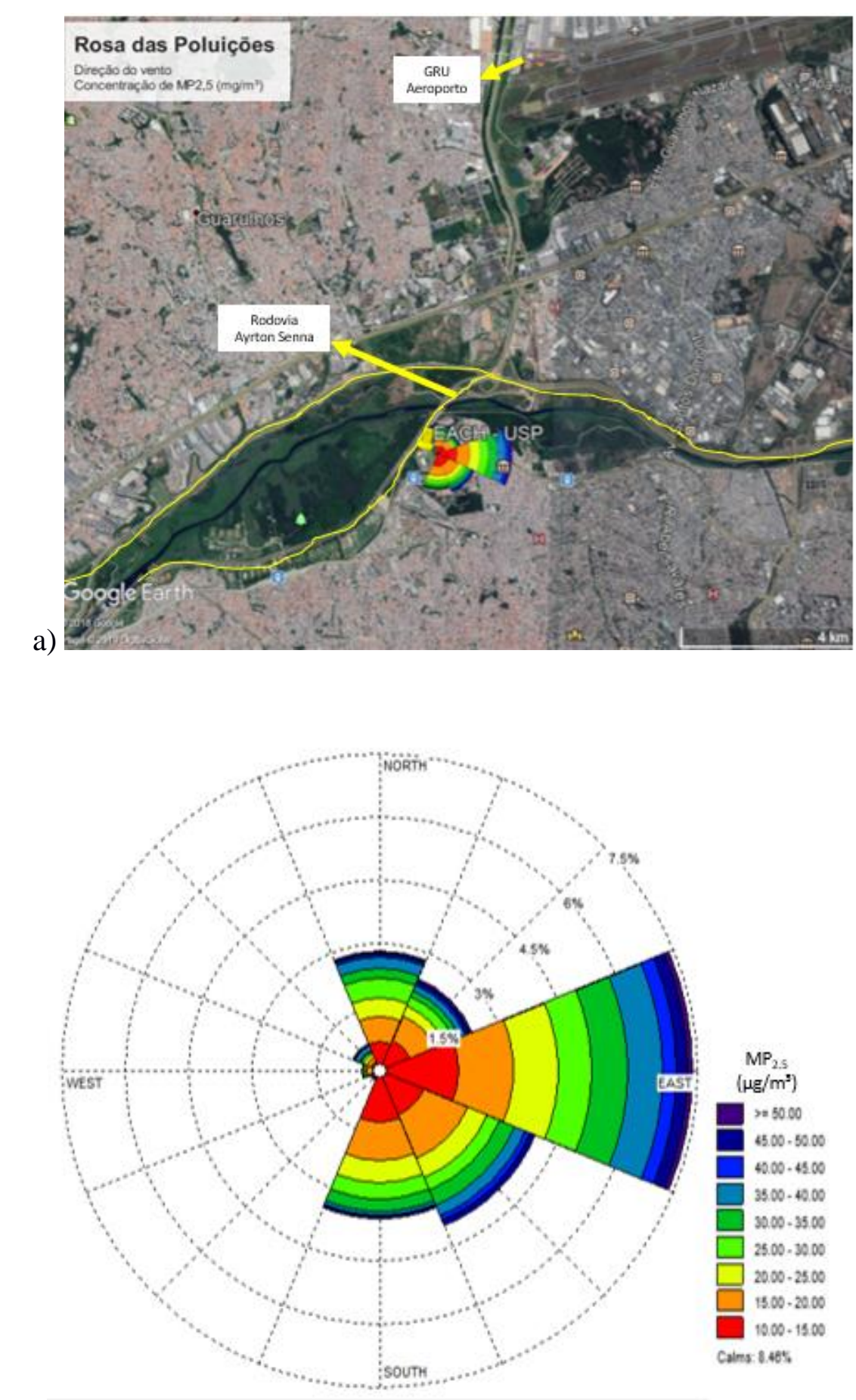

b)

Fonte: Luana Ferreira Vasconcelos, 2020.

Na figura 25a, foi plotada a rosa das poluições na área do campus da EACH utilizando o programa WRplot e Google Earth, e a figura 25b mostra o gráfico em maior escala.

As maiores médias de concentrações do aerossol se encontram no quadrante sudeste (SE), relativo à direção entre $90^{\circ}-180^{\circ}$ (figura 26), atingindo a média de concentração de 18,11 $\mu \mathrm{g} / \mathrm{m}^{3}$ no quadrante, seguido pelo quadrante NE com média $\sim 17 \mu \mathrm{g} / \mathrm{m}^{3}$.

A figura 26 é um histograma de concentração do $\mathrm{MP}_{2.5}$ por quadrante de direção dos 
ventos. Complementando a análise feita com o WRplot na rosa das poluições, demonstrando a prevalência e influência predominante da direção SE, seguida da direção NE.

Figura 26 - Gráfico da média das concentrações de $\mathrm{MP}_{2.5}$ por quadrantes de direção do vento

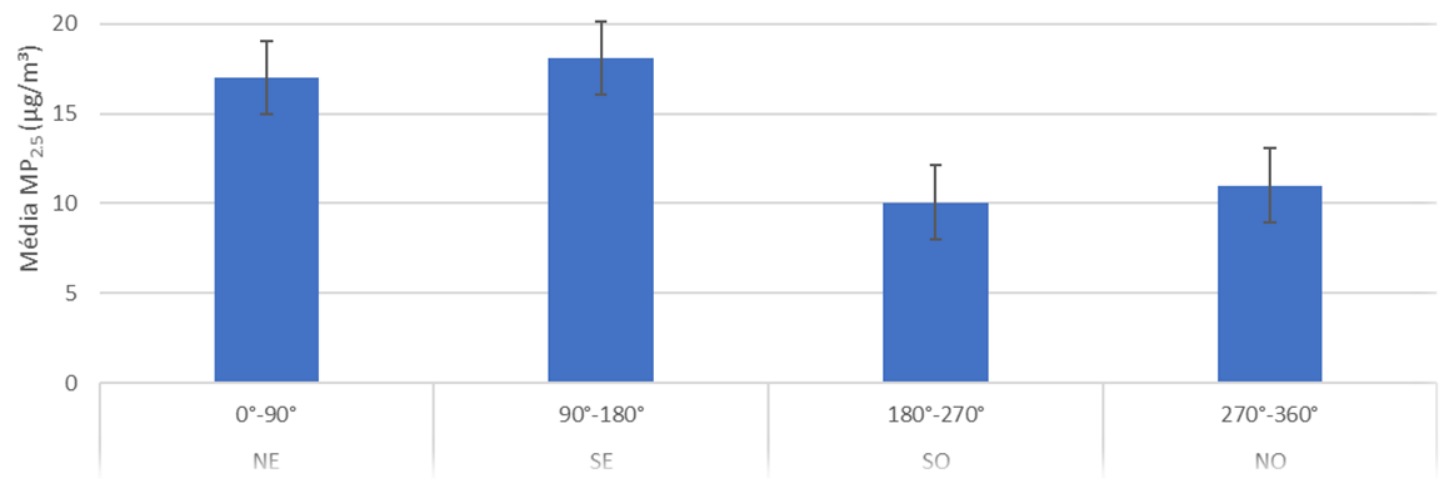

Fonte: Luana Ferreira Vasconcelos, 2020.

\subsubsection{Concentração de $\mathrm{MP}_{2.5}, \mathrm{BC}$ e Veículos.}

A rodovia Ayrton Senna, localizada a 250m da EACH, é uma via principal da RMSP, que possui intenso tráfego de veículos leves e pesados.

No período analisado, passaram no total 36.063.300 de veículos nos dois sentidos da rodovia, sendo 30.349.229 veículos leves ou Ligth Duty Vehicles (LDVs) e 5.714.071 veículos pesados ou Heavy Duty Vehicles (HDVs), conforme dados fornecidos pela Agência de Transporte do Estado de São Paulo (ARTESP).

A figura 27, mostra o total diário por tipo de veículo (LDV e HDV) que circularam pela rodovia Ayrton Senna em ambos sentidos entre abril de 2016 e abril de 2017. O mês de abril de 2017 foi desconsiderado devido à falta de dados para ambos os sentidos da rodovia. Os LDV s correspondem a $84,16 \%$ do total de veículos circulantes, e $18,83 \%$ é correspondem aos HDVs. 
Figura 27 - Total diário de LDVs e HDVs na Rodovia Ayrton Senna, em ambos os sentidos, por todo período amostrado.

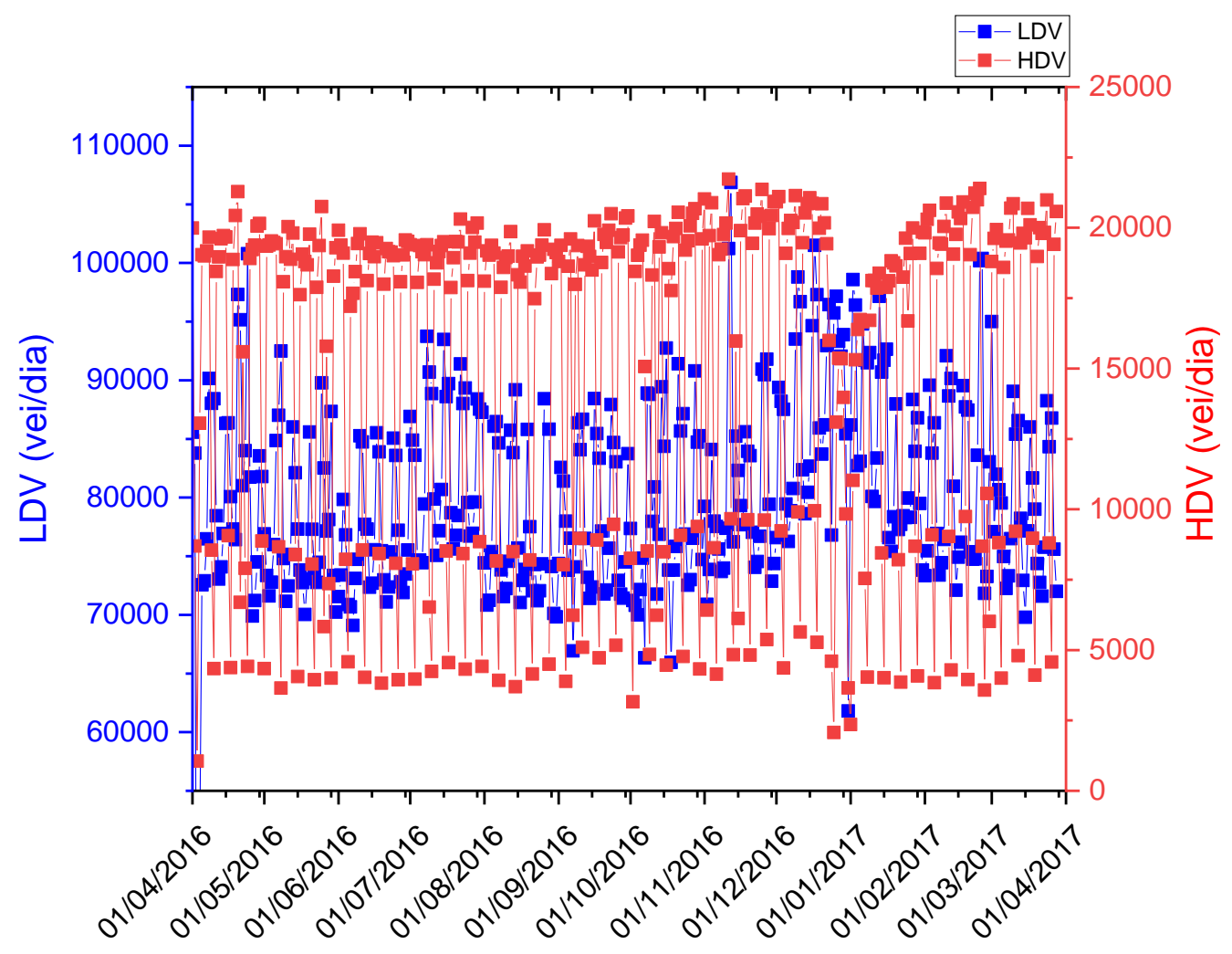

Fonte: Luana Ferreira Vasconcelos, 2020.

Nesta análise temporal, os picos das médias de número de LDVs mensais (figura 28a) ocorrem nos meses de junho, dezembro e janeiro, podendo ser relacionadas aos períodos de férias, no qual há aumento no número de LDVs circulantes pela rodovia Ayrton Senna que liga a RMSP a cidades do interior e litoral. 
Figura 28 - a) gráfico da média de veículos por mês; b) gráfico da média de veículos por semana; c) gráfico da média de veículos por hora.

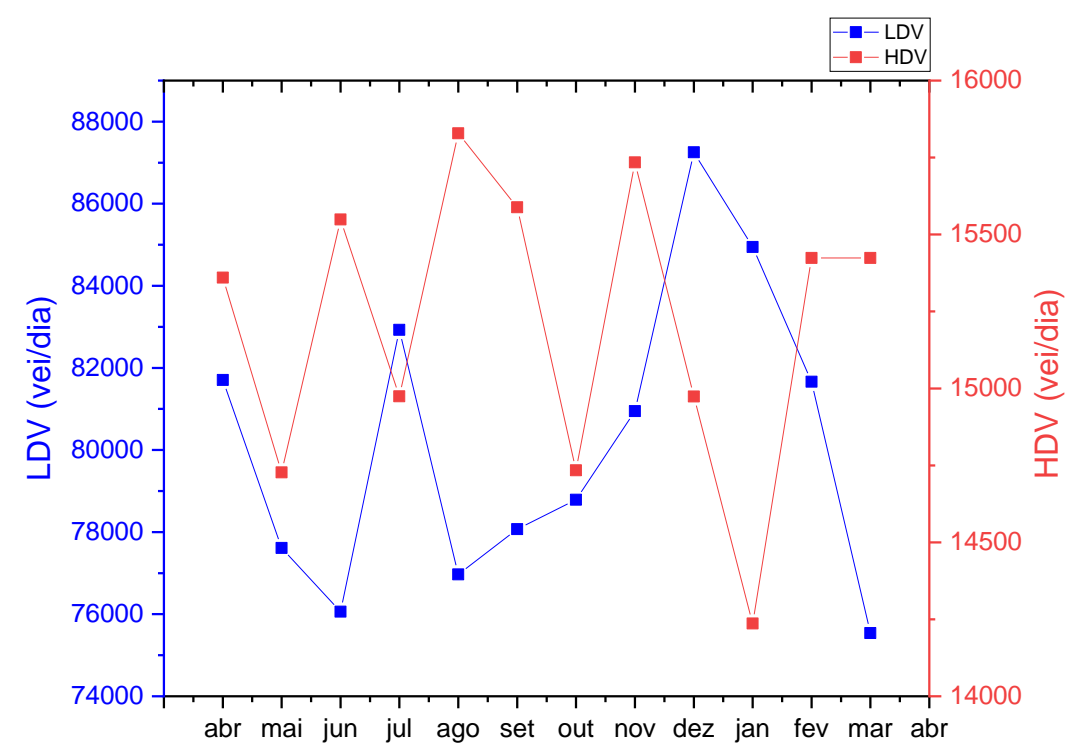

a)
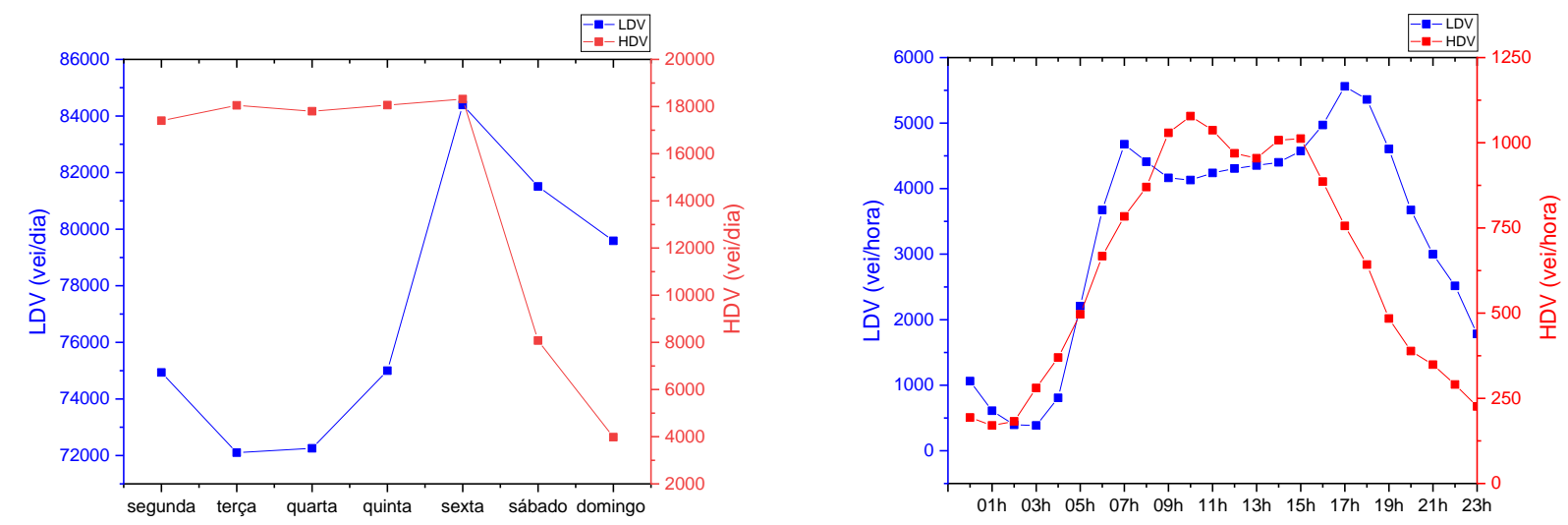

b)

c)

Fonte: Luana Ferreira Vasconcelos, 2020.

Na figura $28 b$ e 28c, analisam-se as médias semanais e horárias dos veículos, onde é mostrada a influência da dinâmica comercial da RMSP. Na figura $27 \mathrm{~b}$ mostra-se o grande número de HDVs de segunda à sexta, e aos finais de semana (sábado e domingo) uma redução brusca de aproximadamente $92 \%$ no número de HDVs na rodovia, enquanto, o número de LDVs para os finais de semana aumenta, dessa forma, pode-se relacionar aos deslocamentos da população para o litoral e interior. Na figura 27c é nítida a influência comercial na concentração veicular, pois há aumento de veículos predominantemente nos horários de pico (7h e 18h). Para os pesados, apesar de haver um horário de restrição de caminhões para as marginais e centro expandido da capital (SÃO PAULO, 2016), a rodovia Ayrton Senna interliga com outras rodovias (Dutra e Fernão Dias), e outras cidades da RMSP, o que pode explicar o alto número 
de HDVs em horários de restrição (5h-9h e 17h-21h).

Relacionando as concentrações médias mensais dos poluentes $\mathrm{BC}$ e $\mathrm{MP}_{2.5}$ (figura 28), com quantidade de LDVs e HDVs, não é possível analisar a correlação entre eles, no entanto, esta relação será evidenciada na escala semanal.

Figura 29 - Concentração média mensal de BC, MP 2,5 e veículos leves (LDV) e pesados (HDV) nos dois sentidos da Rodovia Ayrton Senna para o período total (abril 2016 - abril 2017)

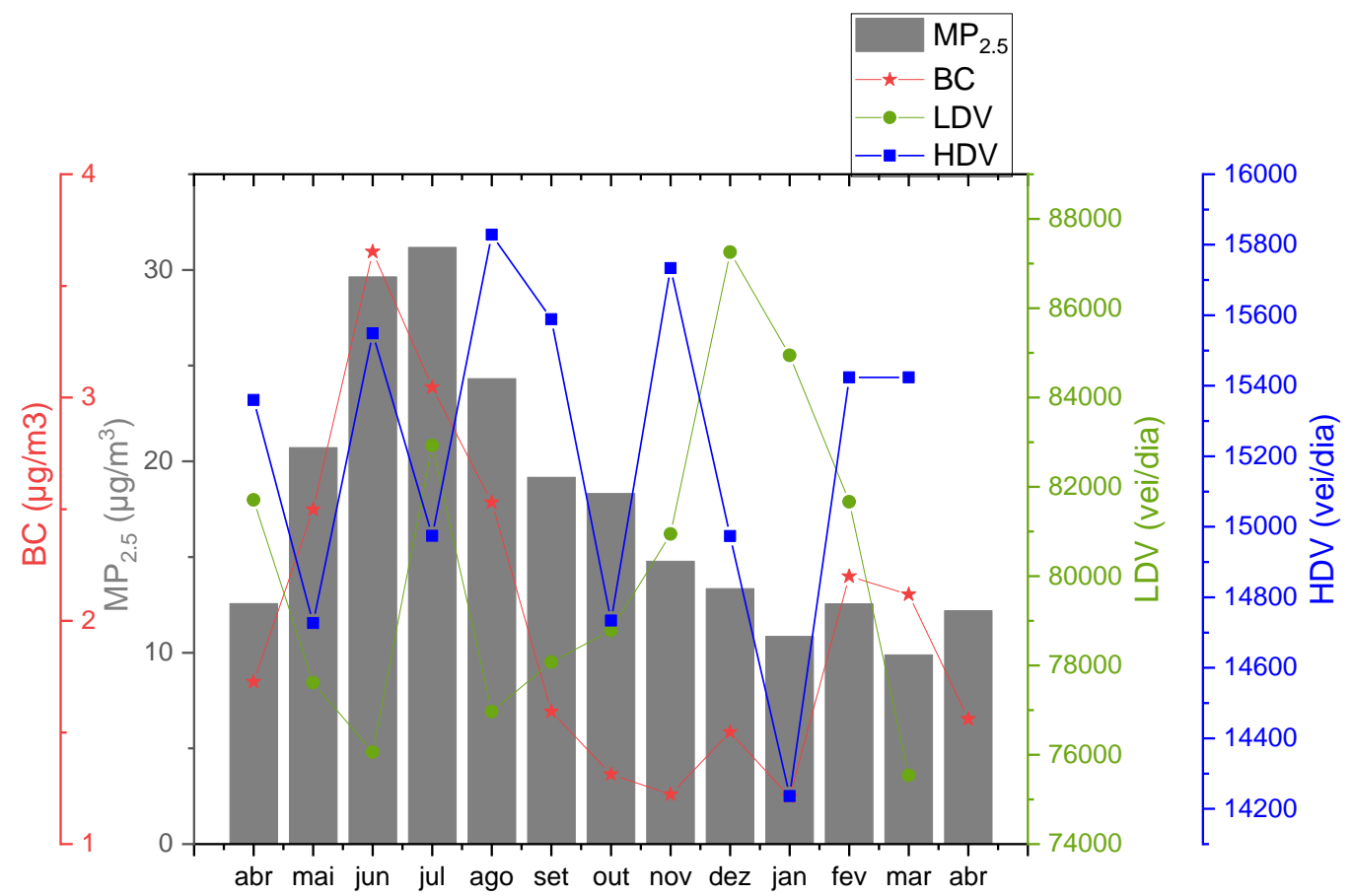

Fonte: Luana Ferreira Vasconcelos, 2020.

Em Miranda et al. (2018), realizou-se um trabalho na EACH, no qual foi feito o monitoramento ambiental do aerossol e BC no ano de 2015, e através do modelo receptor PMF identificou-se a contribuição veicular como sendo a principal fonte emissora do $\mathrm{MP}_{2.5}$ e BC. Os veículos pesados tiveram a maior contribuição na massa do $\mathrm{MP}_{2.5}$, representando $52 \%$ da massa total, seguido da ressuspensão do solo com $26 \%$, veículos leves com $18 \%$ e $4 \%$ de fontes de origem local, podendo ser de fontes industriais.

A análise temporal relacionando os dias semanais com as concentrações dos poluentes e a quantidade de veículos circulantes na rodovia, figura 30, revela maior concentração de veículos pesados de segunda a sexta-feira, e pode-se observar a correlação entre as concentrações de BC e HDVs, principalmente no final da semana. A maior circulação de HDVs 
de segunda à sexta é devido às demandas das atividades comerciais nos dias úteis, onde há maior fluxo de veículos de carga no período semanal, aumentando assim a concentração de BC. Diversos estudos apresentam que apesar da quantidade de HDVs ser inferior quando comparado aos LDVs, os veículos pesados podem chegar a emitir quatro vezes mais poluentes na atmosfera do que os LDVs, pois os HDVs são, predominantemente, movidos através da combustão do diesel, necessitando assim de altas temperaturas para a sua queima, dessa forma emitem além de poluentes primários como $\mathrm{NO}_{2}$ e $\mathrm{NO}, \mathrm{o} \mathrm{BC}$

(MIRANDA et al., 2017).

Apesar do aumento do tráfego de LDVs aos finais de semana, que pode estar relacionado com as atividades de lazer da população, as concentrações de MP são reduzidas, quando comparados aos outros dias da semana, sendo assim, pode-se relacionar que o MP não tem como principal fonte os veículos leves.

Figura 30 - Concentração média de black carbon (BC), MP 2,5 e veículos leves (LDV) e pesados (HDV) nos dois sentidos da Rodovia Ayrton Senna para os dias da semana.

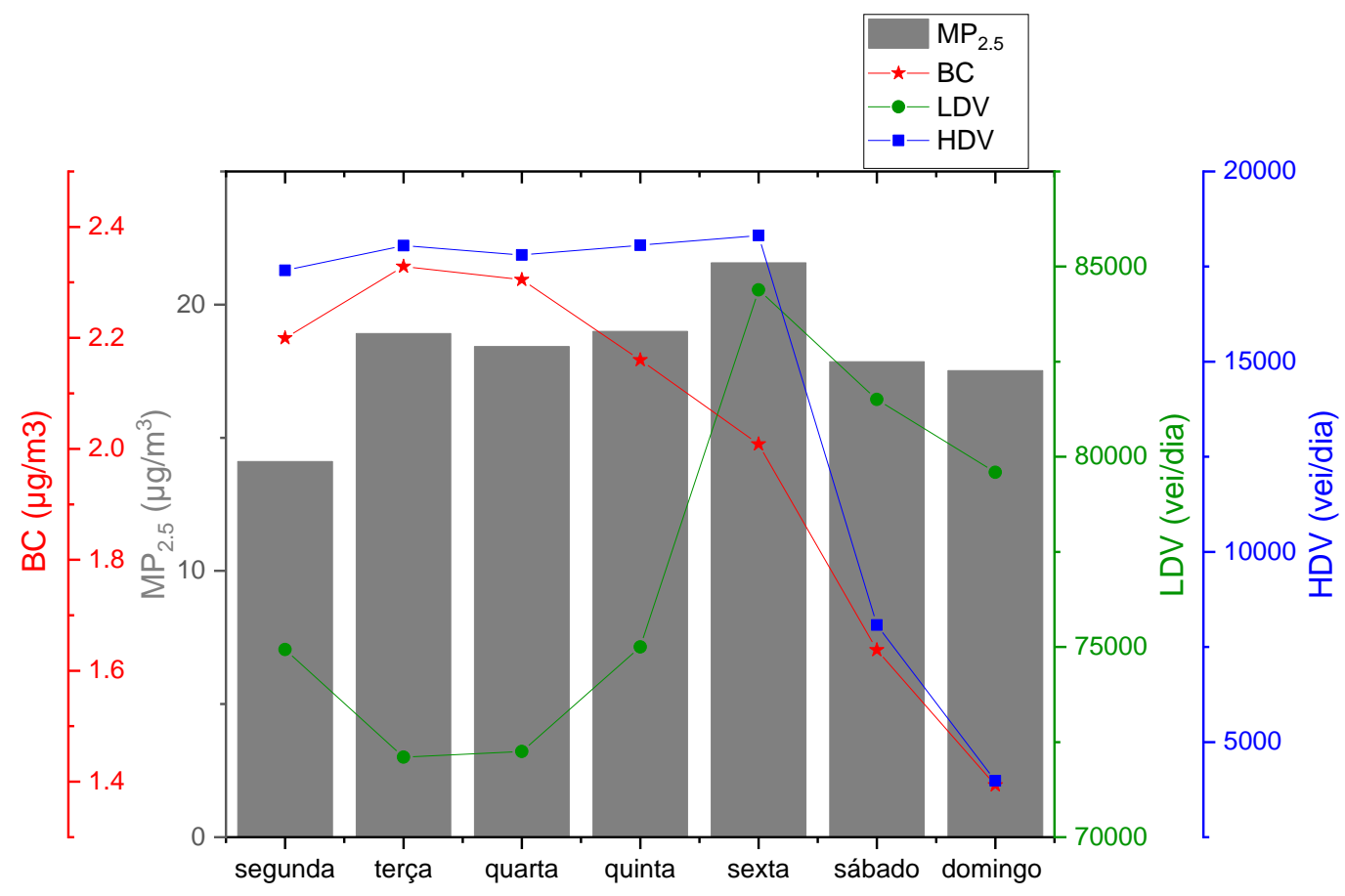

Fonte: Luana Ferreira Vasconcelos, 2020.

Na tabela 2, abaixo, foi realizada a correlação de Pearson, como método complementar de análise da figura 30, no qual é possível demonstrar estatisticamente a correlação entre o poluente BC e a quantidade de veículos pesados na análise semanal. 
Tabela 2 - Correlação de Pearson para as médias semanais de concentração de BC e número de LDVs e HDVs circulantes na rodovia Ayrton Sena.

\begin{tabular}{rrrrr}
\hline & $\mathrm{MP}_{2.5}$ & $\mathrm{BC}$ & $\mathrm{LDV}$ & $\mathrm{HDV}$ \\
\hline $\mathrm{MP}_{2.5}$ & 1 & $-0,863^{*}$ & 0,658 & $-0,757^{*}$ \\
$\mathrm{BC}$ & & 1 & $-0,679$ & $0,949^{*}$ \\
$\mathrm{HDV}$ & & & 1 & $-0,438$ \\
$\mathrm{LDV}$ & & & & 1 \\
\hline
\end{tabular}

$((*)$ significativos em $\mathrm{p}<0,05)$

Fonte: Luana Ferreira Vasconcelos, 2020.

A correlação entre BC e HDV é altíssima quando se analisa a série semanal do comportamento destes. E quando analisamos a correlação entre BC e LDV, é apresentada uma correlação negativa (como mostrado na figura 31), o que nos remete ao fato de que o BC não é o principal poluente emitido pelos veículos leves, apesar de que muitos também utilizam o diesel como combustível.

Na figura 31, analisou-se a concentração diária do BC.

Figura 31: Concentração média diária de BC ao longo do período de estudo

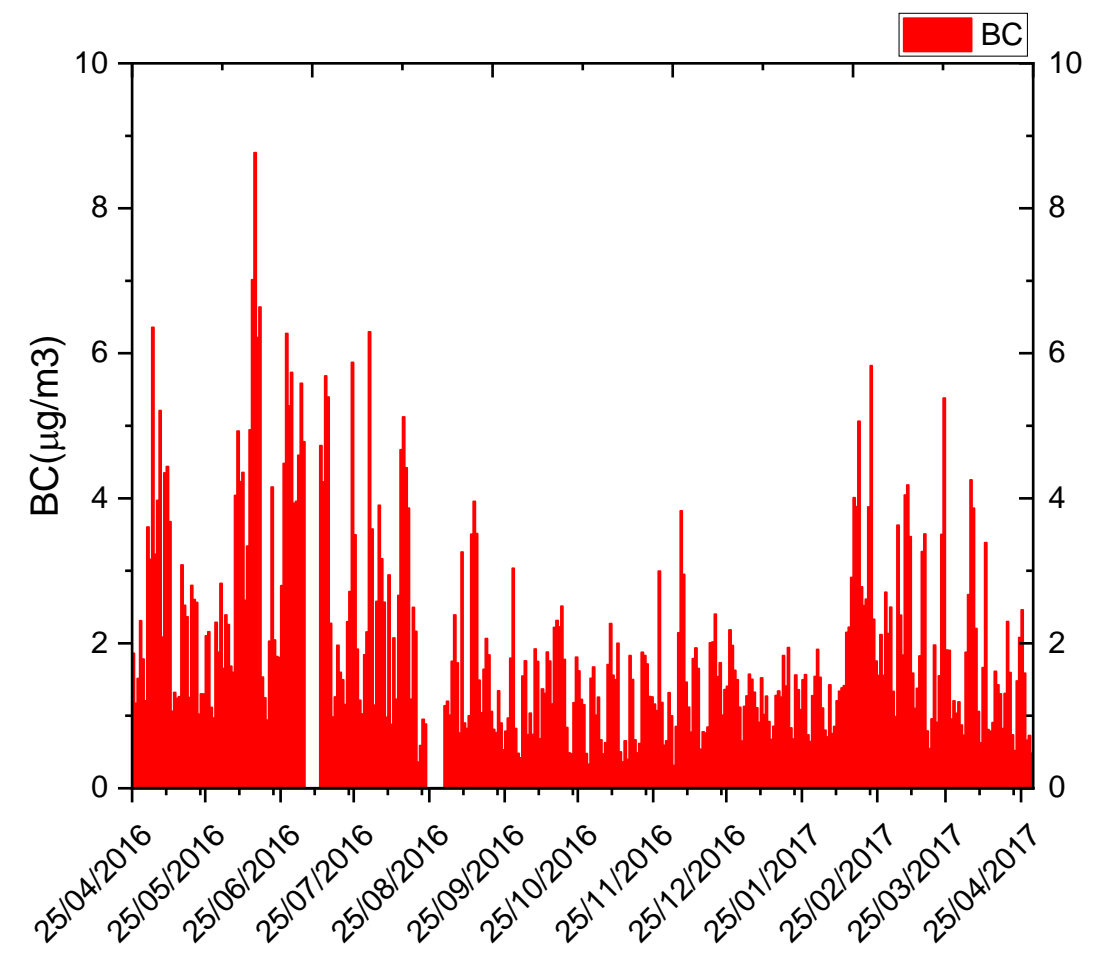

Fonte: Luana Ferreira Vasconcelos, 2020. 
Os resultados das análises demonstraram que alguns dias do período de inverno e verão, registraram os valores mais altos de concentração de BC. No período de inverno, nos meses de junho, julho e agosto, registrou-se a média de $3,12 \mu \mathrm{g} / \mathrm{m}^{3}$, e no período de verão, nos meses de dezembro, janeiro e fevereiro, registrou-se a média de $1,62 \mu \mathrm{g} / \mathrm{m}^{3}$. No mês de junho obteve-se a maior média de concentração de $\mathrm{BC}$ para o período total $\left(3,58 \mu \mathrm{g} / \mathrm{m}^{3}\right)$, atingindo concentrações diárias acima de $16 \mu \mathrm{g} / \mathrm{m}^{3}$. No período de verão, em fevereiro, obteve-se valor médio de $2,23 \mu \mathrm{g} / \mathrm{m}^{3}$, e chegou a atingir concentrações diárias também acima de $16 \mu \mathrm{g} / \mathrm{m}^{3}$.

A concentração elevada de BC para os dias de verão, pode estar relacionada à focos de incêndios locais, como queima de lixo, que são frequentes na região, ou vindos da região central do Brasil.

Segundo estudo realizado por Pereira et al. (2017) na cidade de São Paulo, a contribuição de queima de biomassa representou $20 \%$ da concentração em massa de $\mathrm{MP}_{2.5}$, sendo $40 \%$ relacionado a emissões veiculares. As queimadas possuem significativa importância na concentração do aerossol urbano. Outros compostos carbonáceos também podem estar presentes na composição total da massa do $\mathrm{MP}_{2.5}$.

Segundo dados do INPE (Instituto Nacional de Pesquisas Espaciais), no mês de fevereiro ocorreram aproximadamente 3.265 focos de queimadas em todo território nacional. Os focos de incêndio ocorridos no período amostrado (abril de 2016 à abril de 2017) ocorreram predominantemente no Estado do Mato Grosso, representando 17,02\% do total de focos de queimadas no Brasil, seguido pelos Estados do Pará (13,60\%) e Maranhão (12,49\%). O Estado de São Paulo apresentou 34.295 focos de queimadas em todo o período, representando 1,82\% do total de focos (INSTITUTO NACIONAL DE PESQUISAS ESPACIAIS, 2016).

$\mathrm{Na}$ figura 32, analisam-se as concentrações horárias de $\mathrm{BC}$ para o período total amostrado. 


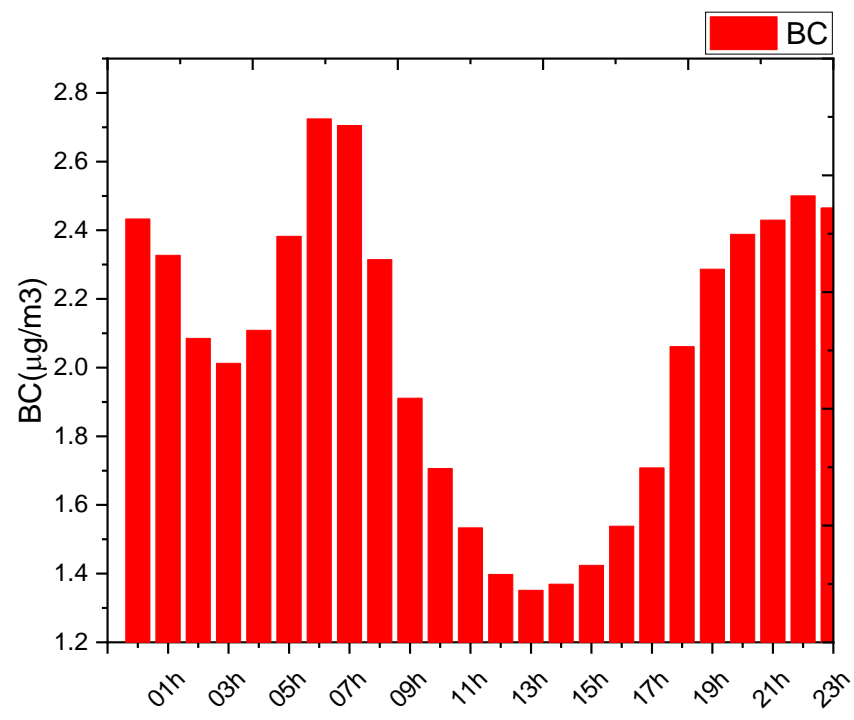

Fonte: Luana Ferreira Vasconcelos, 2020.

Observa-se que na variação horária das concentrações de $\mathrm{BC}$, ocorrem picos predominantemente no período noturno e início do período matutino. A diminuição da concentração de BC no período vespertino está relacionada com a influência da meteorologia, que favorece a dispersão atmosférica.

A portaria $n^{\circ}$ 031/16-SMT.GAB da Secretaria Municipal de Transporte estabelece que a circulação de caminhões fica restrita das $05 \mathrm{~h}$ às $09 \mathrm{~h}$ e das $17 \mathrm{~h}$ às $21 \mathrm{hs}$ de segunda a sexta e das 10:00hs às 14:00 aos sábados. Como já mencionado, apesar desta restrição, a rodovia Ayrton Senna interliga outras rodovias como a Dutra e Fernão Dias, assim como outras cidades da RMSP, o que pode explicar as altas concentrações do poluente BC mesmo em horários com restrição. Outro fator é que também há LDVs movidos a diesel, assim compreende-se o comportamento da concentração de BC nos horários de pico (por volta das 6h e das 17h).

Outro fator relevante que deve ser levado em consideração quanto ao aumento de BC no período noturno, é a influência meteorológica. A altura da camada limite planetária e estabilidade atmosférica nos períodos noturnos, favorecem o surgimento de inversões térmicas, desfavorecendo a dispersão de poluentes, e assim podem ocasionar o aprisionamento e permanência do aerossol na baixa atmosfera (COMPANHIA AMBIENTAL DO ESTADO DE SÃO PAULO, 2013; SÁNCHEZ-CCOYLLO; ANDRADE, 2002; VEMADO; PEREIRA FILHO, 2016).

A figura 33 correlaciona BC e NOx da estação da CETESB Guarulhos-Pimentas, localizada a aproximadamente $3 \mathrm{~km}$ de distância do campus da $\mathrm{EACH}$, a fim de corroborar a relação entre a concentração de $\mathrm{BC}$ e a queima de diesel, pois, devido às altas temperaturas 
exigidas para realização da queima do diesel, emitem também altas concentrações de $\mathrm{NO}_{2}$ e $\mathrm{NO}$ para a atmosfera.

Como pode ser observado nas Figura 33a, 33b e 33c, ambos os poluentes seguem em tendência quando se analisa as concentrações médias mensais, semanais e horárias, mostrando que os poluentes realmente provêm da mesma fonte.

Figura 33 - a) Gráfico de concentração média mensal de BC e NOx; b) Gráfico de concentração média semanal de $\mathrm{BC}$ e NOx; c) Gráfico de concentração média horária de BC e NOx.

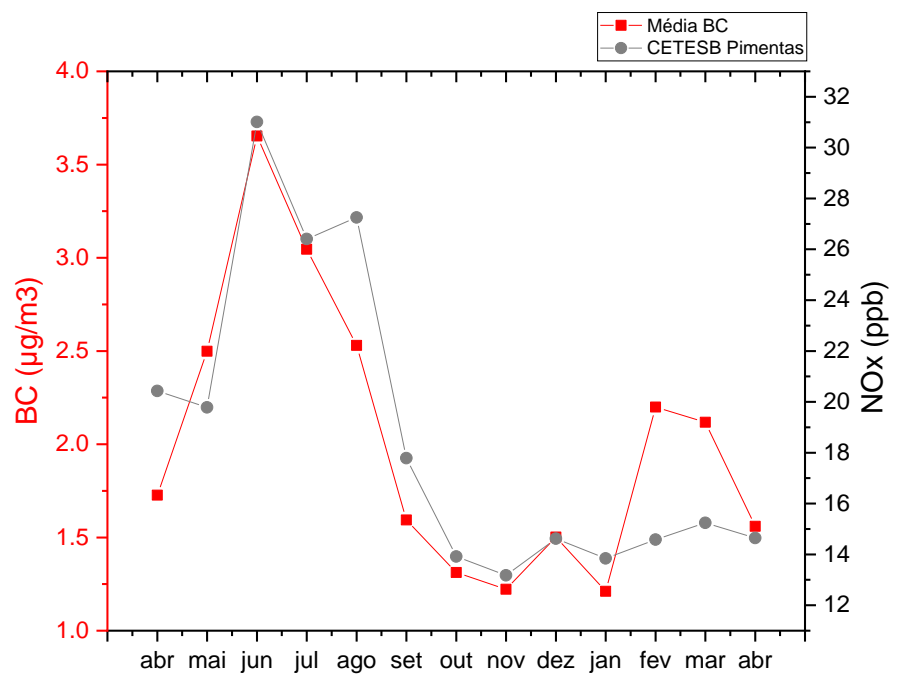

a)
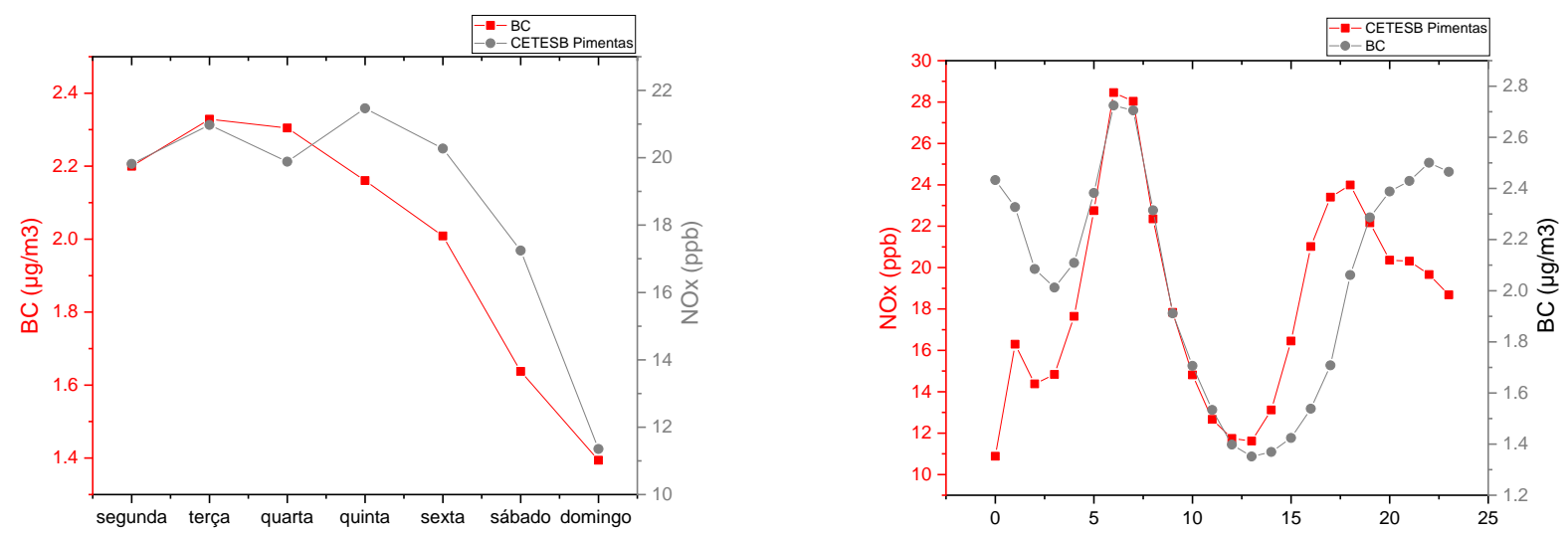

b)

c)

Fonte: Luana Ferreira Vasconcelos, 2020. 


\subsubsection{Concentrações das Espécies Químicas}

Com a análise de fluorescência de raios-X e de cromatografia, foram identificadas 34 espécies (Na, Mg, Al, Si, P, S, Cl, K, Ca, Ti, V, Cr, Mn, Fe, Ni, Cu, Zn, Se, Br, Rh, Pb, F-, $\mathrm{HCOO}^{-}, \mathrm{Cl}^{-}, \mathrm{NO}_{3}{ }^{-}, \mathrm{PO}_{4}{ }^{3-}, \mathrm{SO}_{4}{ }^{2-}, \mathrm{C}_{2} \mathrm{O}_{4}{ }^{2-}, \mathrm{Na}^{+}, \mathrm{NH}_{4}{ }^{+}, \mathrm{K}^{+}, \mathrm{Ca}^{2+}, \mathrm{Mg}^{2+} \mathrm{e} \mathrm{C}_{2} \mathrm{H}_{3} \mathrm{O}_{2}{ }^{-}$)

A figura 34 apresenta a média de concentração das espécies químicas do aerossol para todo o período amostrado. Os principais elementos encontrados foram: $\mathrm{Na}, \mathrm{Al}, \mathrm{Si}, \mathrm{S}, \mathrm{Cl}, \mathrm{K}, \mathrm{Ca}$, $\mathrm{Fe}, \mathrm{Zn}, \mathrm{Cl}^{-}, \mathrm{NO}_{3}{ }^{-}, \mathrm{SO}_{4}{ }^{2-}, \mathrm{Na}^{+}, \mathrm{Ca}^{+2}, \mathrm{~K}^{+}, \mathrm{NH}_{4}{ }^{+}$e $\mathrm{C}_{2} \mathrm{H}_{3} \mathrm{O}^{2-}$.

Figura 34 - Concentração média das espécies químicas continas nas amostras de $\mathrm{MP}_{2 . .5}$

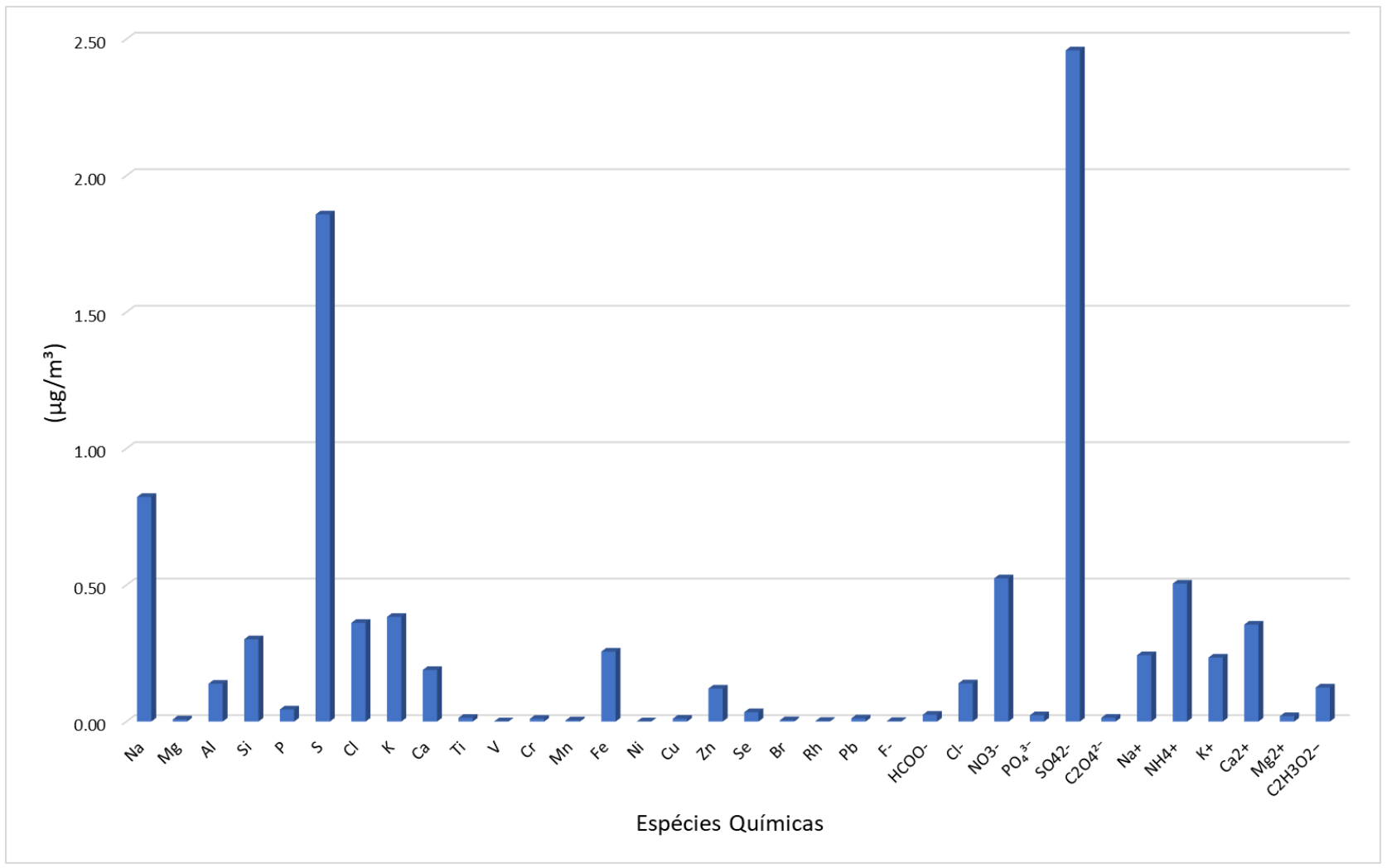

Fonte: Luana Ferreira Vasconcelos, 2020.

A tabela 3 mostra a concentração média das espécies químicas identificadas, sendo $\mathrm{Na}$, $\mathrm{Al}, \mathrm{Si}, \mathrm{S}, \mathrm{Cl}, \mathrm{K}, \mathrm{Ca}, \mathrm{Fe}$ e $\mathrm{Zn}$ as principais espécies associadas com a ressuspensão de poeira de solos não pavimentados, ruas e estradas (MIRANDA et al., 2018).

Espécies derivadas do solo apresentaram altas concentrações, embora espécies químicas de origem de fontes antropogênicos também tenham sido identificados, como o $S$, que deriva de processos de combustão e está presente na forma de sulfato a partir da oxidação do $\mathrm{SO}_{2} . \mathrm{Br}$ e Ca podem ser encontrados em lubrificantes e aditivos em veículos leves, assim como Cu e Zn são comumente adicionados a óleos de motor por suas propriedades antioxidantes. K e seu íon 
são considerados elementos traçadores de queima de biomassa (MIRANDA et al., 2018; SILVA et al., 2010).

Emissões gasosas de veículos $\left(\mathrm{SO}_{2}\right.$ e $\left.\mathrm{NOx}\right)$ podem ser precursores de sulfato, nitrato e amônio. A oxidação de NOx emitida durante a combustão de combustíveis fósseis por veículos, pode ser uma fonte significativa de $\mathrm{NO}_{3}{ }^{-}$. O relatório anual da CETESB também destaca a grande participação do aerossol secundário (principalmente nitrato e sulfato) no material particulado fino (COMPANHIA AMBIENTAL DO ESTADO DE SÃO PAULO, 2020).

O oxalato pode estar associado às emissões pela queima de biomassa e veículos (ZHOU et al., 2015).

Tabela 3 - Média e desvio padrão da concentração de $\mathrm{MP}_{2.5}$, $\mathrm{BC}$ e espécies químicas. $\mathrm{N}$ representa o número de amostras onde a espécie foi detectada, com exceção de $\mathrm{BC}$ em que $\mathrm{N}$ representa o número de medida obtidas pelo monitor MAAP

\begin{tabular}{|c|c|c|c|}
\hline Elementos/Espécies & $N^{o}$ & $\begin{array}{c}\text { Média } \\
\left(\mu \mathrm{g} / \mathrm{m}^{3}\right)\end{array}$ & $\begin{array}{l}\text { Desvio } \\
\text { padrão }\end{array}$ \\
\hline $\mathrm{MP}_{2.5}$ & 114 & 17,71 & 11,45 \\
\hline $\mathrm{BC}$ & 426543 & 1,86 & 1,27 \\
\hline $\mathrm{Na}$ & 110 & 0,82 & 0,78 \\
\hline $\mathrm{Mg}$ & 44 & 0,01 & 0,02 \\
\hline $\mathrm{Al}$ & 113 & 0,14 & 0,14 \\
\hline $\mathrm{Si}$ & 114 & 0,30 & 0,33 \\
\hline $\mathrm{P}$ & 109 & 0,04 & 0,04 \\
\hline$S$ & 112 & 1,86 & 1,24 \\
\hline $\mathrm{Cl}$ & 114 & 0,36 & 0,61 \\
\hline $\mathrm{K}$ & 114 & 0,38 & 0,35 \\
\hline $\mathrm{Ca}$ & 113 & 0,19 & 0,17 \\
\hline $\mathrm{Ti}$ & 113 & 0,01 & 0,01 \\
\hline V & 114 & 0,00 & 0,00 \\
\hline $\mathrm{Cr}$ & 96 & 0,01 & 0,03 \\
\hline $\mathrm{Mn}$ & 88 & 0,00 & 0,00 \\
\hline $\mathrm{Fe}$ & 107 & 0,26 & 0,20 \\
\hline $\mathrm{Ni}$ & 111 & 0,00 & 0,00 \\
\hline $\mathrm{Cu}$ & 77 & 0,01 & 0,01 \\
\hline $\mathrm{Zn}$ & 109 & 0,12 & 0,17 \\
\hline $\mathrm{Se}$ & 109 & 0,03 & 0,09 \\
\hline $\mathrm{Br}$ & 101 & 0,01 & 0,01 \\
\hline $\mathrm{Rh}$ & 107 & 0,00 & 0,01 \\
\hline $\mathrm{Pb}$ & 29 & 0,01 & 0,01 \\
\hline $\mathrm{F}^{-}$ & 106 & 0,00 & 0,00 \\
\hline HCOO- & 52 & 0,03 & 0.03 \\
\hline $\mathrm{Cl}^{-}$ & 112 & 0,21 & 0,33 \\
\hline $\mathrm{NO}_{3}{ }^{-}$ & 113 & 0,51 & 0,69 \\
\hline
\end{tabular}




\begin{tabular}{lrll}
$\mathrm{PO}_{4}{ }^{3-}$ & 9 & 0,29 & 0,07 \\
$\mathrm{SO}_{4}{ }^{2-}$ & 113 & 2,41 & 1,91 \\
$\mathrm{C}_{2} \mathrm{O}_{4}{ }^{2-}$ & 41 & 0.19 & 0,10 \\
$\mathrm{Na}^{+}$ & 113 & 0.22 & 0,18 \\
$\mathrm{NH}_{4}{ }^{+}$ & 113 & 0.49 & 0,41 \\
$\mathrm{~K}^{+}$ & 113 & 0,21 & 0,24 \\
$\mathrm{Ca}^{+2}$ & 113 & 0,28 & 0,18 \\
$\mathrm{Mg}^{+2}$ & 113 & 0,02 & 0,01 \\
$\mathrm{C}_{2} \mathrm{H}_{3} \mathrm{O}^{2-}$ & 12 & 0,13 & 0,01 \\
\hline
\end{tabular}

Fonte: Luana Ferreira Vasconcelos, 2020.

Na tabela 4 é apresentada a correlação de Pearson (r) ente os principais elementos detectados. 
Tabela 4 - Matriz do coeficiente de correlação de Pearson (r) dos principais constituintes do aerossol

\begin{tabular}{|c|c|c|c|c|c|c|c|c|c|c|c|c|c|c|c|c|c|c|c|c|}
\hline & MP2.5 & $B C$ & $\mathrm{Na}$ & $A l$ & Si & $P$ & $S$ & $\mathrm{Cl}$ & $K$ & $\mathrm{Ca}$ & $\mathrm{Fe}$ & $Z n$ & $\mathrm{Cl}-$ & NO3- & SO42- & $\mathrm{Na}+$ & $\mathrm{NH4+}$ & $K+$ & $\mathrm{Ca} 2+$ & $\mathrm{C} 2 \mathrm{H} 3 \mathrm{O} 2-$ \\
\hline MP2.5 & 1 & & & & & & & & & & & & & & & & & & & \\
\hline$B C$ & 0.582379 & 1 & & & & & & & & & & & & & & & & & & \\
\hline $\mathrm{Na}$ & 0.55677 & 0.567267 & 1 & & & & & & & & & & & & & & & & & \\
\hline Al & 0.53551 & 0.510932 & 0.407479 & 1 & & & & & & & & & & & & & & & & \\
\hline Si & 0.555654 & 0.547457 & 0.452758 & 0.938326 & 1 & & & & & & & & & & & & & & & \\
\hline $\mathrm{P}$ & 0.350713 & 0.176074 & 0.18523 & 0.088465 & 0.134382 & 1 & & & & & & & & & & & & & & \\
\hline$S$ & 0.53932 & 0.229974 & 0.298224 & 0.126536 & 0.149309 & 0.720488 & 1 & & & & & & & & & & & & & \\
\hline $\mathrm{Cl}$ & 0.594663 & 0.520606 & 0.645763 & 0.443534 & 0.493082 & 0.004335 & 0.139274 & 1 & & & & & & & & & & & & \\
\hline $\mathrm{K}$ & 0.705296 & 0.596492 & 0.631847 & 0.662314 & 0.614225 & 0.136279 & 0.298784 & 0.581536 & 1 & & & & & & & & & & & \\
\hline $\mathrm{Ca}$ & 0.454932 & 0.401014 & 0.373284 & 0.779181 & 0.837511 & 0.158898 & 0.206382 & 0.546162 & 0.39344 & 1 & & & & & & & & & & \\
\hline $\mathrm{Fe}$ & 0.471468 & 0.518661 & 0.465723 & 0.776125 & 0.820363 & 0.174823 & 0.190308 & 0.477374 & 0.498906 & 0.80741 & 1 & & & & & & & & & \\
\hline $\mathrm{Zn}$ & 0.570486 & 0.603285 & 0.954911 & 0.421622 & 0.469585 & 0.178231 & 0.26428 & 0.633729 & 0.62182 & 0.336316 & 0.460682 & 1 & & & & & & & & \\
\hline $\mathrm{Cl}-$ & 0.551354 & 0.505424 & 0.635308 & 0.447197 & 0.497563 & -0.03774 & 0.07902 & 0.988859 & 0.554063 & 0.546565 & 0.474615 & 0.627493 & 1 & & & & & & & \\
\hline NO3- & 0.687985 & 0.509255 & 0.369527 & 0.305869 & 0.345918 & 0.284298 & 0.432749 & 0.575445 & 0.525279 & 0.32662 & 0.346354 & 0.404039 & 0.521662 & 1 & & & & & & \\
\hline SO42- & 0.495885 & 0.187385 & 0.222267 & 0.094276 & 0.117346 & 0.715998 & 0.986507 & 0.076789 & 0.24442 & 0.187019 & 0.177235 & 0.196202 & 0.022585 & 0.422403 & 1 & & & & & \\
\hline $\mathrm{Na}+$ & 0.478388 & 0.316825 & 0.601273 & 0.416914 & 0.407688 & 0.044202 & 0.243276 & 0.646262 & 0.57423 & 0.513596 & 0.416117 & 0.407742 & 0.633786 & 0.333683 & 0.191639 & 1 & & & & \\
\hline $\mathrm{NH} 4+$ & 0.522371 & 0.229491 & 0.207331 & -0.00278 & 0.029535 & 0.689546 & 0.922586 & 0.155481 & 0.196345 & 0.063663 & 0.075594 & 0.24161 & 0.097138 & 0.573479 & 0.93186 & 0.057026 & 1 & & & \\
\hline $\mathrm{K}+$ & 0.648184 & 0.551445 & 0.565867 & 0.562575 & 0.497201 & 0.096449 & 0.256481 & 0.519532 & 0.978812 & 0.272413 & 0.394866 & 0.559571 & 0.497312 & 0.50828 & 0.215619 & 0.52497 & 0.184198 & 1 & & \\
\hline $\mathrm{Ca} 2+$ & 0.297223 & 0.291792 & 0.205335 & 0.675501 & 0.715102 & 0.092245 & 0.091629 & 0.325766 & 0.257592 & 0.872639 & 0.719725 & 0.179282 & 0.342329 & 0.184539 & 0.09815 & 0.385215 & -0.0263 & 0.168783 & 1 & \\
\hline $\mathrm{C} 2 \mathrm{H} 3 \mathrm{O} 2-$ & 0.222657 & 0.105682 & 0.001922 & 0.169905 & 0.176453 & 0.272411 & 0.211388 & -0.21647 & 0.075651 & 0.02538 & -0.11633 & 0.112473 & -0.26218 & 0.023248 & 0.127488 & -0.24749 & 0.161848 & 0.041278 & -0.05274 & 1 \\
\hline
\end{tabular}
$p<0.5$

Fonte: Luana Ferreira Vasconcelos, 2020. 
A matriz do coeficiente de correlação de Pearson (r) (tabela 3) dos principais constituintes do aerossol estudado, apresenta alta correlação entre o elemento enxofre e o íon sulfato reforçando a origem pela mesma fonte, sendo o segundo a oxidação do S. Os elementos do solo apresentaram altas correlações (Fe. Al. Si, Ca), assim como o sulfato, amônio e nitrato, que se correlacionam às emissões veiculares.

A figura 35 foi gerada a fim de se relacionar composição química e direção do vento. Componentes de solo, como $\mathrm{Ca}, \mathrm{Si}$ e $\mathrm{Fe}$ predominam de várias direções. Elementos relacionados a veículos como $\mathrm{Zn}, \mathrm{Cu}$, $\mathrm{K}$ estão mais relacionados com ventos vindos de direções que têm mais contribuição veicular e menos local. S e BC têm como fontes principais os veículos pesados e predominam das várias vias de tráfego pesado que circundam o ponto de amostragem, como as rodovias Dutra e Ayrton Senna, assim como a Av. Dr Assis Ribeiro. 
Figura 35 - Concentração das principais espécies químicas por direção dos ventos
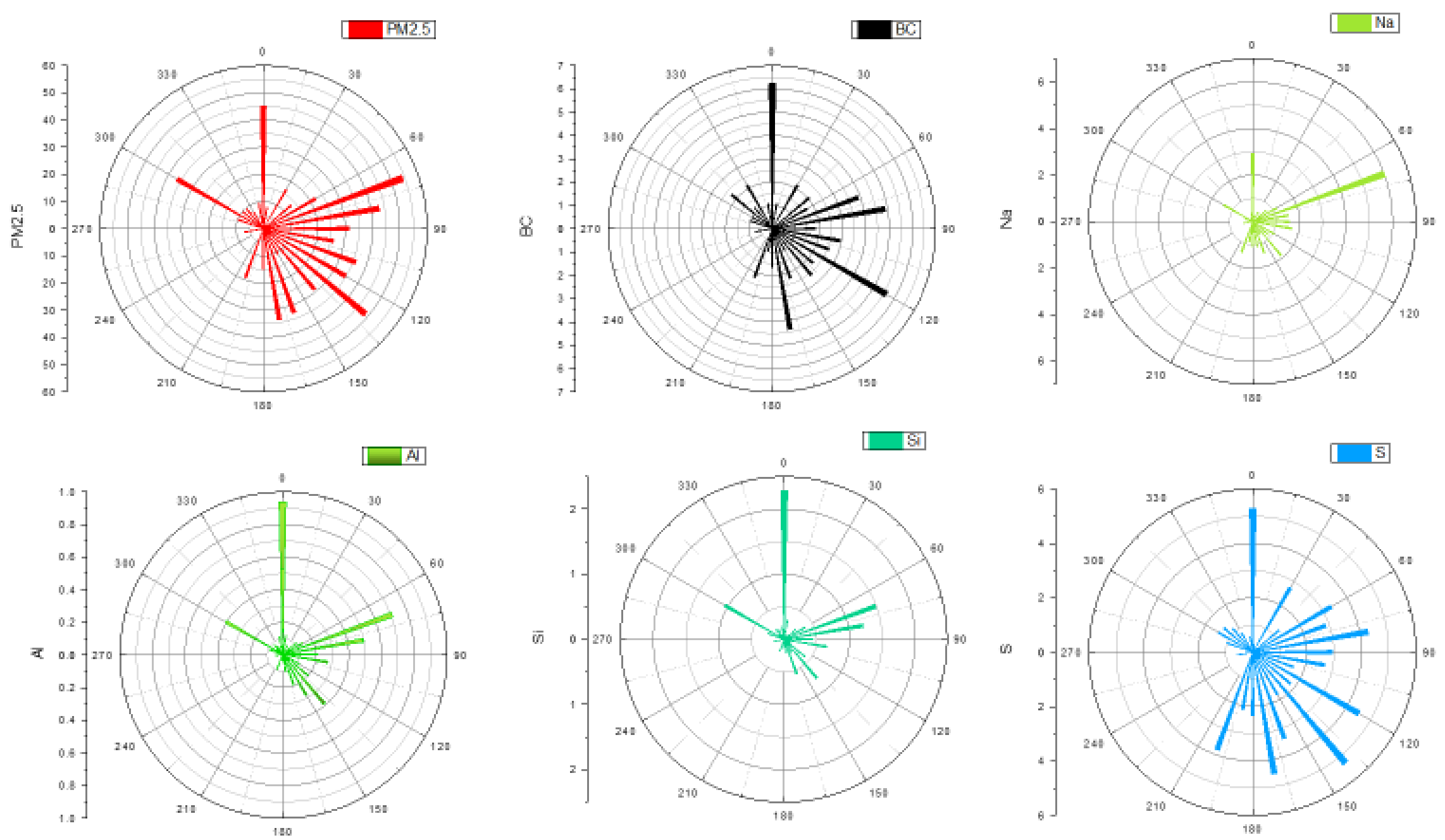

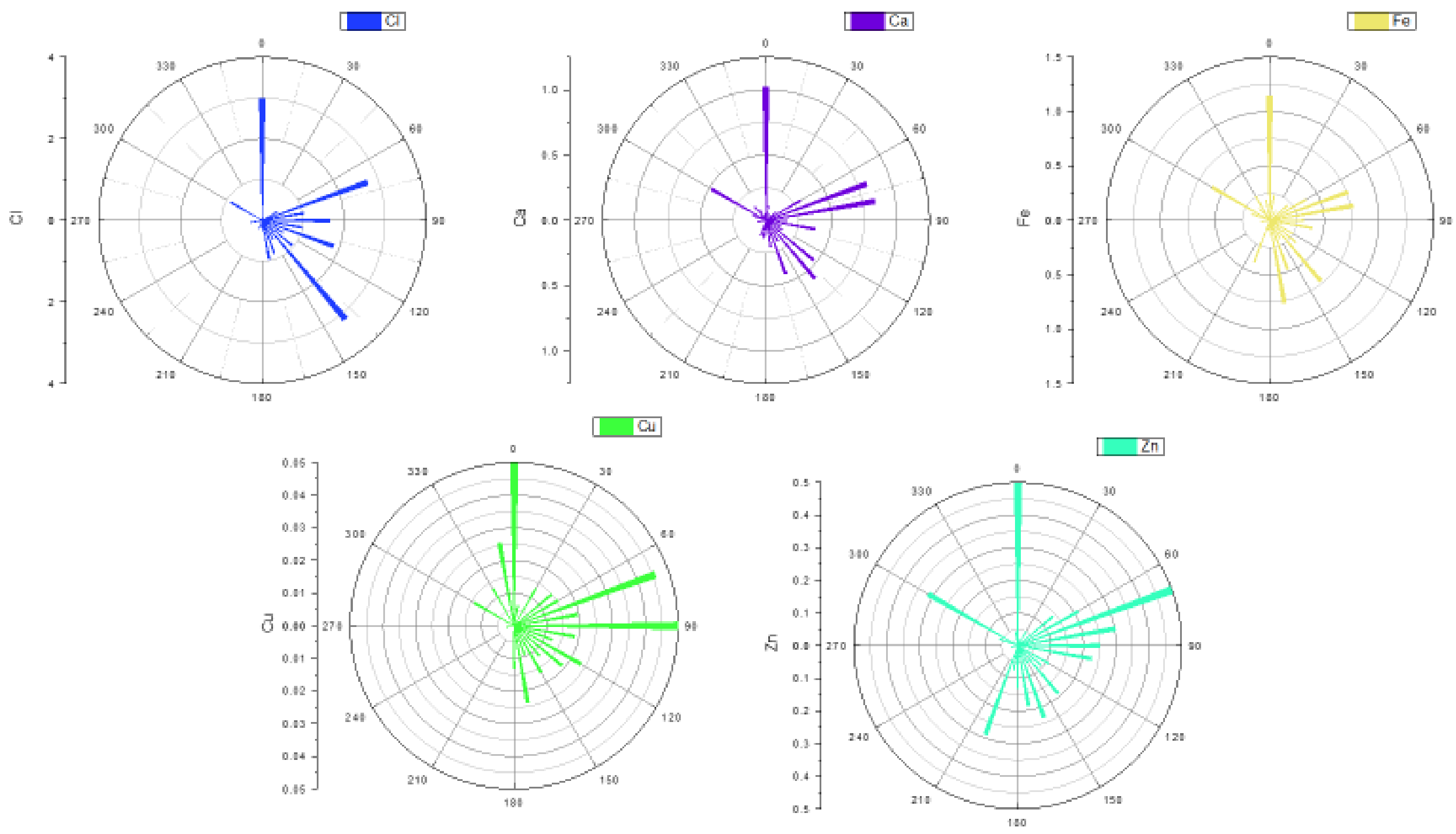

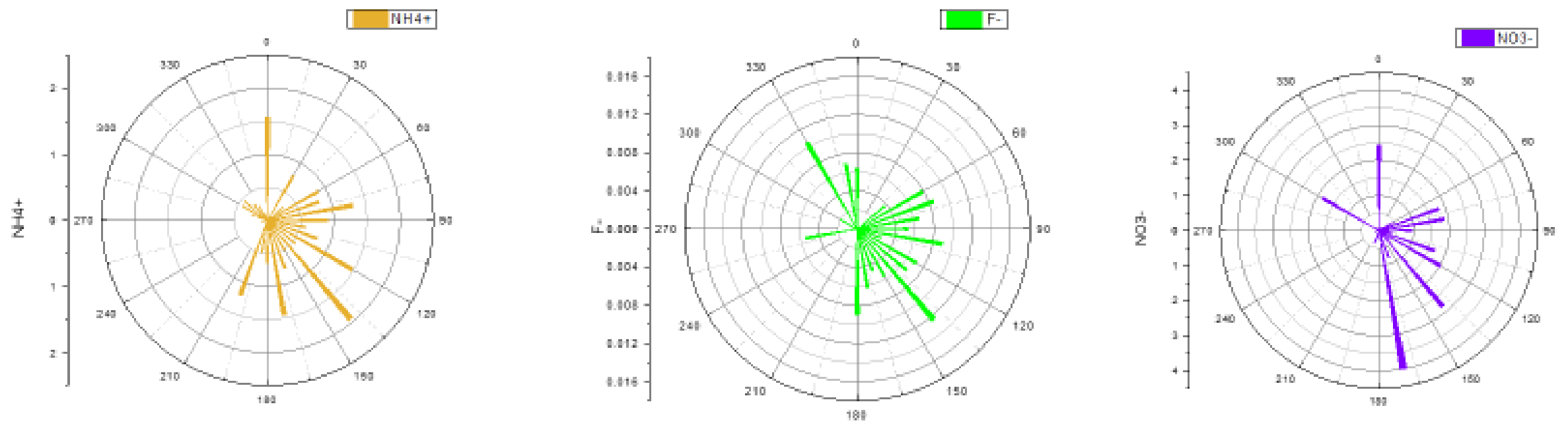

Fonte: Luana Ferreira Vasconcelos, 2020. 
A figura 36 mostra a pluma de poluentes lançada na atmosfera pela indústria CISPER próxima EACH e também a queima (provavelmente de biomassa e lixo) que ocorre quase diariamente no Parque Ecológico do Tietê (em frente ao local de medidas), fatores estes podem contribuir para a composição elementar do aerossol estudado, por exemplo $\mathrm{K}, \mathrm{Pb}, \mathrm{F}^{-}$, BC, entre outros.

Figura 36 - Pluma de poluentes lançada pela Indústria de vidros CISPER e queima de lixo no Parque Ecológico do Tietê (seta amarela).
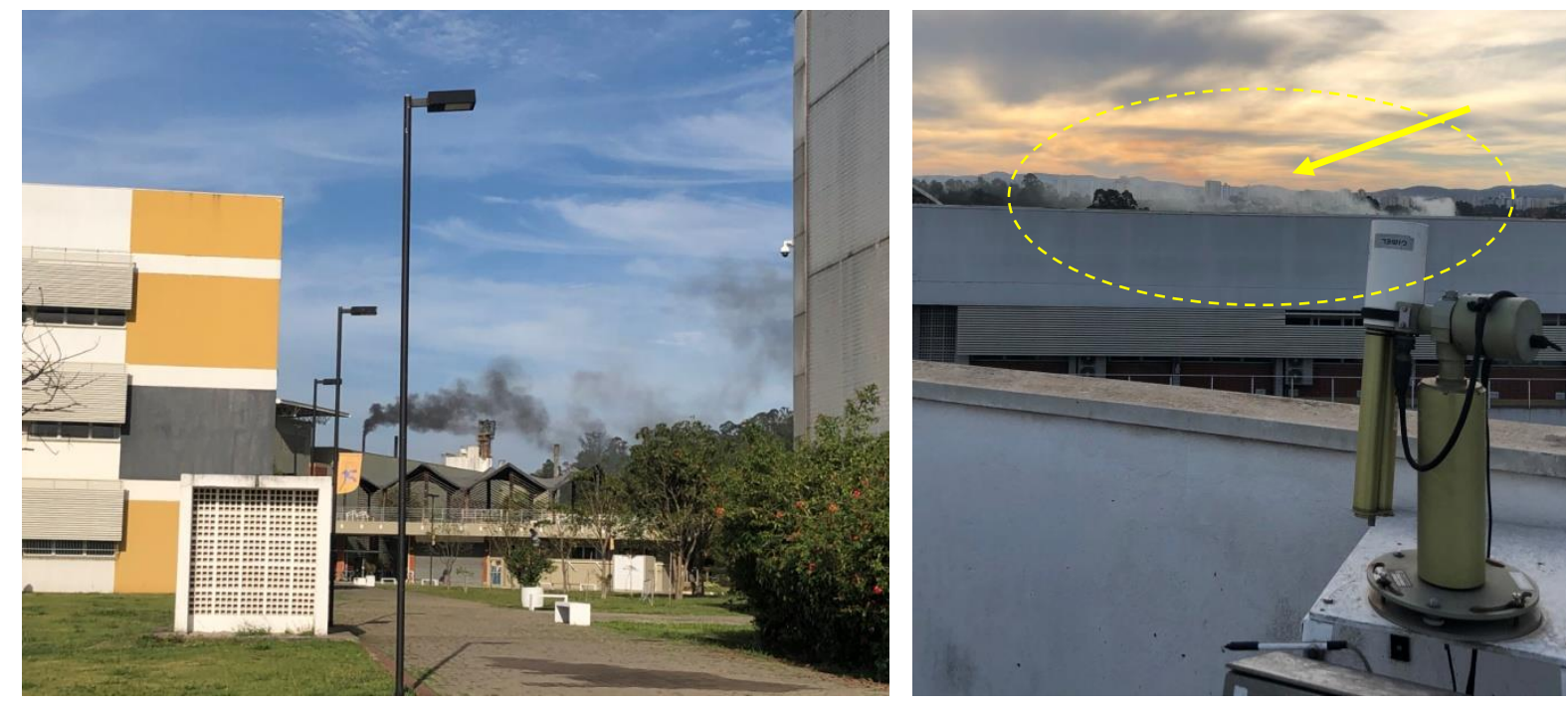

Fonte: arquivo pessoal Regina Maura de Miranda.

Segunda publicação realizada pelo World Bank Group (1998) sobre a produção de vidro e poluição atmosférica, partículas da vaporização e recristalização do vidro emitem $\mathrm{SO}_{2}, \mathrm{NOx}$ e partículas atmosféricas que podem conter metais pesados como o arsênico (As), fluoreto e chumbo, podendo representar de $20 \%-60 \%$ de partículas contendo $\mathrm{Pb}$ e $0,5-2 \%$ contendo o arsênico.

\subsection{Análise por Positive Matrix Fatorization (PMF)}

A análise por PMF apresentou melhor rotação para 4 fatores: veículos leves (LDVs), solo, veículos pesados (HDVs) e fontes locais, respectivamente. Sendo este último, relacionado a queimadas e indústrias da região.

As espécies foram classificadas a fim de eliminar espécies de mesmo elemento e superestimando os erros de variação das amostras para que assim possa melhorar as análises e evitar os erros de reprodução. 
A Tabela 5 apresenta as informações detalhadas sobre os testes com três, quatro, cinco e seis fatores, baseando-se nos diagnósticos propostos por Brown et al. (2015), cuja metodologia foi utilizada para a definição do melhor número de fatores a ser considerado. Somente com 3 fatores as fontes foram 100\% mapeadas, porém, três fontes mostrou-se um número baixo a ser considerado. Considerando cinco fatores, duas fontes locais foram identificadas, mas houve mistura no mapeamento. Com seis fatores o mapeamento não ficou confiável. Na rodada do modelo PMF de três fatores para quatro, houve uma diminuição na razão Qrobust/Qexpected de 0,77 para 0,72 ; entre quatro e cinco fatores a razão passou de 0,72 para 0,71 , e de 0,71 para 0,43 entre cinco e seis fatores. O fato dessas razões se tornarem menores com o aumento do número de fatores, é um indicativo de que muitos fatores podem estar sendo considerados e que 4 fatores pode ser a melhor solução e as fontes foram melhor mapeadas. Somente para o fator 1, veículos leves, uma pequena porcentagem das espécies foi classificada na fonte veículos pesados, e 94\% veículos leves.

Tabela 5- PMF -Tabela de diagnósticos por número de fatores

\begin{tabular}{|c|c|c|c|c|}
\hline Diagnóstico & 3 fatores & 4 fatores & 5 fatores & 6 fatores \\
\hline$\overline{Q_{\text {expected }}}$ & 1421 & 1292 & 1163 & 1034 \\
\hline$Q_{\text {true }}$ & 1065,1 & 875,3 & 757,9 & 373,2 \\
\hline$Q_{\text {robust }}$ & 1099,4 & 931,8 & 827,9 & 448,8 \\
\hline $\mathrm{Q}_{\text {robust }} / \mathrm{Q}_{\text {expected }}$ & 0,77 & 0,72 & 0,71 & 0,43 \\
\hline Fatores com BSmap $<100 \% *$ & 0 & $94 \%$ fator 1 & $\begin{array}{l}99 \% \text { fator } 1 \\
81 \% \text { fator } 3\end{array}$ & $\begin{array}{l}43 \% \text { fator } 1 \\
93 \% \text { fator } 4\end{array}$ \\
\hline BS-DISP fatores com swaps & 0 & 0 & 0 & 0 \\
\hline
\end{tabular}

Fonte: Luana Ferreira Vasconcelos, 2020.

Na figura 37 apresentam-se as concentrações das espécies químicas por fator, relativo as fontes de emissão de poluentes. Em preto, o Fator 1 apresenta em sua maior concentração elementos relacionados à emissão de veículos leves (F-, $\mathrm{Na}, \mathrm{Zn}, \mathrm{Cu}, \mathrm{Ni}$ e $\mathrm{Pb}$ ); em vermelho o Fator 2 apresenta em sua maior concentração elementos relacionados à ressuspensão de poeira de origem crustal (solo) (Al, $\mathrm{Si}, \mathrm{Ca}, \mathrm{Fe}$ ), o atrito dos pneus dos veículos com o asfalto gera partículas que contribuem com essa fonte, bem como a ressuspensão da poeira das vias quando os veículos trafegam; em verde o Fator 3 apresenta em sua maior concentração elementos relacionados à emissão por veículos pesados $\left(\mathrm{BC}, \mathrm{SO}_{4}^{2-}, \mathrm{C}_{2} \mathrm{O}_{4}{ }^{2-}, \mathrm{NH} 4+, \mathrm{P}, \mathrm{Se}\right)$; e em azul, Fator 4 apresenta em maior concentração as espécies químicas relacionadas às emissões locais, podendo estas serem de origem de queima de biomassa ou lixo $\left(\mathrm{NO}_{3}{ }^{-} . \mathrm{C}_{2} \mathrm{O}_{4}{ }^{2-}, \mathrm{Mg}^{2+}, \mathrm{Cl}, \mathrm{Br}\right.$, 
$\mathrm{Pb}$ ), ou também podendo estar relacionadas às emissões da indústria de vidro CISPER, que fica bem próxima à EACH.

O S (enxofre), tanto na forma sólida quando no seu derivado iônico estão relacionados à combustão veicular, assim como também o potássio e seu íon são considerados elementos traçadores de queima de biomassa (HAI et al., 2012).

Figura 37 - PMF - Porcentagem das espécies por fonte

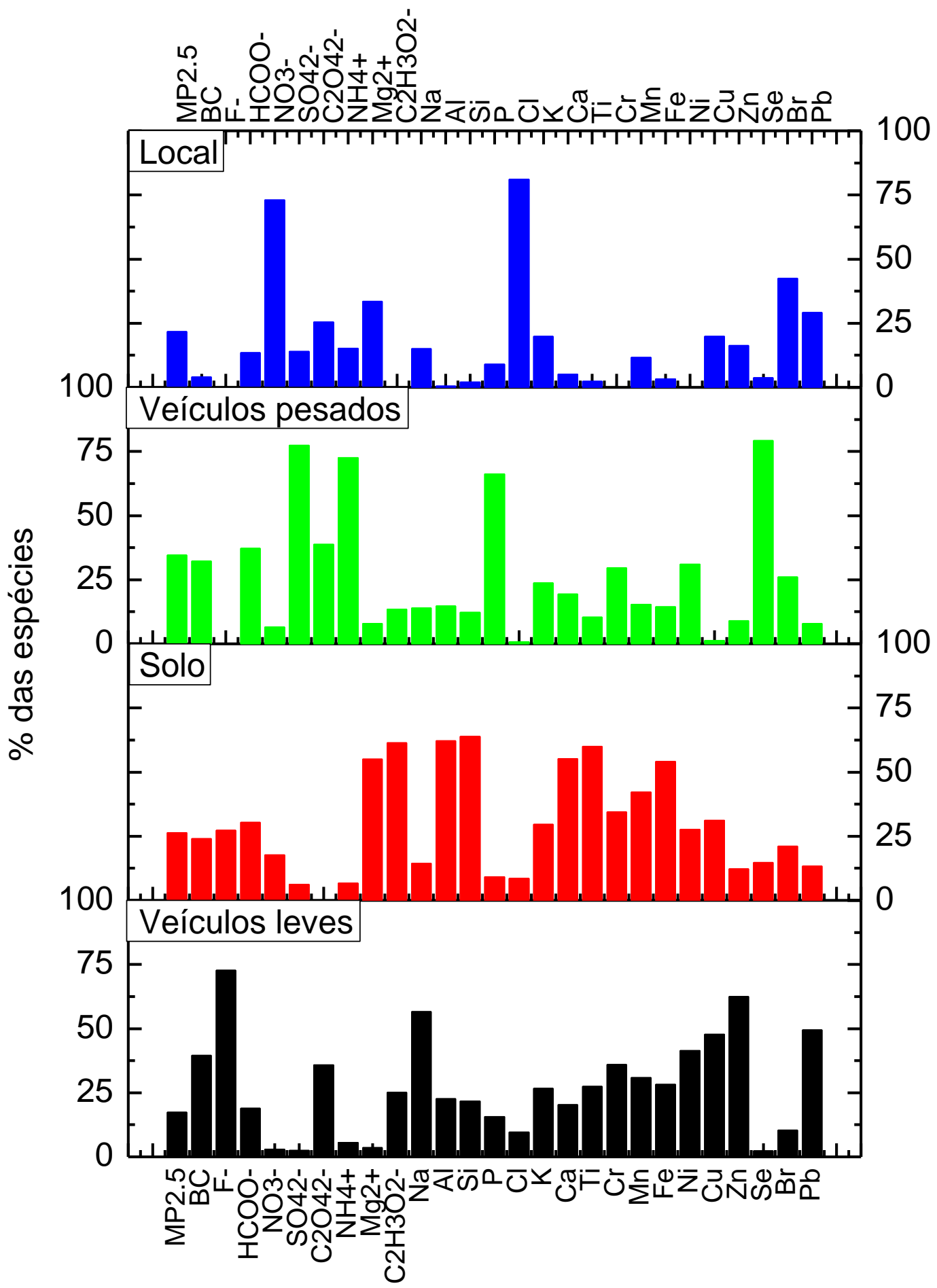

Fonte: Luana Ferreira Vasconcelos, 2020. 
Na figura 38 é ilustrada a contribuição de cada tipo de fonte detectada pelo modelo PMF, onde a fonte que apresenta maior contribuição na concentração do $\mathrm{MP}_{2.5}$ amostrado é correspondente aos veículos pesados com $34,6 \%$, seguido da fonte de origem do solo $(26,3 \%)$, fontes locais $(21,7 \%)$ e veículos leves $(17,3 \%)$.

Figura 38 - Gráfico de pizza da contribuição das fontes

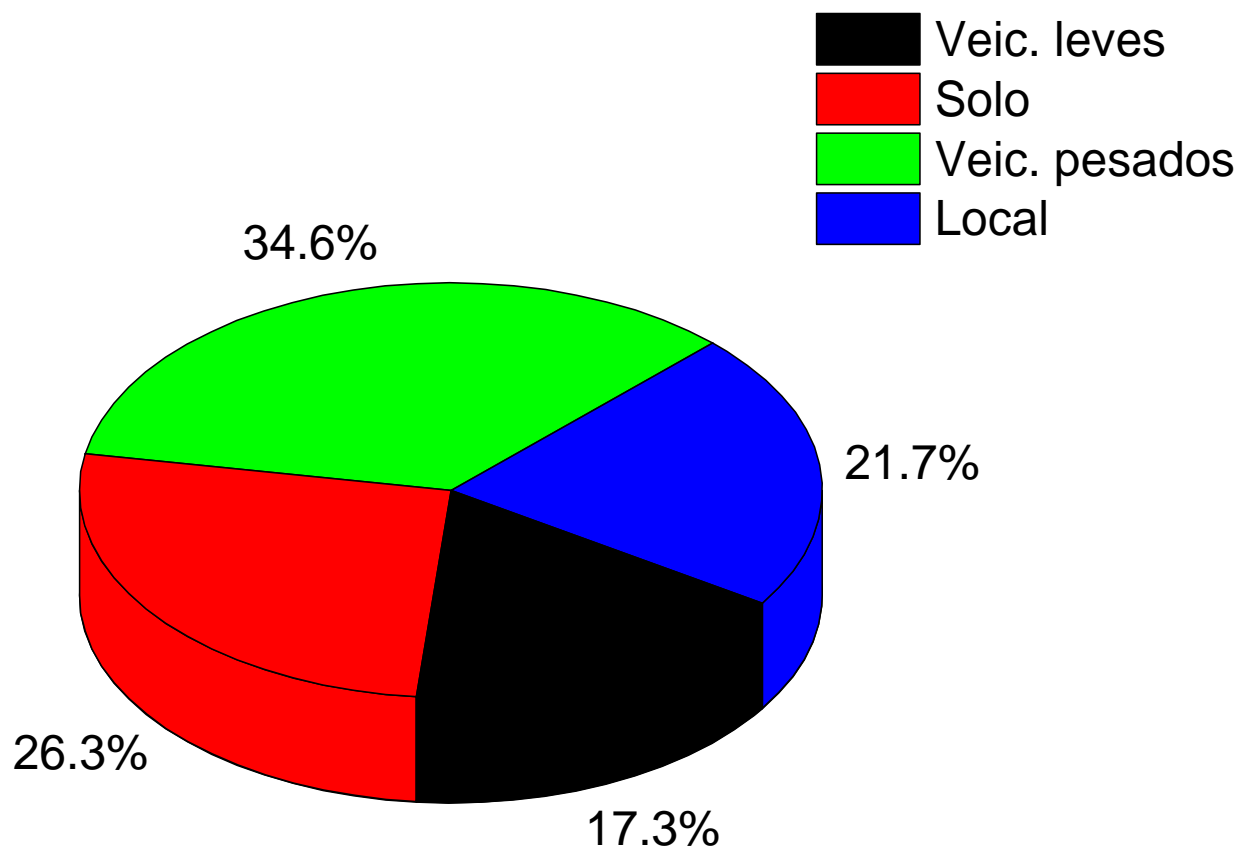

Fonte: Luana Ferreira Vasconcelos, 2020.

Em Miranda et al. (2018), é observado esse padrão de contribuição por fontes para o ano anterior (2015), no qual os HDVs contribuíram com 52\%, Solo 26\%, emissões de LDV $18 \%$ e fontes locais com $4 \%$. 


\section{CONCLUSÕES}

Esta pesquisa realizou o estudo do material particulado fino e do black carbon ao longo do ano de 2016 no campus leste da USP. A concentração média anual do $\mathrm{MP}_{2.5}$ foi de $17,71 \pm$ $11,45 \mu \mathrm{g} / \mathrm{m}^{3}$ e o padrão diário de $24 \mathrm{hs}\left(60 \mu \mathrm{g} / \mathrm{m}^{3}\right)$ não foi excedido. As maiores concentrações ocorreram nos meses de inverno. O black carbon teve concentração média de $1,86 \pm 1,27 \mu \mathrm{g} / \mathrm{m}^{3}$. A partir das análises realizadas foi observado que as concentrações de poluentes são influenciadas diretamente pelas emissões veiculares. Há predominância da influência dos HDVs que representam $34,6 \%$ da contribuição para as concentrações de poluentes, sendo BC relacionado às emissões dos veículos pesados, quando estes são analisados no perfil semanal e horário, verifica-se a tendência da dinâmica comercial da RMSP.

A contribuição da fonte origem do solo é de $26,3 \%$, ficando em segundo lugar entre as fontes mais poluidoras, o que tem relação com a ressuspensão do solo realizada pela passagem de veículos por vias pavimentas e não pavimentadas, e pela ação dos ventos na região.

As fontes locais, relacionadas a queimas de lixo, biomassa e emissões industriais representam $21,7 \%$ das emissões. Elementos traçadores da produção de vidro foram detectados pelas técnicas utilizadas.

Apesar da quantidade de LDVs representar mais de $83 \%$ do total de veículos que passaram pela rodovia Ayrton Senna durante o período amostrado, a sua contribuição como fonte emissora de aerossol foi de $17,3 \%$.

Além das contribuições das fontes locais emissoras de poluentes, pode-se concluir que as concentrações de aerossol urbano são influenciadas diretamente pela meteorologia, pois os parâmetros meteorológicos são determinantes nas concentrações, estando relacionados à dispersão dos poluentes. A umidade relativa do ar, direção e velocidade do vento possuem grande importância na dispersão do aerossol. Assim, foi possível verificar que as concentrações de $\mathrm{MP}_{2.5}$ e BC foram mais altas nos meses de inverno, quando as condições meteorológicas não são favoráveis à dispersão dos poluentes. E as concentrações do aerossol são mais altas quando a direção do vento predominante vem de NE e SE.

Os resultados deste trabalho continuam evidenciando a forte influência das emissões veiculares na qualidade do ar em São Paulo, evidenciando também, que as concentrações do material particulado fino continuam muito acima do recomendado pela OMS. Como foi mencionado, políticas públicas como o PROCONVE têm sido implementadas há muitos anos, porém são necessárias medidas adicionais para melhorar a qualidade do ar na cidade.

O incentivo à pesquisa assim como a ampliação dos monitoramentos de qualidade de ar, são imprescindíveis para o avanço nos estudos das ciências atmosféricas a fim de subsidiar o 
avanço de novas tecnologias e políticas de controle de emissão de poluentes.

A Zona Leste da capital paulistana, é uma região altamente povoada, com importantes vias de tráfego, aeroporto internacional de Guarulhos e indústrias, que são fontes com alto potencial para a degradação da qualidade do ar, além de serem potentes emissores de espécies químicas que podem ser prejudiciais à saúde humana. Dessa forma, como apresentado neste trabalho, a região necessita de mais estudos contínuos para monitoramento de poluentes, assim como estudos utilizando outros tipos de análise para identificação de mais poluentes, e espécies químicas, como no caso dos compostos carbonáceos, que não foram o foco deste trabalho e requerem de outras instrumentações para realizá-las, além de melhorias nas implementações de políticas públicas de controle.

A complementação da Agenda de ação de Genebra para combater a poluição do ar, deve ser enfatizada junto com os objetivos para o desenvolvimento sustentável, pois o número de mortes causado pela poluição pode se equiparar a uma pandemia silenciosa, além das questões climáticas que a poluição atmosférica contribui e que afeta o sistema terrestre como um todo. 


\section{REFERÊNCIAS ${ }^{3}$}

AIR POLUTION. Changing Air Quality \& Clean Air Acts. [1952]. Disponível em: http://www.air-quality.org.uk/03.php. Acesso em: dez 2020

ALISSON, E. Proálcool: uma das maiores realizações do Brasil baseadas em ciência e tecnologia. 2016. Disponível em: http://agencia.fapesp.br/proalcool-uma-das-maioresrealizacoes-do-brasil-baseadas-em-ciencia-e-tecnologia/24432/. Acesso em: 18 dez. 2020

ALVES, C. Aerossóis atmosféricos: perspectiva histórica, fontes, processos químicos de formação e composição orgânica. Química Nova, v. 28, n. 5, p. 859-870, 2005.

ANDRADE, M. F.; ORSINI, C. Relation Between Aerosol Sources and Meteorological Parameters for Inhalable Atmospheric Particles in São Paulo City, Brazil. Atmospheric Environment, v. 28, n. 14, p. 66-82, 1994.

ANDRADE, M. F.; MIRANDA, R. M.; FORNARO, A.; KERR, A.; OYAMA, B.; ANDRE, P. A.; SALDIVA, P. Vehicle emissions and PM2.5 mass concentrations in six Brazilian cities. Air Qual. Atmos. Health. v. 5, n. 1, p. 79-88, 2010. DOI: http://dx.doi.org/10.1007/s11869010-0104-5. Disponível em:

https://www.sciencedirect.com/science/article/pii/S1352231001003636?casa_token=wJ6wSrJ MPxgAAAAA:SticQpiNlpwlLePublzEkCqB1983XgEDdJnAiDIlfnG4VHBgFcxX8PkBfGq0 3hEGzvJwsPF-Cw. Acesso em: 2018

ANDRADE, M. F.; KUMAR, P.; FREITAS, E. D.; YNOUE, R. Y.; MARTINS, J. MARTINS, L. D.; NOGUEIRA, T.; PEREZ-MARTINEZ, P.; MIRANDA, R. M.; ALBUQUEREQUE, T.; GONÇALVEZ, F. L.T.; OYAMA, B.; ZHANG, Y. Air quality in the megacity of São Paulo: Evolution over the last 30 years and future perspectives. Atmospheric Environment, v. 159, p. 66-82, 2017. DOI: https://doi.org/10.1016/j.atmosenv.2017.03.051. Disponível em:

https://www.sciencedirect.com/science/article/abs/pii/S1352231017302212?via\%3Dihub Acesso em: 2018

BAIRD, C. Química Ambiental. 4. ed. Porto Alegre: Bookman, 2011.

BARROS, H. R.; LOMBARDO, M. A. A ilha de calor urbana e o uso e cobertura do solo em São Paulo. GEOUSP espaço e tempo. São Paulo. v. 20, n. 1, p.160-177, 2016.

BELL, M. L.; DAVIS, D. L.; FLETCHER, T. A retrospective assessment of mortality from the London smog episode of 1952: the role of influenza and pollution. Environmental Health Perspectives. v. 112, n. 1, p. 6-8, 2004. DOI: 10.1289/ehp.6539. Disponível em: https://ehp.niehs.nih.gov/doi/pdf/10.1289/ehp.6539. Acesso em: dez. 2020

BRAGA, A.; BÖHM, G. M.; PEREIRA, A. A.; SALDIVA, P. Poluição atmosférica e saúde Humana. Revista USP, São Paulo, v. 51, n.1, p. 58-71, 2001.

BOLETIM CLIMATOLÓGICO ANUAL DA ESTAÇÃO METEOROLÓGICA DO

IAG/USP. Instituto de Astronomia e Geofísica da Universidade de São Paulo. 2016 e 2017.

Disponível em: http://www.estacao.iag.usp.br/Boletins/2016.pdf

Disponível em: http://www.estacao.iag.usp.br/Boletins/2017.pdf Acessado em: 03/2021

\footnotetext{
${ }^{3}$ De acordo com a Associação Brasileira de Normas Técnicas (ABNT NBR 6023).
} 
BOUERES, L. C. S.; ORSIN, C. M. Q. Fine and coarse elemental components in the urban aerosol of São Paulo, Brazil. Nuclear Instruments and Methods. v. 181, n. 1, p. 417-424, 1981.

BROWN, S.G.; EBERLY, S.; PAATERO, P.; NORRIS, G. A. Methods for estimating uncertainty in PMF solutions: Examples with ambient air and water quality data and guidance on reporting PMF results. Science of The Total Environment. v. 518-519, p. 626-635, 2015. DOI: https://doi.org/10.1016/j.scitotenv.2015.01.022. Disponível em: https://www.sciencedirect.com/science/article/pii/S004896971500025X?via\%3Dihub Acesso em: dez. 2020.

COMPANHIA AMBIENTAL DO ESTADO DE SÃO PAULO. Relatório de Qualidade do ar 1998. São Paulo 1999.

. Relatório Qualidade do ar no Estado de São Paulo 2013. São Paulo, 2014. Relatório Qualidade do ar no Estado de São Paulo 2016. São Paulo, 2017. Relatório Qualidade do ar no Estado de São Paulo 2018. São Paulo 2019. Relatório Qualidade do ar no Estado de São Paulo 2019. São Paulo 2020.

Disponíveis em: http://cetesb.sp.gov.br/ar/publicacoes-relatorios/. Acesso em: 2017.

Estudo das partículas submicrométricas $\left(\mathbf{m p}_{1}\right)$ e comparação com partículas inaláveis finas $\left(\mathbf{M P}_{2.5}\right)$ na atmosfera de São Paulo. Disponível em: https://cetesb.sp.gov.br/ar/wp-content/uploads/sites/28/2020/07/Relat\%C3\%B3rio-MP12019.pdf. Acesso em: 2020

CHANDRAPPA, R.; CHANDRA KULSHRESTHA, U. Sustainable air pollution management - theory and practice. Springer International Publishing Switzerland. Suíça. cap. III, p. 109-1010, 2016. DOI: 10.1007/978-3-319-21596-9. Disponível em: https://www.springer.com/br/book/9783319215952. Acesso em: 2019

BRASIL. Conselho Nacional Do Meio Ambiente. Resolução nº 03, 28 de junho de 1990. Dispõe sobre padrões de qualidade do ar, previstos no PRONAR. Diário Oficial [da] República Federativa do Brasil, Brasilia, DF, 22 agosto 1990. Seção 1, p. 15937-15939. Disponível em: http://www.mma.gov.br/port/conama/legiabre.cfm?codlegi=100. Acesso em: 2018

BRASIL. Conselho Nacional Do Meio Ambiente. Resolução no 491, de 19 de novembro de 2018. Dispõe sobre padrões de qualidade do ar. Diário Oficial [da] República Federativa do Brasil, Brasília, DF, 21 nov. 2018, Ed. 223, Seção: 1, p. 155.

BRASIL. Ministério das Cidades. Departamento Nacional de Trânsito. Relatórios Estatísticos. Frotas de veículos. 2018. Disponível em: https://www.denatran.gov.br/estatistica/635-frota-2018. Acesso em: julho 2018

CONNERTON, P., ASSUNÇÃO, J. V., MIRANDA, R. M., SLOVIC, A. D., PÉREZMARTÍNEZ, P. J., RIBEIRO, H. Air Quality during COVID-19 in Four Megacities: Lessons and Challenges for Public Health. International Journal of Environmental Research and Public Health. v. 17, n. 14, p. 2-24, 2020. DOI:10.3390/ijerph17145067. Disponível em: https://www.mdpi.com/1660-4601/17/14/5067. Acesso em: 2020

DANNI-OLIVEIRA, I. M., Poluição do ar como causa de morbidade e mortalidade da população urbana. Revista RA'E GA, Curitiba, n. 15, p. 113-126, 2008. Editora UFPR. 
FINLAYSON-PITTS, B.J., PITTS JR., J.N. Chemistry of the Upper and Lower

Atmosphere: Theory, Experiments, and Applications. 1. ed. San Diego: Academic Press, 2000 .

FIRKET, J. Fog along the Meuse valley. 1936. University of Liége. DOI:

https://doi.org/10.1039/TF9363201192. Disponível em:

https://pubs.rsc.org/en/content/articlelanding/1936/TF/tf9363201192\#!divAbstract. Acesso em: 2019

GUARIEIRO, L., L., N.; VACONCELLOS, P., C.; SOLCI, M., C. Poluentes atmosféricos provenientes da queima de combustível fósseis e biocombustíveis: uma breve revisão.

Revista Virtual de Química. São Paulo: Sociedade brasileira de Química. v. 3, n. 5, 2011. Disponível em: http://qnint.sbq.org.br/novo/index.php?hash=tema.76. Acesso em: 2018.

HAI, C.D., OAHN, N.T.K. Effects of local, regional meteorology and emission sources on mass and composition of particulate matter in Hanoi. Atmospheric Environment v. 78, p. 105-112, 2012. DOI: 10.1016/j.atmosenv.2012.05.006. Disponível em:

https://www.sciencedirect.com/science/article/abs/pii/S1352231012004530. Acesso em: nov. 2020.

HUANG, L., LI, J., ZHAO, D., ZHU, J. A fieldwork study on the diurnal changes of urban microclimate in four types of ground cover and urban heat island of Nanjing, China. Building and Environment. v. 43, n. 1, p. 7-17, 2008. DOI: 10.1016/j.buildenv.2006.11.025.

Disponível em: https://www.sciencedirect.com/science/article/abs/pii/S1352231012004530. Acesso em: 2017

HINDS, W. C. Aerosol technology: Properties, behavior and measurement of airbone particles. Nova York: John Wiley \& Sons. 1982. Cap. IV.

INSTITUTO BRASILEIRO DE GEOGRAFIA E ESTATÍSTICA (IBGE). População no último censo. São Paulo, 2018. Disponível em: https://cidades.ibge.gov.br/brasil/sp/saopaulo/panorama Acesso em: 2018.

INSTITUTO NACIONAL DE PESQUISAS ESPACIAIS (INPE). Banco de dados de queimadas. Brasil, 2016 Disponível em:

http://queimadas.dgi.inpe.br/queimadas/bdqueimadas/\#. Acesso em: 2020.

KANAYA, Y., TAKETANI, F. KOMAZAKI, Y, LIU, X., KONDO, Y. SAHU, L. K., IRIE H., TAKASHIMA, H. Comparison of black carbon mass concentrations observed by MultiAngle Absorption Photometer (MAAP) and Continuous Soot-Monitoring System (COSMOS) on Fukue Island and in Tokyo, Japan. 2013. Aerosol Science and Technology. v. 47, n. 1, p. 1-10, 2013. DOI: 10.1080/02786826.2012.716551. Disponível em:

https://www.tandfonline.com/doi/full/10.1080/02786826.2012.716551. Acesso em: nov. 2020.

KLANOVICZ, J. FERREIRA. C. B. A fabricação de uma cidade tóxica: A Tribuna de Santos e os desastres tecnológicos de Cubatão (Brasil) na década de 1980. 2018. Revista Cadernos do Ceom. V. 31 pg. 48. DOI: 10.22562/2018.48.01. Disponível em: https://bell.unochapeco.edu.br/revistas/index.php/rcc/article/view/3979. Acesso em: ago. 2019. 
MODEL 5012 - Instruction Manual Multi Angle Absorption Photometer (MAAP). 2009. Disponível em: http://tools.thermofisher.com/content/sfs/manuals/EPM-manualModel\%205012\%20MAAP.pdf

MIRANDA, R. M; ANDRADE, M. F., FORNARO, A., ASTOLFO, R, ANDRÉ, P. A., SALDIVA, P. Urban air pollution: a representative survey of PM2.5 mass concentrations in six Brazilian cities. Air Qual Atmos Health. v. 5, n. 1, p. 63-77, 2012. DOI 10.1007/s11869010-0124-1. Disponível em: https://link.springer.com/article/10.1007/s11869-010-0124-1. Acesso em: 2018.

MIRANDA, R. M., PÉREZ-MARTINEZ, P. J.; ANDRADE, M. F., RIBEIRO, F. N. D. Relationship between black carbon (BC) and heavy traffic in São Paulo, Brazil. 2017.

Transportation Researches Part D: Transport and Environment. v. 68, n. 1, p. 84-98, 2017. DOI: http://dx.doi.org/10.1016/j.trd.2017.09.002. Disponível em: https://www.sciencedirect.com/science/article/abs/pii/S1361920917300603?via\%3Dihub. Acesso em: 2018.

MIRANDA, R. M; ANDRADE, M. F., RIBEIRO, F. N. D., FRANCISCO, K. J. M., PÉREZMARTINEZ, P. J. Source apportionment of fine particulate matter by Positive Matrix Factorization in the metropolitan area of São Paulo. Journal of Cleaner Production, v. 202, p. 253-263, 2018. DOI: https://doi.org/10.1016/j.jclepro.2018.08.100 Disponível em: https://www.sciencedirect.com/science/article/pii/S0959652618324429?via\%3Dihub. Acesso em: 2019

MIRAGLIA, S. G. E. K.; GOUVEIA, N. Custos da poluição atmosférica nas regiões metropolitanas brasileiras. Ciência \& Saúde Coletiva. v. 19, n. 10, p. 4141-4147, 2014. DOI: 10.1590/1413-812320141910.09232014. Disponível em:

https://www.scielo.br/scielo.php?pid=S1413-81232014001004141\&script=sci_arttext. Acesso em: 2019.

METORHM. Manual cromatógrafo iônico profissional 850. 2019. Disponível em: https://www.metrohm.com/pt-br/documents/87818002. Acesso em: 2021

NASCIMENTO, A. P.; SANTOS, J. M.; MIL, J. G.; SOUZA, J. B.; REIS JÚNIOR, N. C.; REISEN, V. A. Associação entre concentração de partículas finas na atmosfera e doenças respiratórias agudas em crianças. Revista de Saúde Pública. v. 51, n. 3, 2017.

DOI:10.1590/S1518-8787.2017051006523. Disponível em:

https://www.scielo.br/scielo.php?script=sci_arttext\&pid=S0034-89102017000100202. Acesso em: 2018.

NORRIS, G., DUVALL, R., BROWN, S., BAI, S. EPA Positive Matrix Factorization (PMF) 5.0 Fundamentals and User Guide. Washington: U.S. Environmental Protection Agency Office of Research and Development, 2014. Disponível em: https://www.epa.gov/airresearch/positive-matrix-factorization-model-environmental-data-analyses. Acesso em: 2019.

ORGANIZAÇÃO DAS NAÇÕES UNIDAS. Os 17 Objetivos para o desenvolvimento sustentável. 2015. Disponível em: https://nacoesunidas.org/pos2015/agenda2030/ Acesso em: 2020

PAATERO, P., Eberly, S., Brown, S. G., Norris, G. A. Methods for estimating uncertainty in factor analytic solutions. 2014. Atmospheric Measurement Techniques. V. 7, P. 781-797. Disponível em: www.atmos-meas-tech.net/7/781/2014/. Acesso em: 2019 
PANICKER, A.S., PANDITHURAI, G., SAFAI, P.D., DIPU, S., DONG-IN LEE. On the contribution of black carbon to the composite aerosol radiative forcing over an urban environment. Atmospheric Environment, v. 44, n. 25, p. 3066-3070, 2010.

DOI:10.1016/j.atmosenv.2010.04.047. Disponível em:

https://www.sciencedirect.com/science/article/pii/S1352231010003547. Acesso em: 2017

PEREIRA, G.M., TEINILA, K., CUSTODIO, D. SANTOS, A.G., XIAN, H, HILLAMO, R., ALVEZ, CA, ANDRADE, J.B., ROCHA, G.O, KUMAR, P. BALASUBRAMANIAN, R. ANDRADE, M.F. VASCONCELLOS, P.C. Particulate pollutants in the Brazilian city of São Paulo: 1-year investigation for the chemical composition and source apportionment.

Atmospheric Chemistry Physicis. v. 17, p. 11943-11969, 2017. DOI:10.5194/acp-17-119432017. Disponível em: https://acp.copernicus.org/articles/17/11943/2017/. Acesso em: out 2020

PETZOLD, A., OGREN, J. A., FIEBIG, M., LAJ, P., LI, S. M., BALTENSPERGER, U., HOLZER-POPP, T., KINNE, S., PAPPALARDO, G., SUGIMOTO, N., WEHRLI, C., WIEDENSOHLER, A., ZHANG, X. Y. Recommendations for the interpretation of "black carbon" measurements. 2013. Atmospheric Chemistry Physics Discuss. V. 13. P. 94859517. DOI:10.5194/acpd-13-9485-2013

QIN, T., F.; PlATTNER, D.; TIGNOR, G., K.; ALLEN, M.; et al. Climate Change 2013: The Physical Science Basis. Contribution of Working Group I to the Fifth Assessment Report of the Intergovernmental Panel on Climate Change. In: THE INTERGOVERNMENTAL PANEL ON CLIMATE CHANGE. Cambridge e New York: Cambridge University Press, 2013. Disponível em: https://www.ipcc.ch/report/ar5/wg1/. Acesso em: 2018.

REFF, A., EBERLY, S. I., BHAVE, P. V. Receptor modeling of ambient particulate matter data using positive matrix factorization: review of existing methods. J Air Waste Manag Assoc. Londres. v. 57, n. 2, p. 146-54, 2007.

RUDDIIMMAN, W. F. Earth's Climate Change: Past and Future. 3. ed. New York: W. H. Freeman Company. 2014. p. 377.

SALDIVA, P. H., LICHTENFELS, A. J., PAIVA, P. S., BARONE, I. A., MARTINS, M. A., MASSAD, E., PEREIRA, J. C., XAVIER, V. P., SINGER, J. M., BOHM ,G. M. Association between air pollution and mortality due to respiratory diseases in children in São Paulo,

Brazil: a preliminary report. Environmental Research. v. 65, n. 2, p. 218-225, 1994. DOI: 0013-9351/94. Disponível em:

https://www.sciencedirect.com/science/article/pii/S0013935184710334/pdf?md5=b3086ddcb 131c1ffa551b0ef514ebc49\&pid=1-s2.0-S0013935184710334-main.pdf. Acesso em: 2018.

SÁNCHEZ-CCOYLLO, O. R.; ANDRADE, M. F. The influence of meteorological conditions on the behavior of pollutants concentrations in São Paulo, Brazil. Environmental Pollution. v. 116, p. 257-263, 2002.

SDG - KNOWLEDGE HUB. WHO Global Conference Recommends Reducing Deaths from Air Pollution by Two-Thirds by 2030. 2018. Disponível em: https://sdg.iisd.org/news/who-global-conference-recommends-reducing-deaths-from-airpollution-by-two-thirds-by- 
2030/\#: :text=Efforts\%20to\%20combat\%20air\%20pollution,the\%20Paris\%20Agreement\%2 0on\%20climate. Acesso em: dez. 2020.

SÃO PAULO (Cidade). Atlas ambiental do município de São Paulo. 1999. Disponível em: http://atlasambiental.prefeitura.sp.gov.br/mapas/112.pdf

SÃO PAULO (Estado). Secretaria de planejamento e gestão. Município de São Paulo e o mercado de trabalho. 2015. Disponível em:

https://www.seade.gov.br/produtos/midia/2017/01/MSP_Indicadores_25jan_2.pdf. Acesso em: $03 / 2021$.

SÃO PAULO (Cidade). Secretaria municipal de transportes. Portaria $n^{\circ}$ 031/16SMT.GAB. 2016. Disponível em: http://www.cetsp.com.br/media/466400/031-16.pdf

SÃO PAULO (Estado). Assembleia legislativa do Estado de São Paulo. Decreto Estadual no 59.113, de 23 abril de 2013. Estabelece novos padrões de qualidade do ar e dá providências correlatas. Disponível em:

https://www.al.sp.gov.br/repositorio/legislacao/decreto/2013/decreto-59113-23.04.2013.html. Acesso em: 2017

SÃO PAULO (Cidade). Secretaria Municipal de Desenvolvimento Urbano (SMDU). Observasampa: Observatório de indicadores da cidade de São Paulo. 2021. Disponível em: http://observasampa.prefeitura.sp.gov.br/. Acessado em: 03/2021

SEINFELD, J. H.; PANDIS, S. N. Atmospheric chemistry and physics: from air pollution to climate change. 2. ed. New Jersey: Wiley. 2006.

SETTI, L., PASSARINI, F., GENNARO, G., BARBIERI, P., PERRONE, M. G., PIAZZALUNGA, A., BORELLI, M., PALMISANI, J., GILIO, A., PISCITELLI, P., MIANI, A. The potential role of particulate matter in the spreading of COVID-19 in northern italy: first evidence-based research hypotheses. 2020a. MedRciv. Bologna Itália. Ahead of print. DOI: https://doi.org/10.1101/2020.04.11.20061713. Disponível em: https://www.medrxiv.org/content/10.1101/2020.04.11.20061713v1. Acesso em: maio 2020a.

SETTI, L., PASSARINI, F., GENNARO, G., BARBIERI, P., PERRONE, M. G., BORELLI, M., PALMISANI, J., GILIO, A., PISCITELLI, P., MIANI, A. Airborne transmission route of COVID-19: why 2 meters/ 6 feet of inter-personal distance could not be enough. International Journal of Environmental Research and Public Health. v. 17, n. 8, p. 2932, 2020 b. DOI:10.3390/ijerph17082932. Disponível: https://www.mdpi.com/1660-4601/17/8/2932/htm. Acesso: maio 2020.

SILVA, M. F., ASSUNÇÃO, J. V., ANDRADE, M. F., PESQUERO, C. R. Characterization of metal and trace element contents of particulate matter (PM10) emitted by vehicles running on brazilian fuels - hydrated ethanol and gasoline with $22 \%$ of anhydrous ethanol. J. Toxicol. Environ. Health, Part A. v. 73, n. 13-14, p. 901-909, 2010. DOI: https://doi.org/10.1080/15287391003744849. Disponível em: https://www.tandfonline.com/doi/full/10.1080/15287391003744849. Acesso em: 2019

TYSON, N. D. Neil DeGrasse Tyson Quotes: 75+ Life-Changing Neil DeGrasse Tyson Quotes You Should Know. ed. [S.l.]: Amazon. 2019. Ebook. Disponível em: https://www.amazon.com.br/Neil-DeGrasse-Tyson-Quotes-Life-Changingebook/dp/B07PLQP1L3. Acesso em: 19 dez. 2020. 
UNIVERSIDADE FEDERAL DE SÃO JOÃO DEL-REI. Química analítica - Cromatografia líquida. Disponivel em: https://www.ufsj.edu.br/portal2-

repositorio/File/frankimica/Quimica\%20Analitica\%20Aplicada\%20II/CL\%20e\%20HPLC.pdf

VEMADO, F.; PEREIRA FILHO, A. J. Severe Weather Caused By Heat Island and Sea Breeze Efects in the Metropolitan Area Of São Paulo. 2016. Hindawi Publishing Corporation Advances in Meteorology. Volume 2016. Disponivel em:

http://dx.doi.org/10.1155/2016/8364134

VERÍSSIMO, T. G. Análise do aerossol atmosférico em Acra, capital de Gana. Dissertação (Mestre em Física) - Instituto de Física da Universidade de São Paulo. São Paulo, 2016.

WORLD HEALTH ORGANIZATION. Air quality guidelines: global update 2005: particulate matter, ozone, nitrogen dioxide and sulphur dioxide. Europa, 2006. Disponível em: http://www.euro.who.int/_data/assets/pdf_file/0005/78638/E90038.pdf?ua=1. Acesso em: 2018

Clean air for health: Geneva Action Agenda. 2018. Disponível em:

https://www.who.int/phe/news/clean-air-for-health/en/. Acesso em: 2019

Coronavirus Disease (COVID-19) Dashbord. Disponível em:

https://covid19.who.int/. Acesso em: 2020

WORLD BANK GROUP - Pollution Prevention and Abatemend Handbook. Glass Manufacturing. 1998. Environmental, Healh and Safety. Disponível em: https://www.ifc.org/wps/wcm/connect/f6c6e013-9ef2-46b0-b945-

842f7003a227/glass_PPAH.pdf?MOD=AJPERES\&CVID=jkD22Qo. Acesso em: nov. 2020

WU, X.; NETHERY, R. C.; SABATH, B. M.; BRAUN, D.; DOMINICI, F. Exposure to air pollution and COVID-19 mortality in the United States. 2020. Science Advances. Nova York DOI: 10.1126/sciadv.abd4049. Disponível em:

https://advances.sciencemag.org/content/6/45/eabd4049. Acesso em: 2020.

YNOUE, R. Y. Modelagem numérica da formação, crescimento e transporte das partículas inorgânicas secundárias constituintes do aerossol urbano na região metropolitana de São Paulo. 2004. Tese (Doutorado em Ciências) - Departamento de Ciências Atmosféricas da Universidade de São Paulo, São Paulo, 2004.

ZHOU, Y., HUANG, X. H., BIAN, Q., GRIFFITH, S. M., LOUIE, P. K. K., YU, J. Z. Sources and atmospheric processes impacting oxalate at a suburban coastal site in Hong Kong: Insights inferred from 1 year hourly measurements. 2015. Journal of Geophysical Research: Atmospheres. V.120, pg. 18.

Disponível em: https://agupubs.onlinelibrary.wiley.com/doi/full/10.1002/2015JD023531 Acessado em: 03/2021

ANEXO A - DIREÇÃO E VELOCIDADE DO VENTO MENSAL DO PERÍODO AMOSTRADO (ABRIL 2016 - ABRIL 2017) 


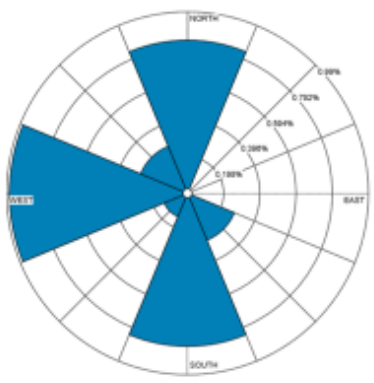

Abril 2016

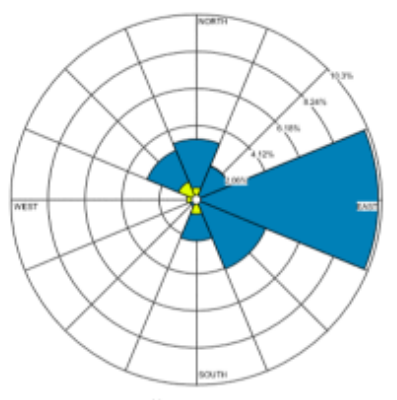

Julho 2016

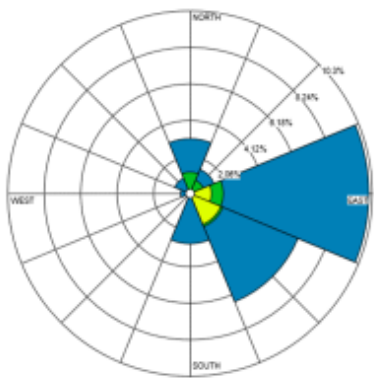

Maio 2016

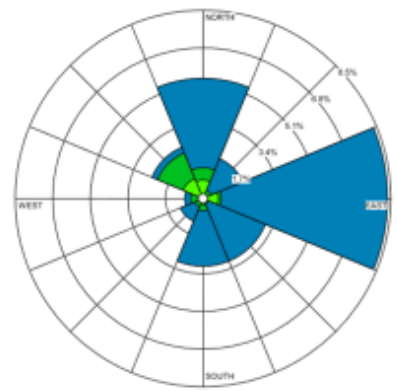

Junho 2016

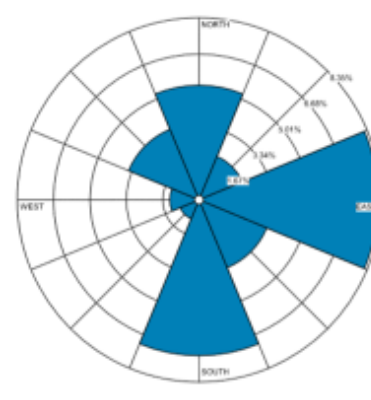

Agosto 2016

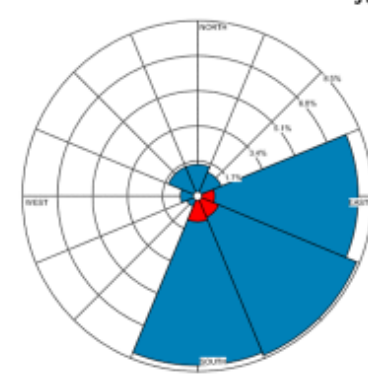

Setembro 2016
WIND SPEED

$(\mathrm{m} / \mathrm{s})$

$>=11.10$

$8.80-11.10$

$5.70-8.80$

$3.60-5.70$

$2.10-3.60$

$0.50-2.10$

Calms: $0.00 \%$

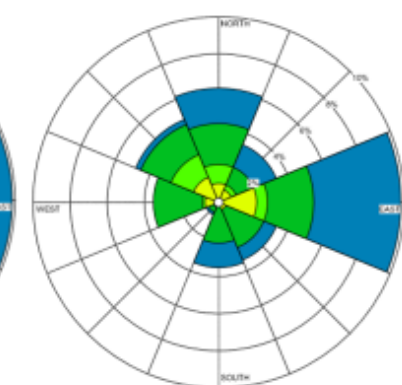

Janeiro 2017

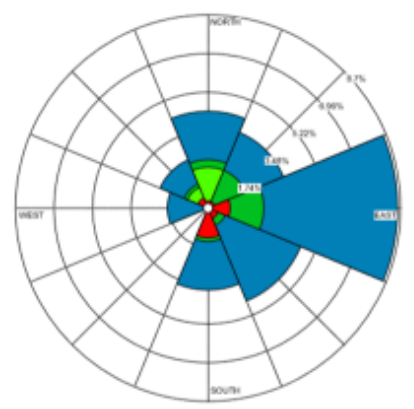

Fevereiro 2017

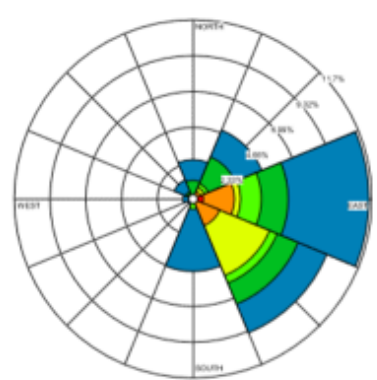

Novembro 2016

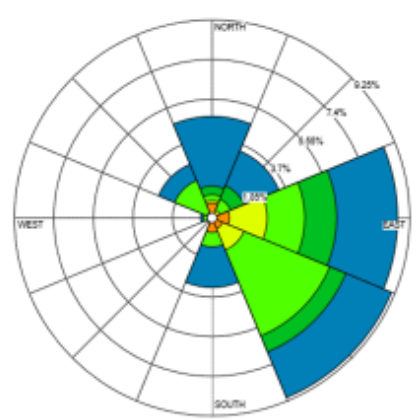

Março 2017

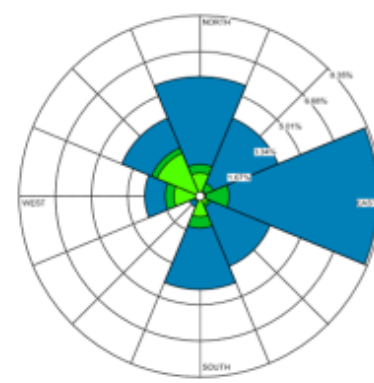

Dezembro 2016

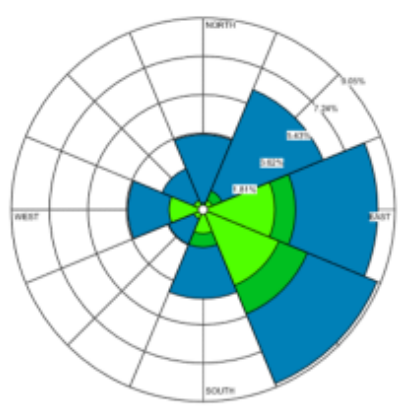

Abril 2017
WIND SPEED $(\mathrm{m} / \mathrm{s})$

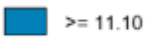

$8.80-11.10$

$570-880$

$3.60-5.70$

$2.10-3.60$

$0.50-2.10$

Calms: $0.00 \%$ 